Florida International University FIU Digital Commons

\title{
An analysis of six original Latin jazz compositions and arrangements
}

Ruben Caban

Florida International University

DOI: $10.25148 /$ etd.FI14052514

Follow this and additional works at: https://digitalcommons.fiu.edu/etd

Cart of the Composition Commons

\section{Recommended Citation}

Caban, Ruben, "An analysis of six original Latin jazz compositions and arrangements" (2011). FIU Electronic Theses and Dissertations. 1951.

https://digitalcommons.fiu.edu/etd/1951

This work is brought to you for free and open access by the University Graduate School at FIU Digital Commons. It has been accepted for inclusion in FIU Electronic Theses and Dissertations by an authorized administrator of FIU Digital Commons. For more information, please contact dcc@fiu.edu. 
FLORIDA INTERNATIONAL UNIVERSITY

Miami, Florida

AN ANALYSIS OF SIX ORIGINAL LATIN JAZZ COMPOSITIONS AND

ARRANGEMENTS

A thesis submitted in partial fulfillment of the

requirements for the degree of

MASTER OF MUSIC

by

Ruben Caban

2011 
To: Dean Brian Shriner

College of Architecture and the Arts

This thesis, written by Ruben Caban, and entitled An Analysis of Six Original Latin Jazz Compositions and Arrangements, having been approved in respect to style and intellectual content, is referred to you for judgment.

We have read this thesis and recommend that it be approved.

Karen Fuller

Mike Orta

Gary Carnpbell,/Major Professor

Date of Defense: March 7, 2011

The thesis of Ruben Caban is approved.

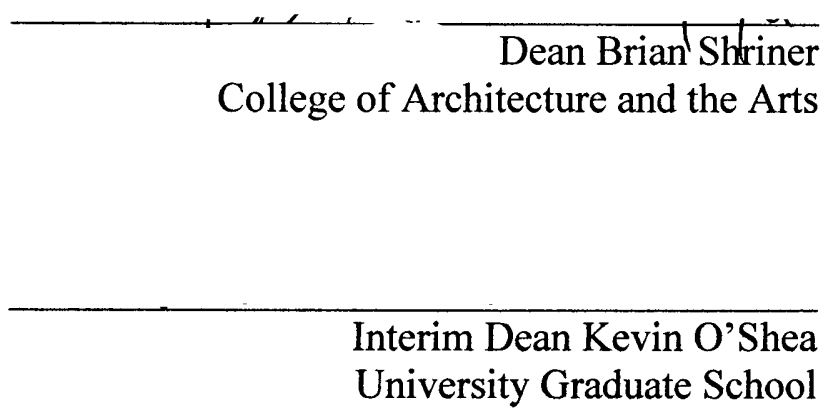

Florida International University, 2011 


\section{DEDICATION}

I would like to dedicate this work to my late friend and esteemed colleague Chris O'Farril. 


\section{ABSTRACT OF THE THESIS \\ AN ANALYSIS OF SIX ORIGINAL LATIN JAZZ COMPOSITIONS AND \\ ARRANGEMENTS}

by

Ruben Caban

Florida International University, 2011

Miami, Florida

Professor Gary Campbell, Major Professor

The purpose of this thesis is to examine the cross-cultural fusion of jazz harmony and Afro Caribbean rhythms. These six compositions were chosen for the composers Master's recital to demonstrate how his writing technique was influenced by his cultural and musical experience during his years of study and performance in the United States and abroad. The instrumentation was chosen to exemplify the fusion of the traditional percussive sounds of Latin music with jazz harmony, melody and improvisation. It is important to note that even though one of the compositions, E.T., is not written in a Latin style, it was nonetheless the product of a Puerto Rican composer, and it exemplifies his influences as a cross-cultural composer and soloist. Scores of the six musical works are provided in an Appendix, and a live recording of the recital is included. 


\section{TABLE OF CONTENTS}

CHAPTER

PAGE

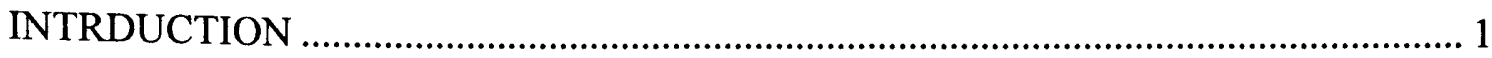

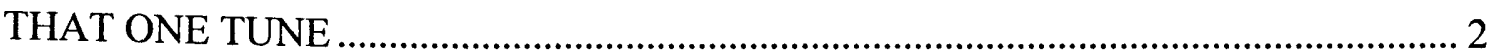

E.T.

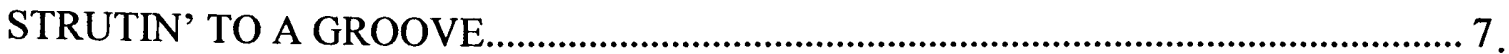

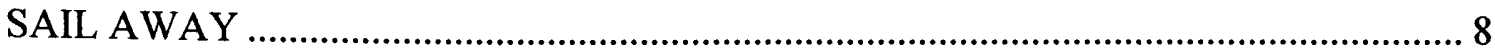

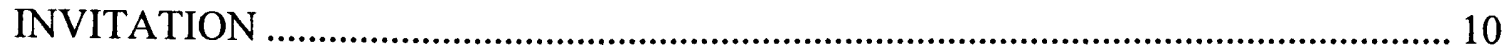

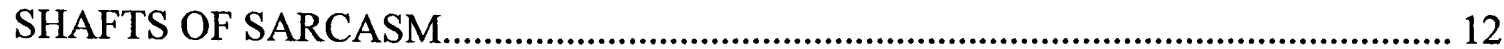

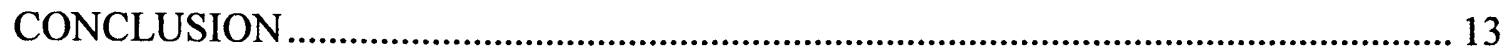

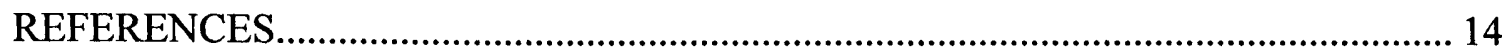

APPENDIX 


\section{LIST OF FIGURES}

FIGURE

PAGE

That One Tune

Example 1-1: Melodic motif.................................................................................. 2

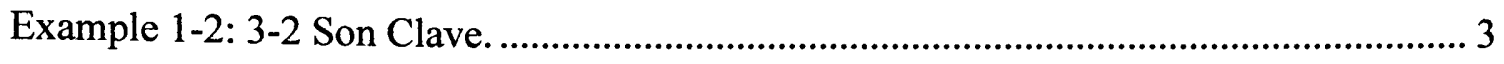

Example 1-3: 2-3 Son Clave. .................................................................................... 3

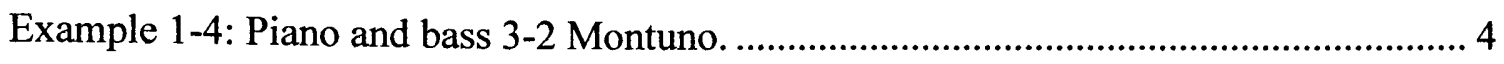

E.T.

Example 2-1: Triad Pairs. .......................................................................................... 6

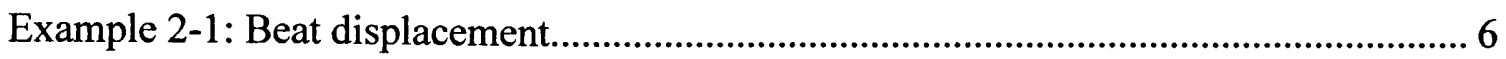

Strutn' To A Groove

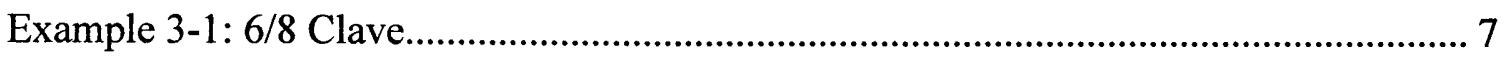

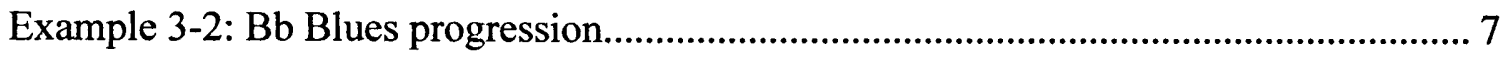

Sail Away

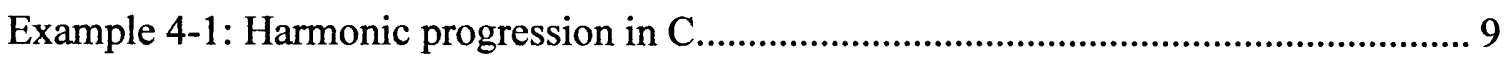

Example 4-2: Harmonic progression in Eb.................................................................. 9

Invitation

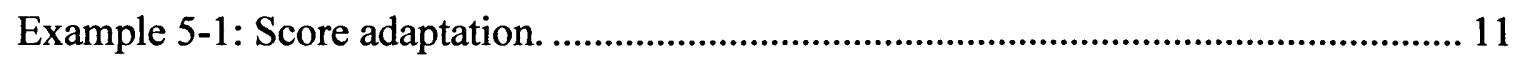

Shafts Of Sarcasm

Example 6-1: Basic 12-Bar Blues progression in F.................................................... 12

Example 6-2: Progression used for Shafts of Sarcasm. ............................................... 13 


\section{INTRODUCTION}

The fusion of Latin music and jazz has played an important role in the development of jazz as we know it today. In order to better comprehend the compositions being performed, it is important to understand how this fusion came to be. Even though historical records are limited or nonexistent, we do know that during the late 1800 s the first influence of Latin music was brought to New Orleans by Mexican brass bands such as the $8^{\text {th }}$ Regiment Mexican Cavalry Band, which played danzas and mazurkas at the World Industrial Cotton Centennial Exposition, predating the first jazz recordings of the Original Dixie Land Jazz Band. Jellyroll Morton referred to this early rhythmic influence on early ragtime as the 'Latin Tinge".

Although Latin musics syncopated rhythms were absorbed by early ragtime pianists, Latin music in its traditional form was not popularized among mainstream United States listeners until Don Azpiazu's 1937 performance in New York's Palace Theater of The Peanut Vendor.' This event introduced the American public to traditional Afro-Caribbean rhythms and instruments. The term Afro-Caribbean is used loosely in the following analysis to describe the percussive sounds of Cuban and Puerto Rican heritage.

Throughout the 40s and 50s, jazz legend Dizzy Gillespie joined forces with various Cuban musicians such as composer Mario Bauza and band leader Chano Pozo to create the Cubop movement, an innovative fusion of jazz and Afro-Caribbean rhythms that incorporated bebop style lines alongside traditional Cuban rhythms into a Big Band setting. Pianist Eddie Palmieri made his contributions to the genre with his 1993 record Palmas, which brought about the instrumental and arranging style that fused popular

\footnotetext{
${ }^{1}$ Roberts, 1 .
} 
Afro-Caribbean dance music, (Salsa), with jazz harmony. ${ }^{2}$ It was this instrumental model, together with aspects of traditional swing, funk and hard bop, that were used in the composition and arrangement of the works presented here.

These six pieces provide examples of the different ways this fusion can be achieved. Four of the pieces; That One Tune, Strut'n To A Groove, E.T. and Shafts of Sarcasm are original compositions. Sail Away by Tom Harrel and Invitation by Bronislaw Kaper were arranged and adapted specifically for this performance. The following is an in depth analysis of these works, focusing on the melodic, harmonic structure and rhythmic concepts used in their construction.

\section{THAT ONE TUNE}

The opening number is an original composition entitled That One Tune. This song has a 32-bar head and was written in AABA form. (In jazz, the melody is often referred to as the head.) This one is set in the key of D minor, since the repeated A section of the head clearly outlines a D minor triad in second inversion: the fifth (A), the flattened third $(\mathrm{F})$ and root (D), combine to form a motif.

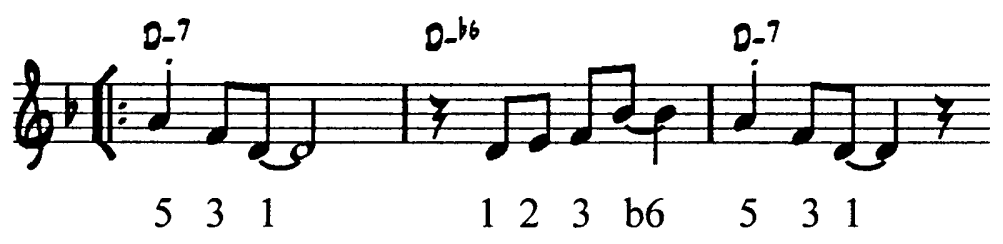

Example 1-1: Melodic motif

This motif is complemented by a series of two descending ii-V progressions, first in D minor (E-7 b5, A7b9) then in C major (D-11, G7b9). These give a sense of forward

\footnotetext{
${ }^{2}$ Roberts, 224.
} 
motion before landing on a bVI- IV7- V7 (BbMaj7- G7\#11-A7b9) turnaround back to the tonal center of $\mathrm{D}$ minor.

The B section, also referred to as the bridge or release, brings out a lighter harmonic color by traveling to F Major, the relative major of the key. The harmony travels back to the $\mathrm{D}$ minor A section via a reoccurring, pivoting altered chord (A7b9). It is during this section that the rhythmic aspects of Afro-Caribbean music come into play.

In Afro-Caribbean rhythms the Son Clave is a two- bar, reversible passage, most commonly conceived in $4 / 4$ that serves as a compositional guide.

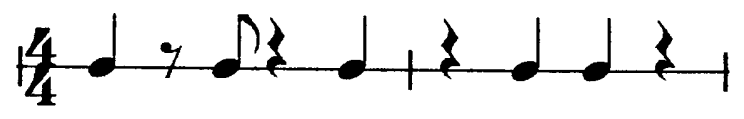

Example 1-2: 3-2 Son Clave

When reversed the 3-2 Clave becomes a 2-3 Clave.

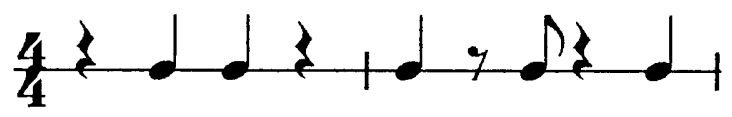

\section{Example 1-3: 2-3 Son Clave}

This is usually played by clave sticks or woodblock and is always conceptually present, even when it is not being literally played by any instrument. It is common for modern composers to take creative liberties with its use, but the clave remains a compositional guide: the melody can be rhythmically identical to the clave or simply land on only a few of the five strokes of the clave. ${ }^{3}$

The presence of both Afro-Caribbean and swing aspects are apparent from the beginning of this composition. The introduction is scored for tutti (horns, piano and bass)

\footnotetext{
${ }^{3}$ Sheller, 13.
} 
in which the rhythm section establishes a 3-2 Son Clave. The song abruptly changes to a walking bass to set up the A section as swing.

At the end of the A section's second iteration, a two beat percussion send-off takes the tune to the bridge where the trombone takes the melody. Here the song conveys the impression of a cheerful, danceable Salsa, in contrast to the prevailing minor sound in the A section. The soloists improvise over the form as it oscillates between the swing characteristic feel of the A sections and the Salsa style of the B section. This switch to salsa calls for a multiple array of rhythms, besides the clave, played by the traditional Afro-Caribbean percussion section, the piano and the bass. This style of playing is commonly referred to as montuno.

Montuno, also known by musicians as guajeo or tumbao, consists of a series of ostinatos played by the piano and bass, supported by the polyrhythm played in the percussion section. Below is a piano and bass montuno in 3-2 clave:

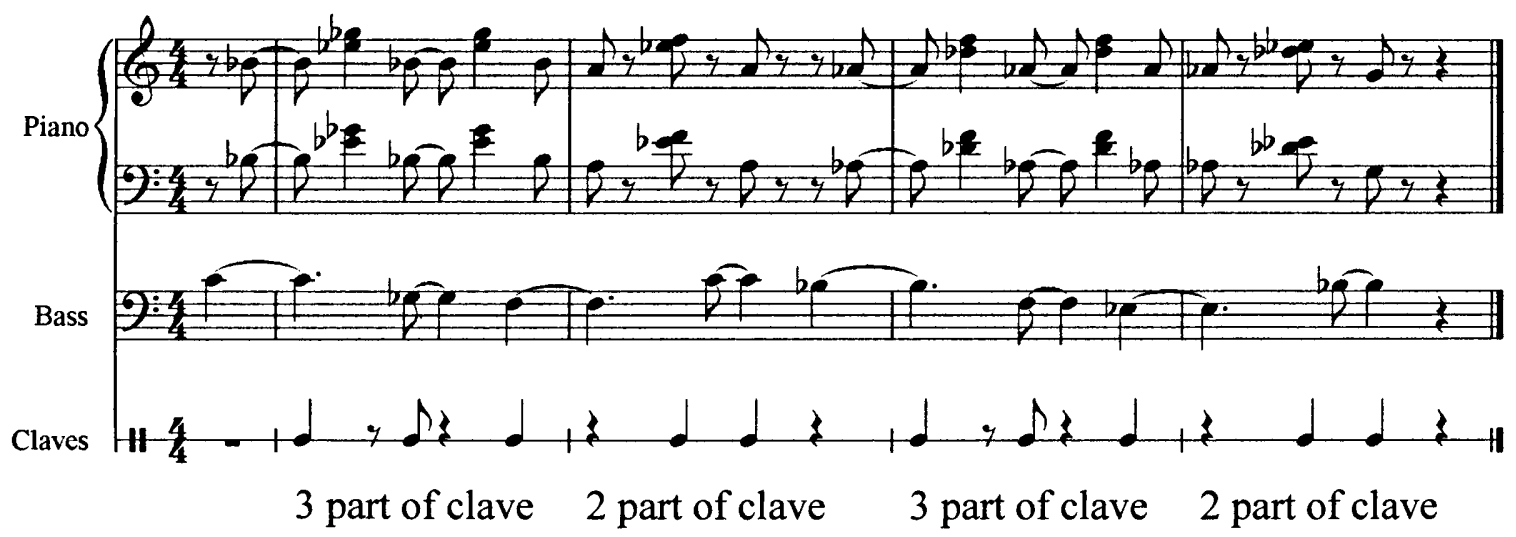

Example 1-4: Piano and bass 3-2 Montuno 
Since That One Tune does not have soli, it relies heavily on the journey in which the live improvisations take the listener through its multicultural form. This is a theme carried on by the next composition.

\section{E.T.}

E.T. is a jazz-rock fusion piece that switches between a harbop shuffle style and a funk feel. It was composed as an improvisational vehicle using a 32-bar head with an ABCA form. Harmonically, this piece simply travels through the different harmonic qualities of $\mathrm{C}$ minor and $\mathrm{C}$ diminished. Due to the abrupt modulations throughout the form, the key signature is left in the key of $\mathrm{C}$ and accidentals were used to notate any alteration.

The melody dictates the harmony by making use of the harmonic qualities of $\mathrm{C}$ harmonic minor (C- Major7 b6). After a direct modulation to a relative minor (EbMaj7b6), the head travels through a pair of descending minor ii-V7 progressions. It is here where the melody brings out an angular texture with the use of triad pairs.

Triad pairs are a collection of six note clusters. In this composition they are two major triads a whole step apart. They were derived from the melodic minor parent scale of each chord in the ii-V7 progression. For example: modally, an E-7b5 chord is the sixth degree of a $\mathrm{G}$ melodic minor scale. If we build triads using the harmonic structure of the $\mathrm{G}$ melodic minor scale we find that the fourth (C) and fifth degree (D) build two major triads. By inverting the triads and using neighboring tones (NT), one can create different textures of sound as illustrated below by scale degree: 


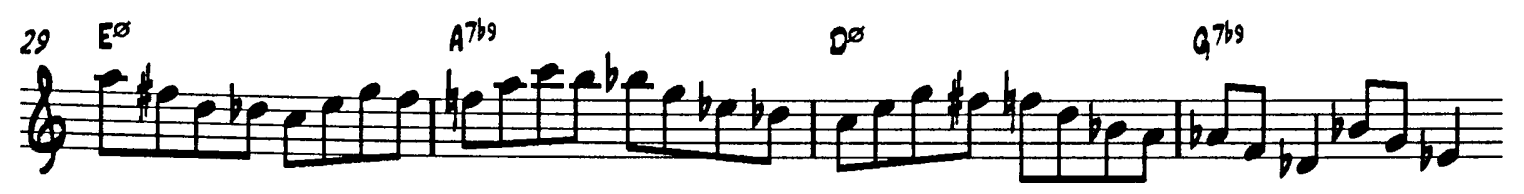

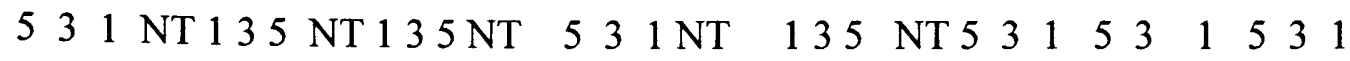
Example 2-1: Triad Pairs

While the trumpet, trombone and tenor saxophone are playing the triad pairs in straight eighth notes in $4 / 4$, the rhythm section is displacing the beat with a syncopated line that gives a contrasting aura of $3 / 4$. This use of beat displacement in the ensemble clearly notates the Afro-Caribbean influence and how it can be fused with concepts of jazz harmony.

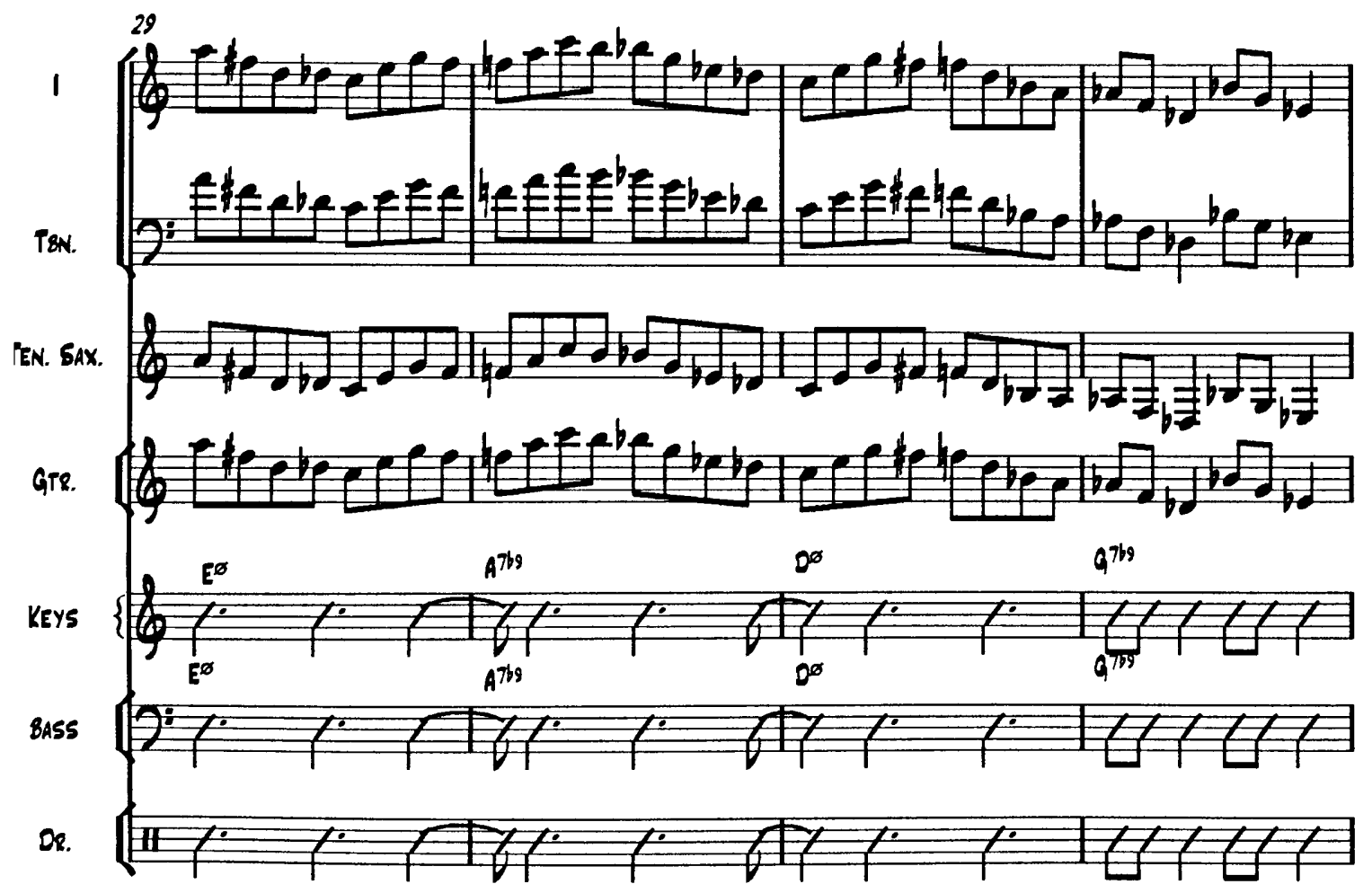

Example 2-2: Beat displacement 
After this angular sequence, the piece abruptly modulates again, this time to a $\mathrm{C}$

diminished chord. The modulations gradually bring out darker qualities of the same tonal root of $\mathrm{C}$ until we reach the down beat of the bridge. At this point all harmonic instruments drop out while the style switches to a heavy funk feel. The melody seems to echo between the three horns and the feedback of the electric guitar before recapitulating the last A section of the form.

\section{STRUT'N TO A GROOVE}

Afro-Cuban, Blues and a double time feel montuno are fused together in Strut'n To A Groove. Switching between three rhythmic styles sets a mood of tension and release. This is more apparent in the switch between the intense Afro-Cuban section and the aloof swing section. The listener must pay close attention to the traditional nuances of each genre as the performers navigate through the form.

Afro-Cuban music is a hybrid of African sacred music in $6 / 8 .^{4}$ This polyrhythmic style has its own clave to serve as the compositional guide. This implied pulse is played over 4/4 triplets in the melody:

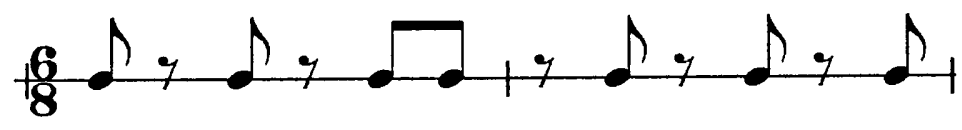

Example 3-1: 6/8 Clave

The first form of this composition is a deceptive 12-bar, Bb blues in Afro-Cuban style. The harmony does not follow a common blues progression of:

$\mathrm{Bb} 7|\mathrm{Bb} 7| \mathrm{Bb} 7|\mathrm{Bb} 7| \mathrm{Eb} 7|\mathrm{~Eb} 7| \mathrm{Bb} 7 \mid \mathrm{G} 7$ | C-7| $\mathrm{F} 7|\mathrm{Bb} 7| \mathrm{Bb} 7 \mid$

$\begin{array}{lllllll}17 & \text { IV7 } & \text { I7 } & \text { VI7 } & \text { ii7 } & \text { V7 } & 17\end{array}$

Example 3-2: Bb Blues progression

\footnotetext{
${ }^{4}$ Mauleon-Santana, 2.
} 
Instead it switches prematurely on the fourth bar of the form to the IV chord for one measure and bounces back to the tonal center of Bb7\#9. The style abruptly switches to swing for two measures and falls back into the Afro-Cuban feel.

The mixing around of styles and harmonic progressions does not end there. The harmony switches to a more common 12-bar blues progression and the rhythm section switches to a swing style. This is played only on the first chorus of every soloist. Beginning on the second chorus, the rhythm section switches to a double time 3-2 montuno. As the soloist burns through the up tempo style, the rhythm section sends him off with a four bar Afro-Cuban tag. This takes the form back to the original swinging blues progression and the next soloist.

\section{SAIL AWAY}

Tom Harrel (b. 1946) has gained notoriety both as a trumpet player and composer. Born in Urbana, Illinois and raised in the west coast, he had the privilege to tour as a sideman in Big Bands such as Stan Kenton, Woody Herman, and Horace Silver during the late 60 s and Early 70s. While in New York during the late 70 s and 80 s, he played with Bill Evans, Cecil Payne, the Lee Konitz Nonet and the Phil Woods Quintet. Even though he lives in a constant battle with schizophrenia, he has successfully led his own groups both live and in the studio. ${ }^{5}$ Sail Away, originally recorded in a bossa noval style, is one of his many compositions. In order to keep the stylistic theme of Afro-Caribbean music, this piece is interpreted in a bolero style.

\footnotetext{
${ }^{5}$ Yanow, Allmusic.com.
} 
A bolero is ballad which derives from a Cuban style of romantic singing known as trova $^{6}$. In instrumental ensembles, the percussion section maintains a slow tempo tumbao while the piano and bass improvise an accompaniment using the phrasing of the melody and the harmonic structure as a guide.

In Sail Away, the melody and harmony are intertwined in a dance around five different tonal centers. Tom Harrel makes use of transitional chord progressions to move through the keys of $\mathrm{C}$ Major, Eb Major, G Major, E Major and A Major. He utilizes a iii-VI7-iiV7-I- vi progression to announce the key of C Major:

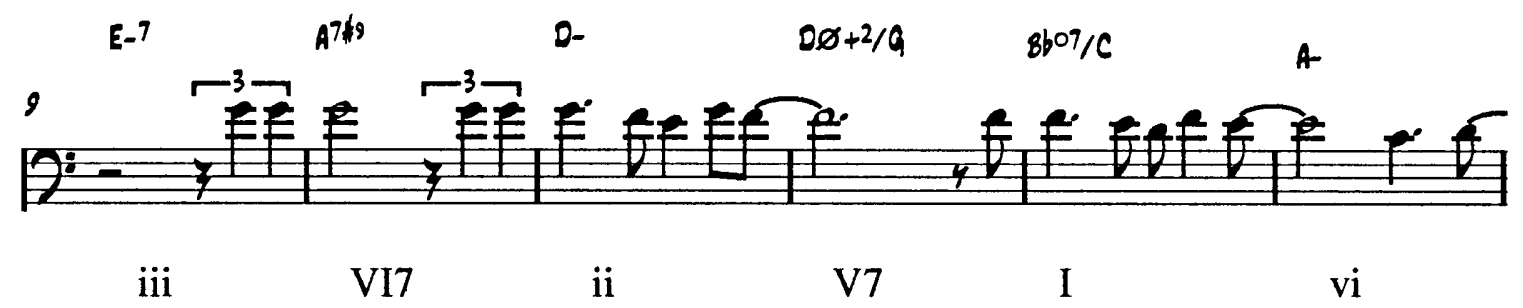

Example 4-1: Harmonic progression in C

In the $\mathrm{C}$ section he uses the same iii-VI7-ii-V-I-vi progression in $\mathrm{Eb}$ to bring on this brief tonal center.

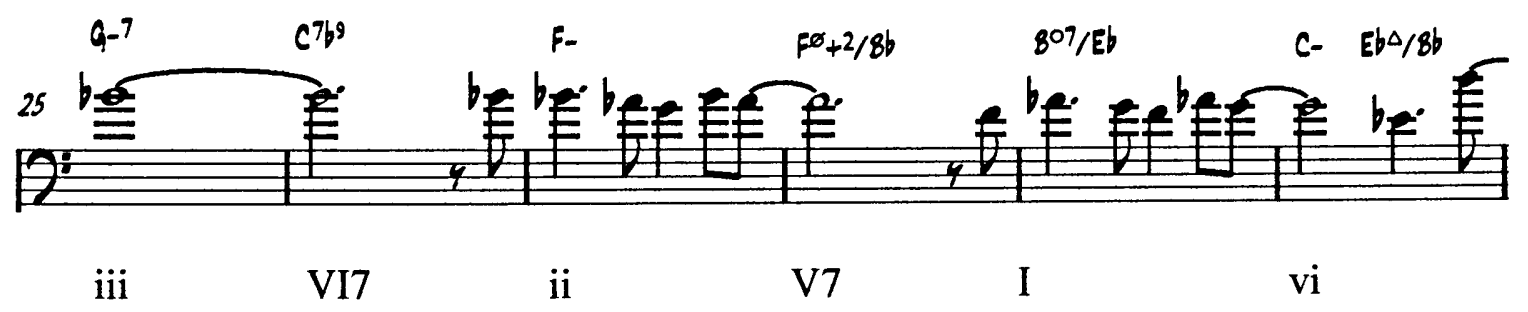

Example 4-2: Harmonic progression in $\mathrm{Eb}$

\footnotetext{
${ }^{6}$ Mauleon-Santana, 65.
} 
By the down beat of the $\mathrm{D}$ section it modulates once more through a minor ii-V progression into the key of G Major.

From here the piece modulates again up a fourth using the same ii-V-I method of modulation to the key of E Major. The tension is increased by modulating once more, in the same manner, up a fourth to the key of A Major before releasing back to the original melodic and harmonic statement in the key of C via a bVII- VI- ii-V- I progression.

\section{INVITATION}

Polish composer Bronislaw Kaper (Feb. 5, 1902-April 26 1983) is responsible for some of the most memorable film scores in the Hollywood film industry from the 1930s through the 1960s. Invitation was originally composed for the MGM film "A Life of Her Own" in 1950. It was used once more by MGM Studios in 1952 in another film entitled "Invitation". The piece has become a jazz standard over the years and recorded by numerous jazz musicians. This particular arrangement is an adaptation of a four trombone arrangement by Les Sebina. It was changed from a straight ahead swing style to the more percussive Afro-Caribbean feel of Salsa. The arrangement was also re-harmonized for trumpet, trombone and Baritone Saxophone.

The word salsa literally means sauce in Spanish. It is a mixture of condiments or "spice". The musical genre of Salsa music is described by Gerard Sheller as:

"Salsa is the New York sound, developed primarily by Puerto Rican New Yorkers, known as Nuyoricans or Neoyoricans. The genesis of the music reflects several sometimes contradicting attitudes: a desire to forge roots in Cuban music, an interest in 
adopting the musical lexicons of jazz and rock, and an often politically motivated wish to create a pan-Latin American music.",

This salsa adaptation of Invitation has a 48 bar form. Since it was transposed a whole step up from its original key of $\mathrm{C}$ minor, it now lays in $\mathrm{D}$ minor. It makes a modulation a minor third up to $\mathrm{F}$ minor before pivoting to the bridge in the key of $\mathrm{Db}$ Major. Here, Kaper uses a series of descending ii-V-I progressions a whole step apart to navigate through the different tonal centers that the melody outlines.

The Soli is one chorus of a Les Sebina original statement. In order to make this section fit to this musical genre, the score was adapted with a more elaborate percussion chart in 2-3 clave. Furthermore, the percussion section is provided with detailed instructions on how to split the hits and accents between the conga, bongo and timbales:

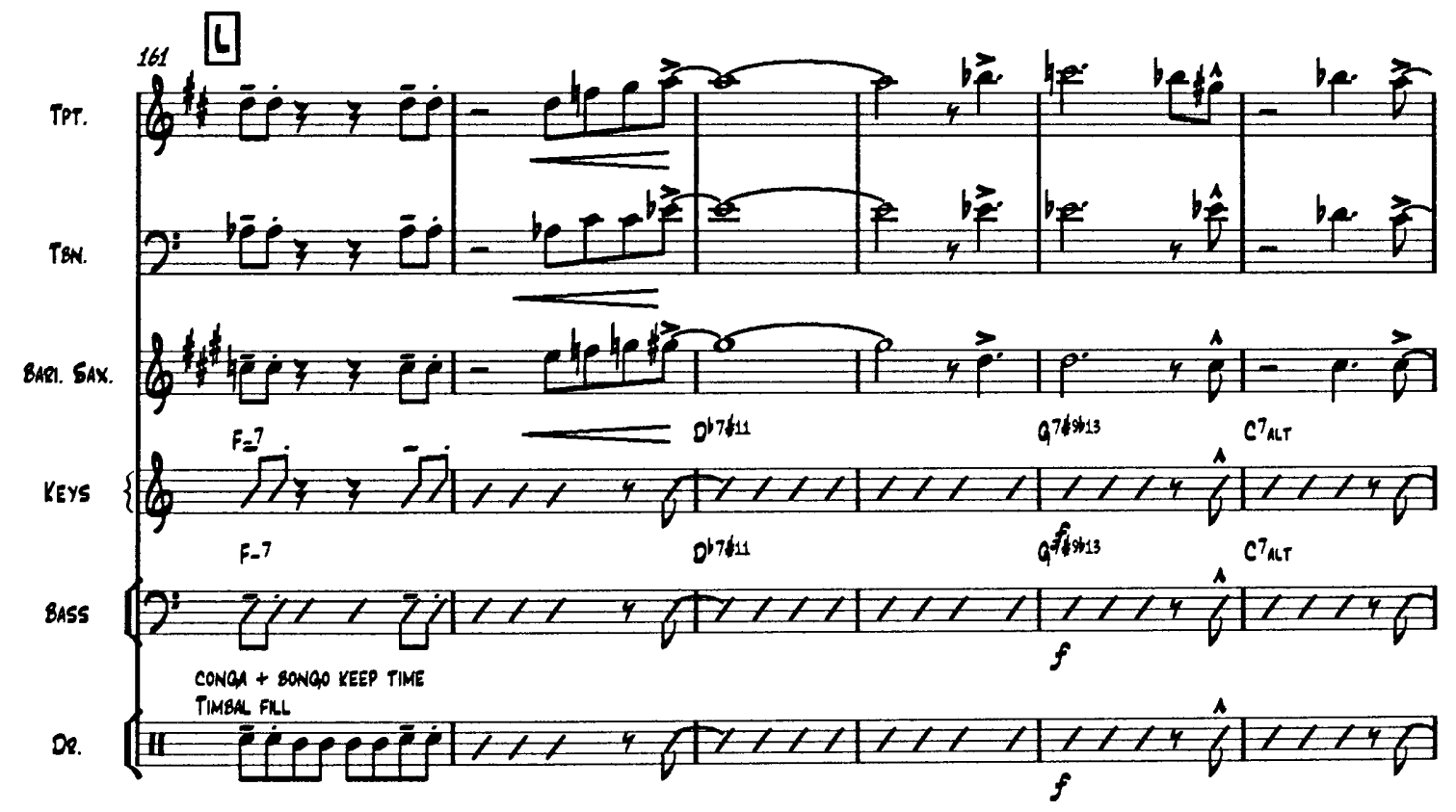

Example 5-1: Score adaptation

${ }^{7}$ Sheller, 3. 


\section{SHAFTS OF SARCASM}

During the late 1950s and 1960s, Rhythm and Blues musicians began using traditional Afro-Caribbean instruments such as congas and bongos in their recordings. Bo Diddley's 1955 recording of I'm A Man, and Get It Together by James Brown are examples of this incorporation. ${ }^{8}$ Young salsa musicians of the time wanted to reach a wider public so they fused the bluesy harmony of jazz and non-Hispanic, inner-city music together with traditional Afro-Caribbean rhythms. They borrowed elements of jazz harmony by adding the upper extensions of diatonic chords with alterations and voicing in fourths. This style of arranging is still used by modern salsa arrangers.

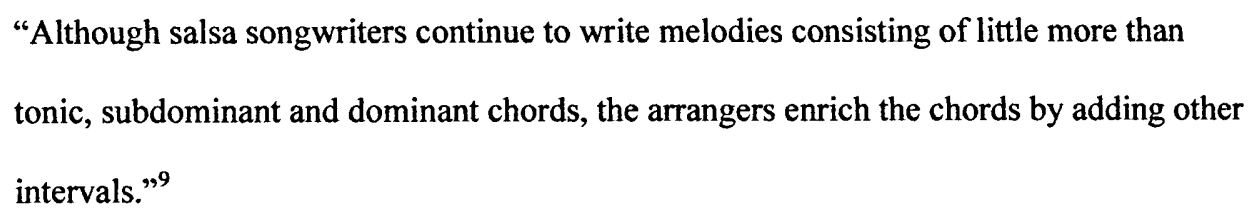

Shafts of Sarcasm is an original composition in a straight forward Latin Bugalu style.

The melody is written over an F blues progression with an I7-I7-V7-bVI7-I7 (F7-F7-

C7-C\#7-I) turnaround instead of the more common 17-VI7-ii7-V7-I7 (F7-D7-G-7-

C7-F7) turnaround of traditional blues.

F7| F7| F7| F7| Bb7| Bb7| F7| D7 | G-7| C7| F7| F7 ||

$\begin{array}{lllllll}17 & \text { IV7 } & \text { I7 } & \text { VI7 } & \text { ii7 } & \text { V7 } & \text { I7 }\end{array}$

Example 6-1: Basic 12-Bar Blues progression in $\mathrm{F}$

\footnotetext{
${ }^{8}$ Mauleon-Santana, 77.

${ }^{9}$ Sheller, 9.
} 
F7| F7| F7| F7| Bb7| Bb7| F7| F7 | C7| Db7| F7| F7||

$\begin{array}{llll}17 & \text { IV7 } & \text { I7 } & \text { V7 bVI7 I7 }\end{array}$

Example 6-2: Progression used for Shafts of Sarcasm

The Soli consists of two choruses of blues. The first chorus is an original statement by the composer. While the second chorus quotes trumpeter Nat Adderley's solo in Jive Samba, from the Latin Cool album released by Fania Records in 2001. The rhythm section sets a fun mood with a son montuno in 2-3 clave.It is adorned with busy bongo feels in the introduction and between the soli section and recapitulation of the melody.

\section{CONCLUSION}

The fusion of Afro-Caribbean rhythms with jazz harmony plays an integral part in the constant evolution of jazz. Latin Music influenced the birth of jazz and now jazz is returning the favor by lending its harmonic vocabulary to its long time relative. As Globalization continues in this age of communication, we can only hope for new ideas and influences from around the world. The recital exemplifies the multi-cultural marriage of jazz and Latin music as experienced by the composer. 


\section{REFERENCES}

Burlingame, Sandra.'Kaper, Branislown'Naxos Music Library. http://fiu.naxosmusiclibrary.com.ezproxy.fiu.edu/jazz/composer/btm.asp?compos erid=22546 (Accessed January 4, 2011).

Campbell, Gary. Connecting Jazz Theory. Milwaukee, WI: Hudson Publishing Inc., 1998.

Gerard, Charley and Marty Sheller. Salsa: The Rhythm of Latin Music. Crown Point, IN: White Cliffs Media Company, 1989.

Mauleon-Santana, Rebeca. 101 Montunos. Petaluma, CA: Sher Music, 1999.

Roberts, John Storm. Latin Jazz: The First of the Fusions, 1880's to Today. New York: Schirmer Books, 1999.

Yanow, Scott.'Tom Harrel Biography'. All Music.com, http://www.allmusic.com/artist/tom-harrell-p84276(Accessed January 4, 2011). 
Appendix: Scores

That ONE TUNE

$$
d=200
$$

RUSEN CABAN
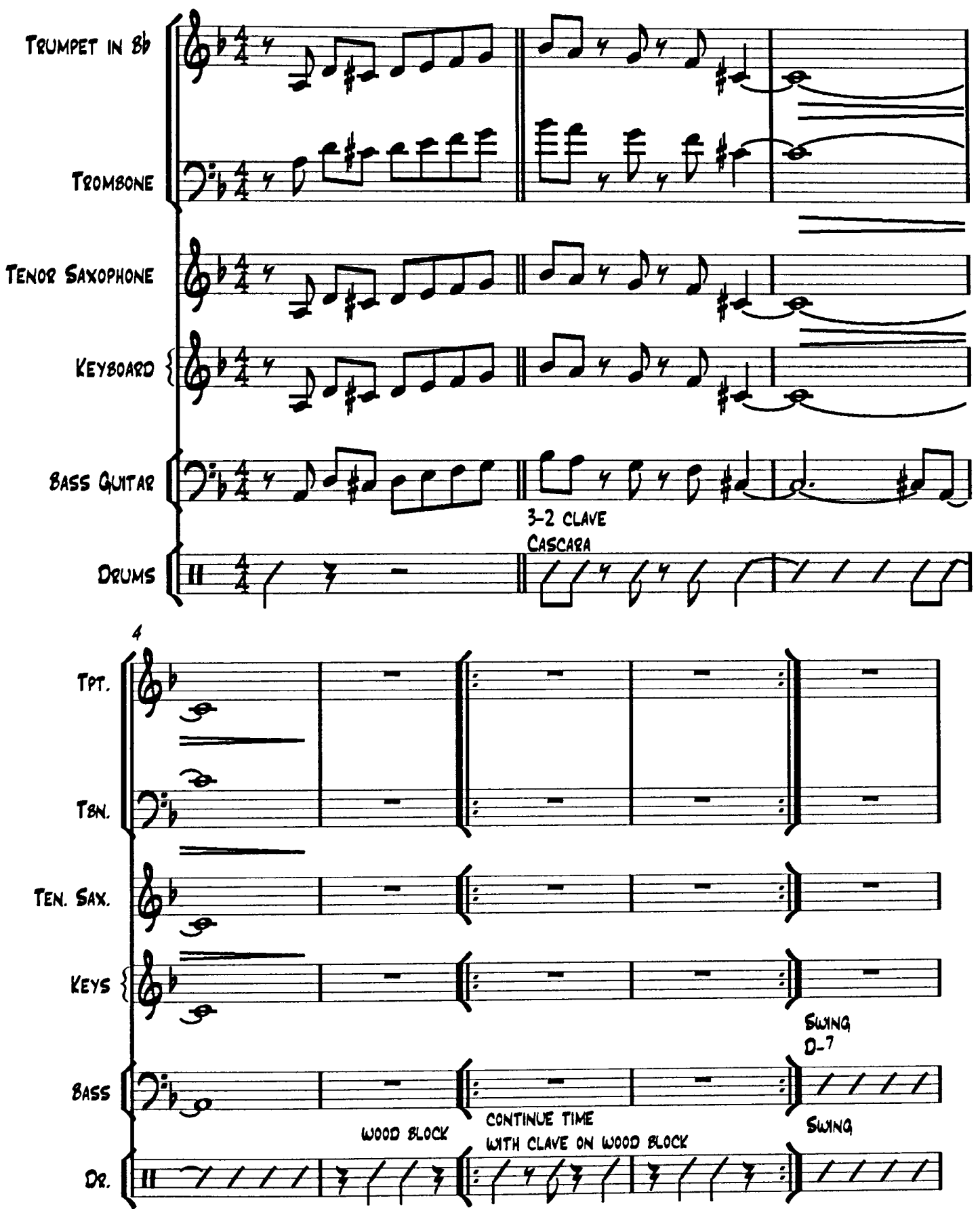

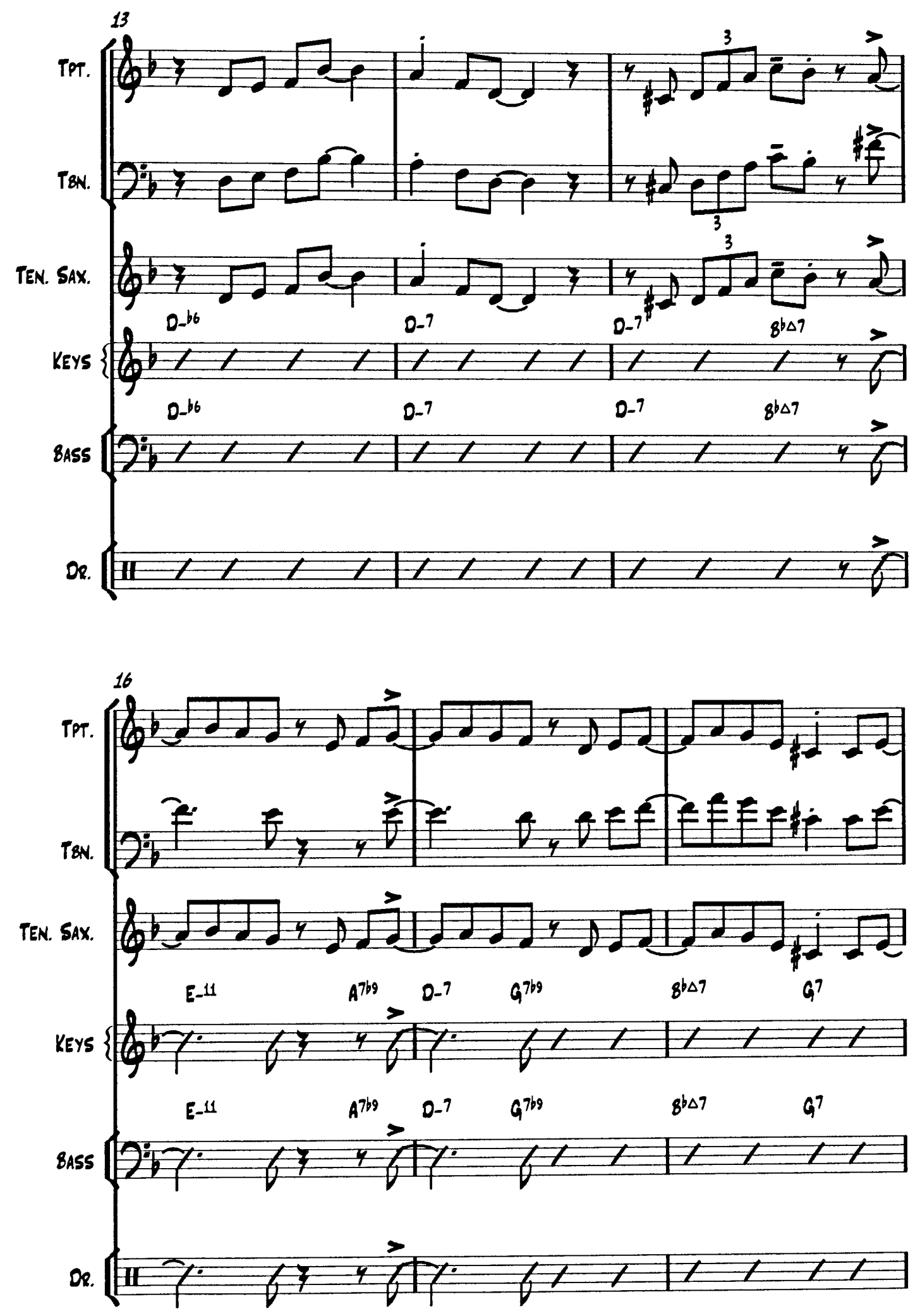


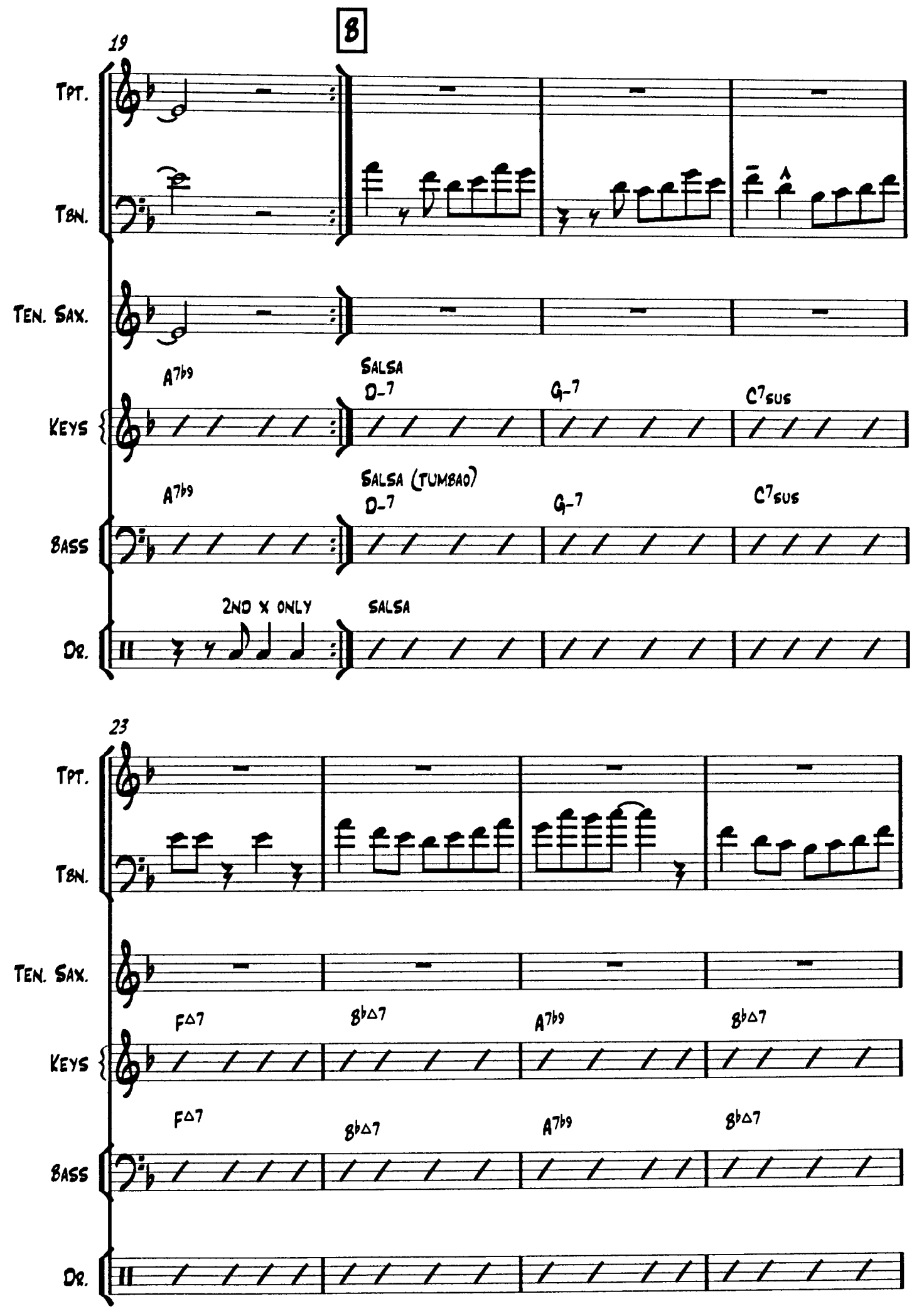



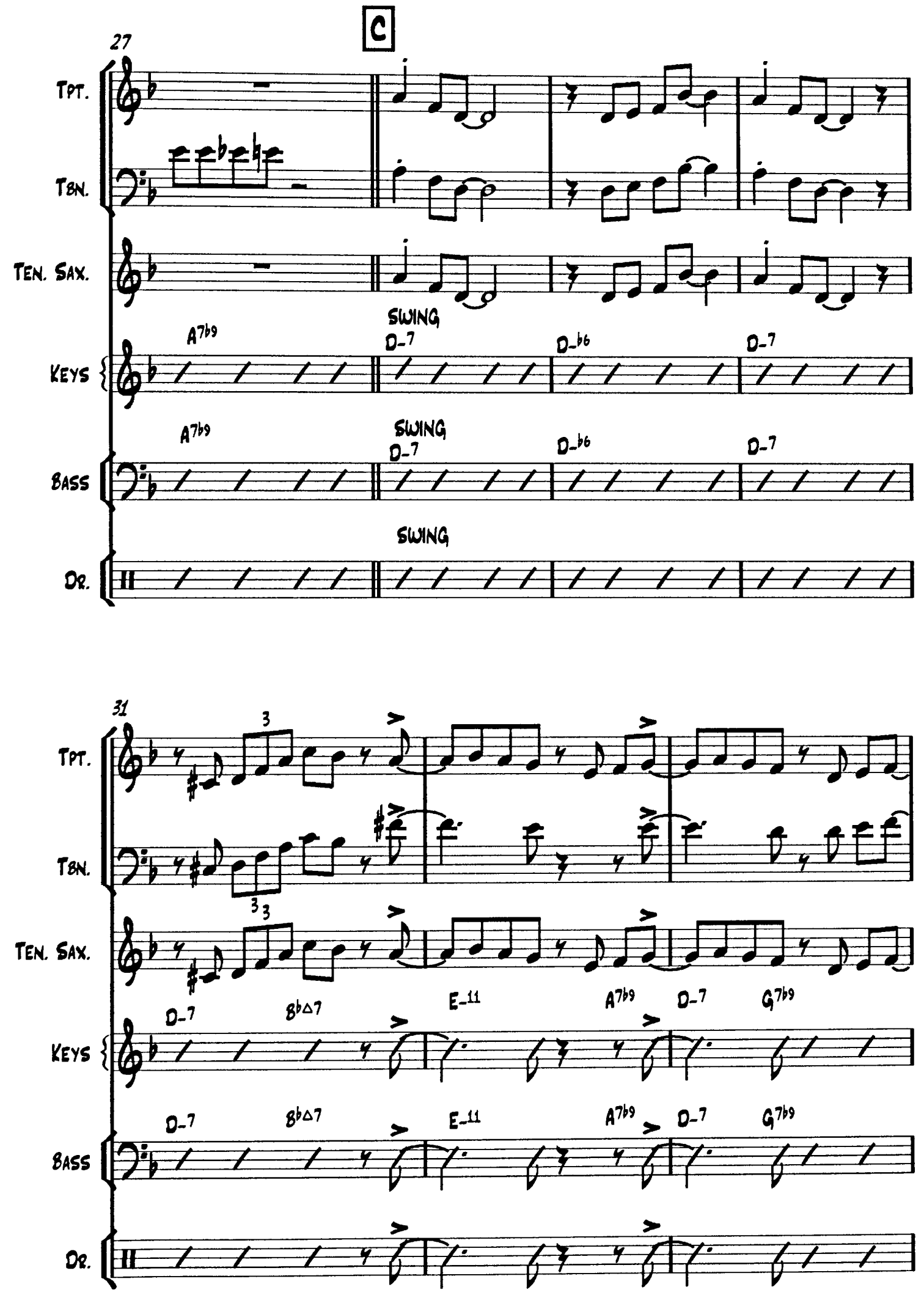

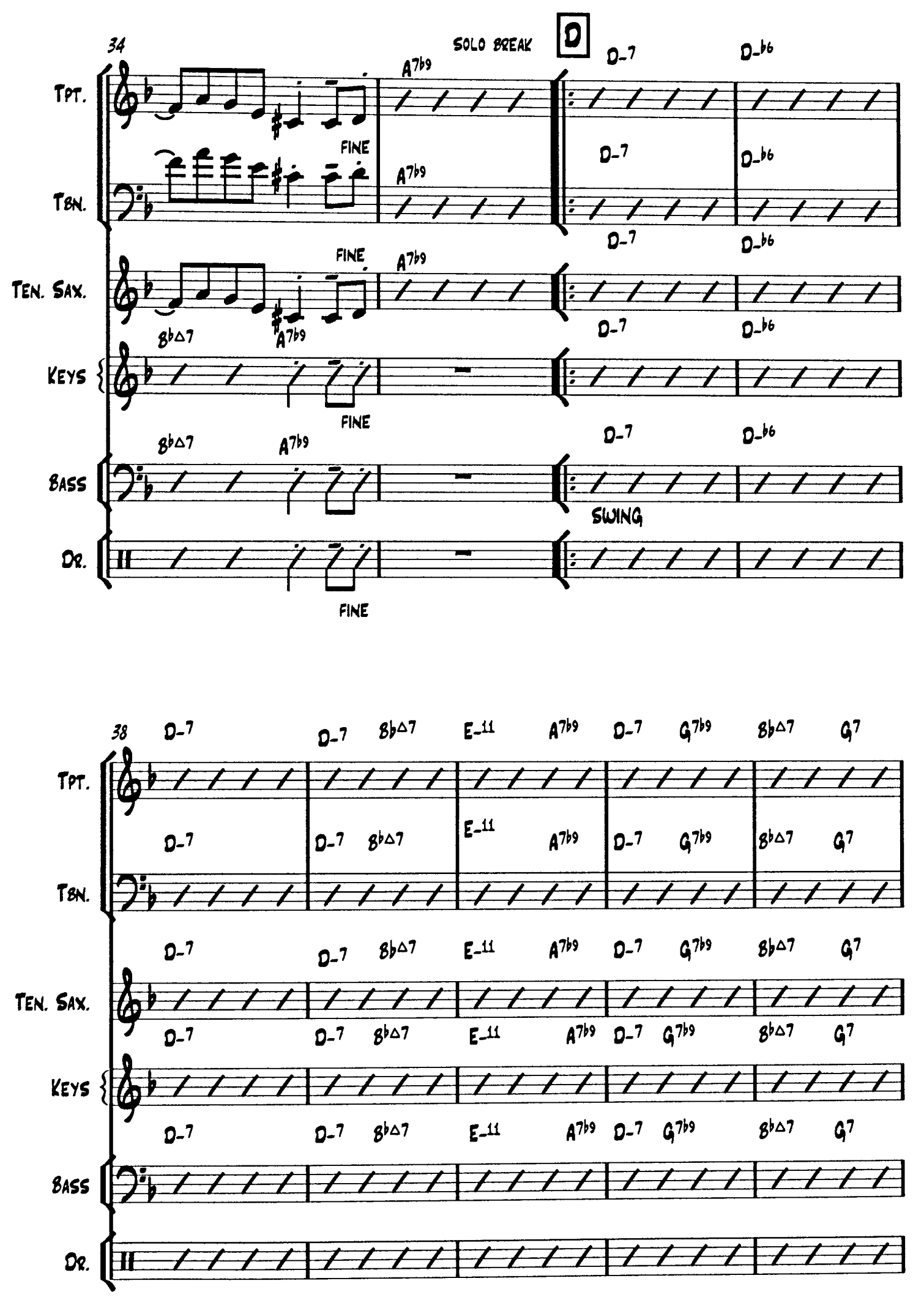


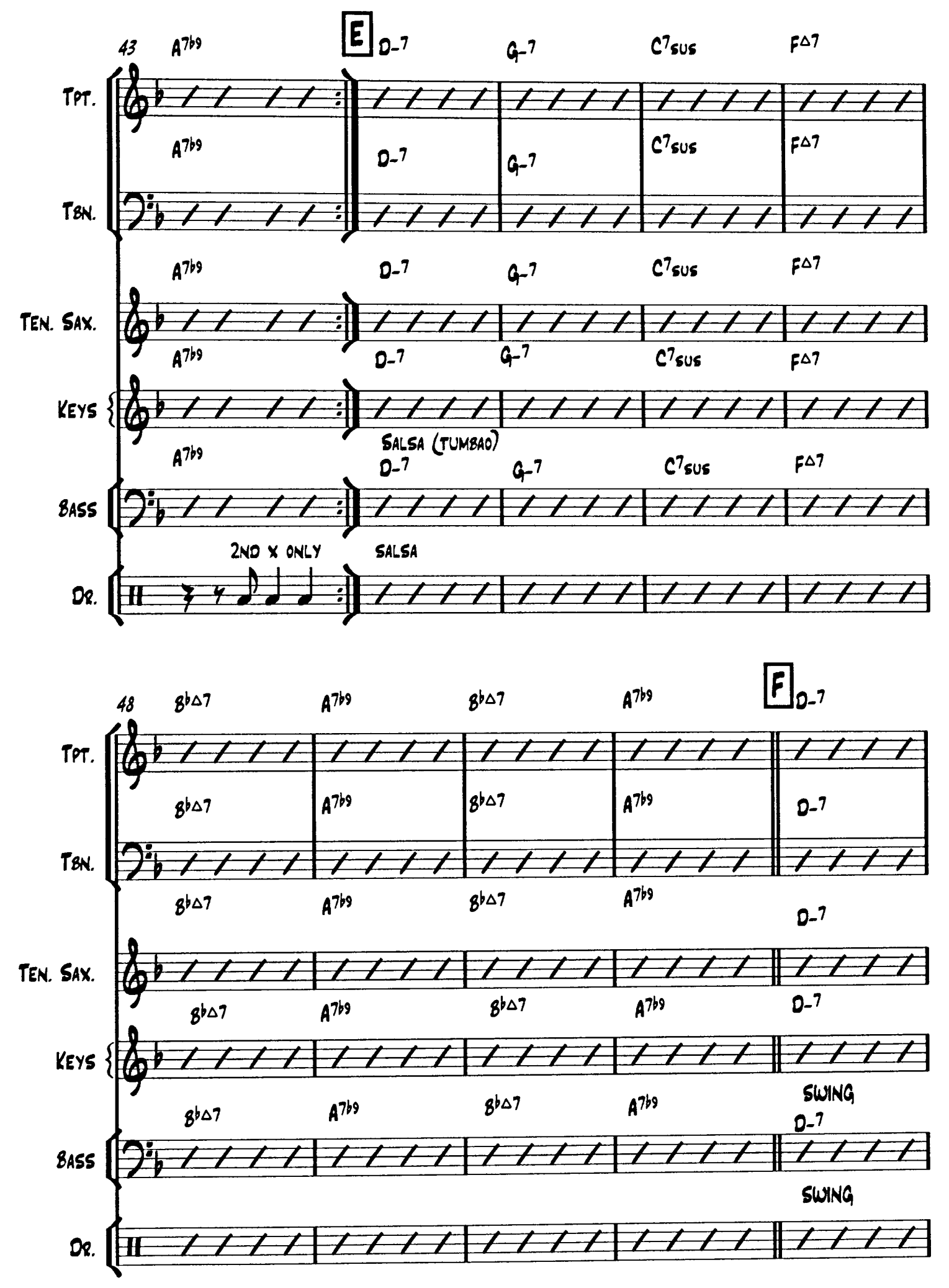



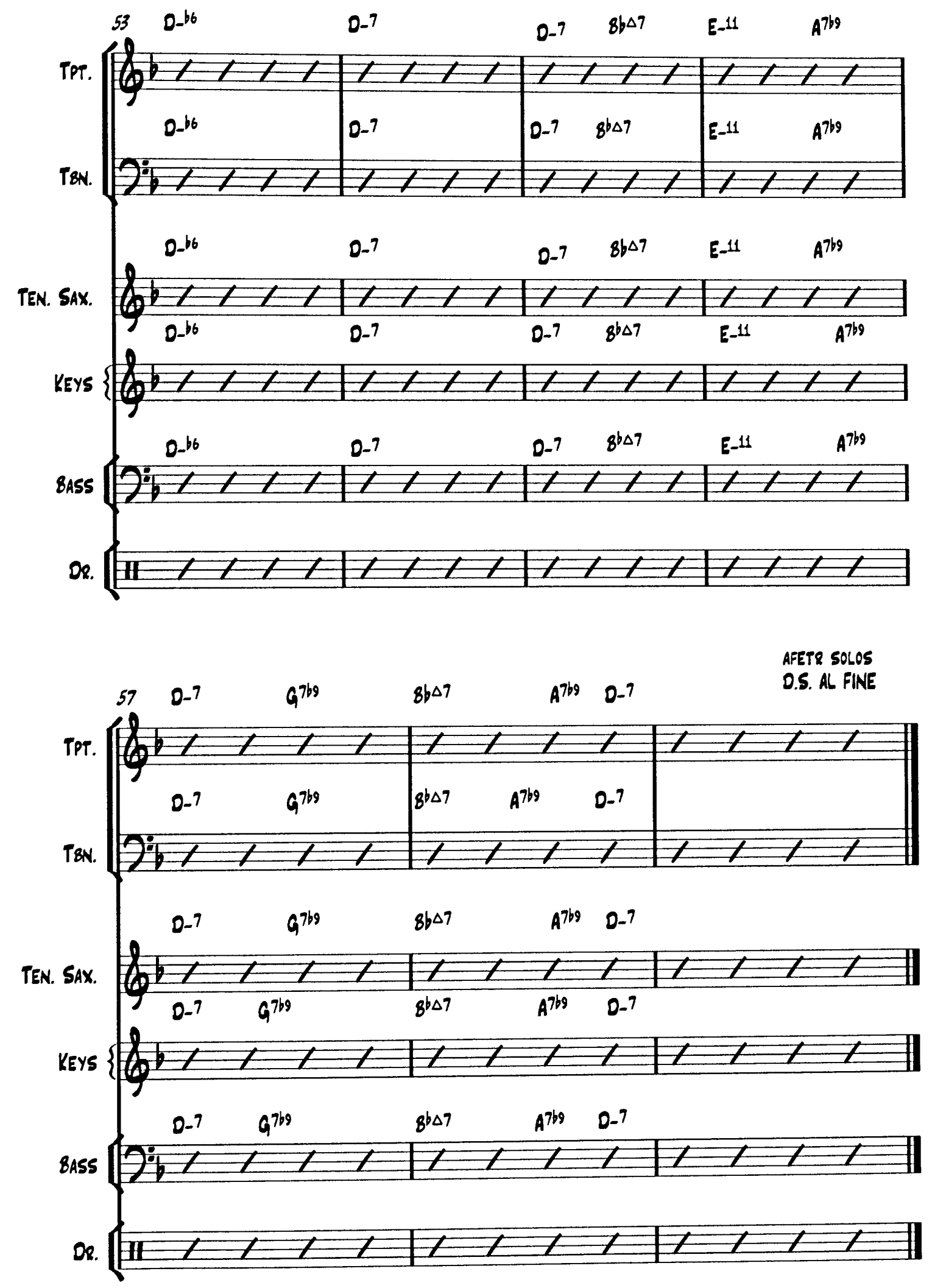
E.T.

$d=200$

ruben Caban
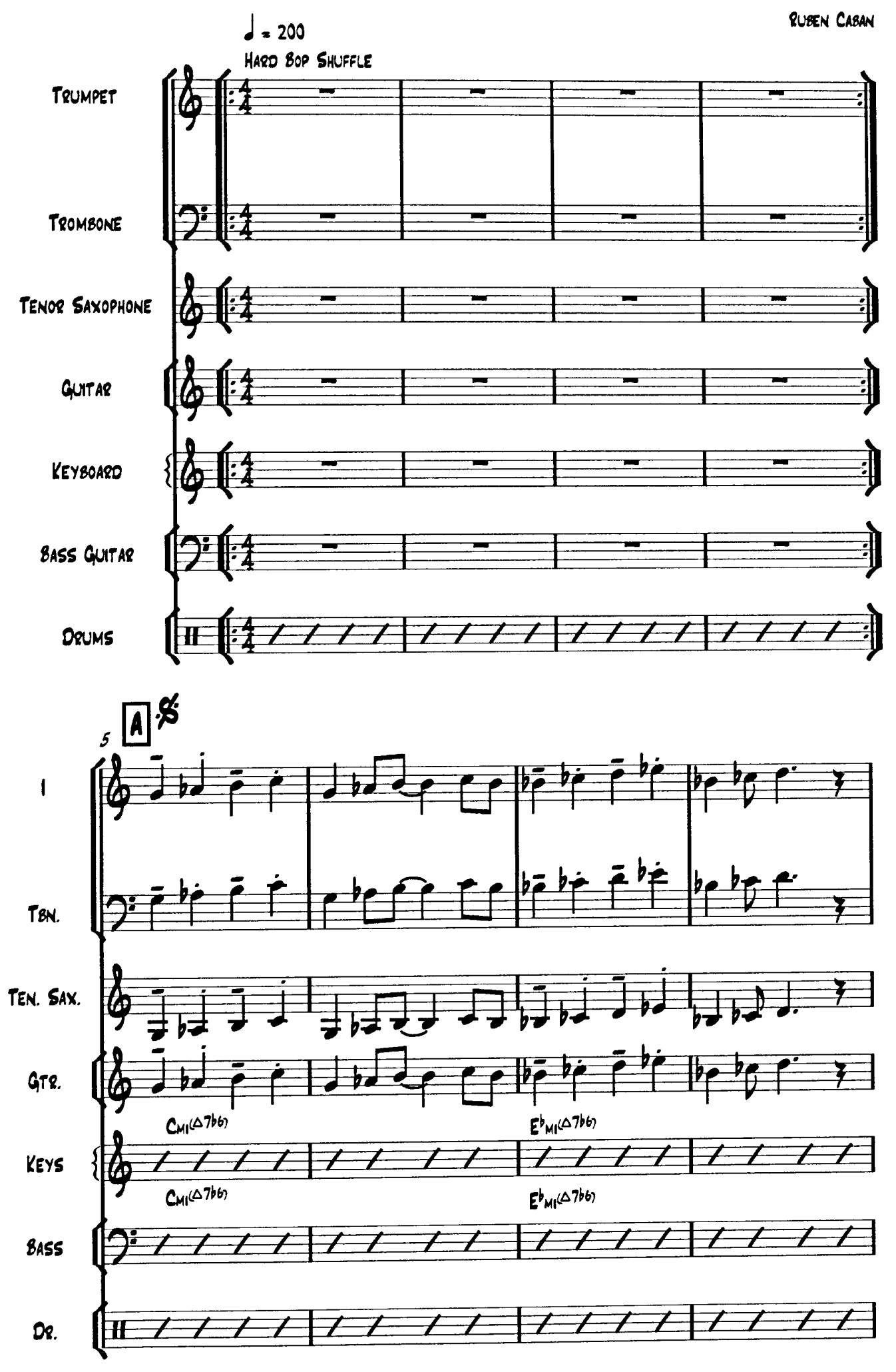

22 


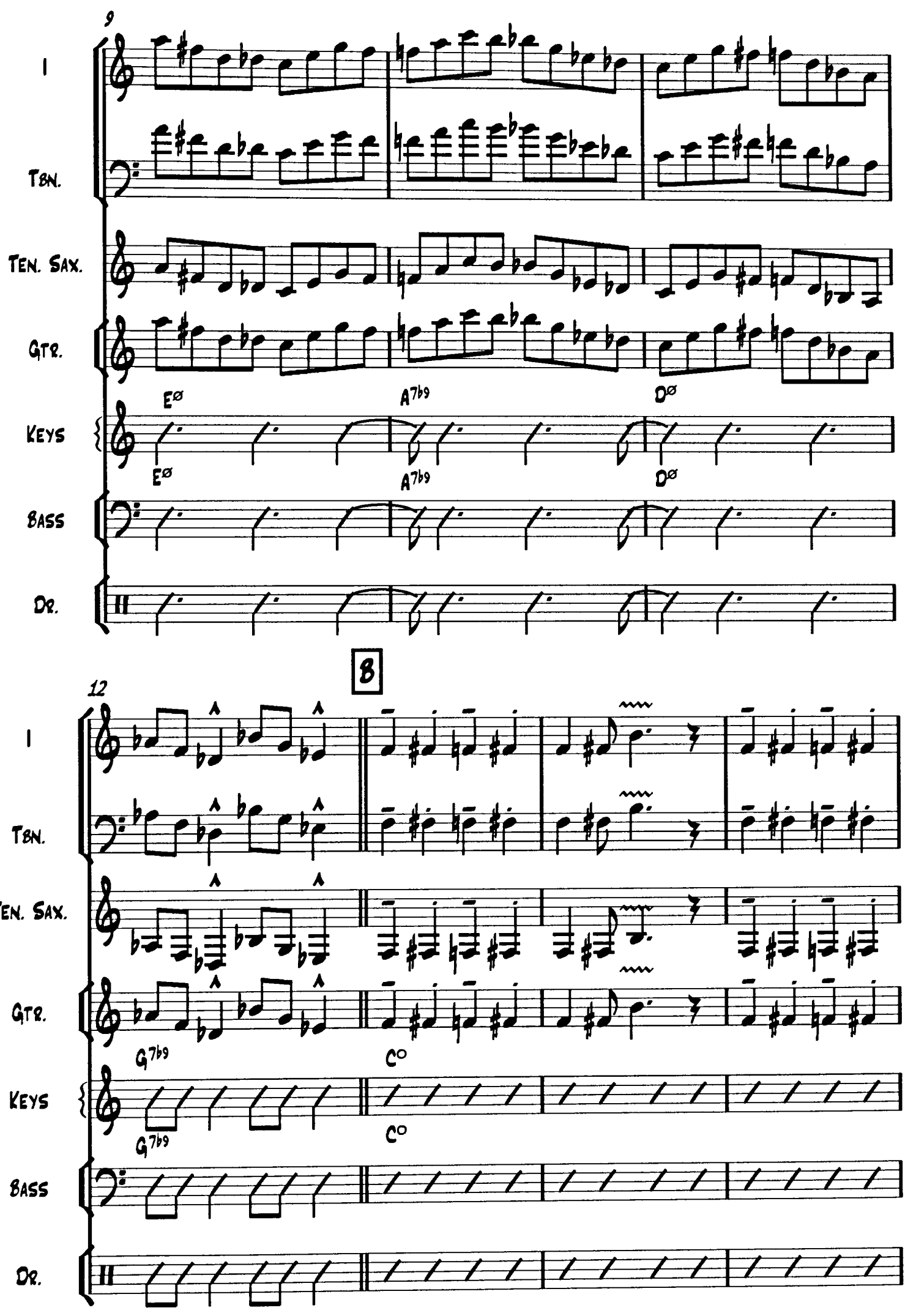




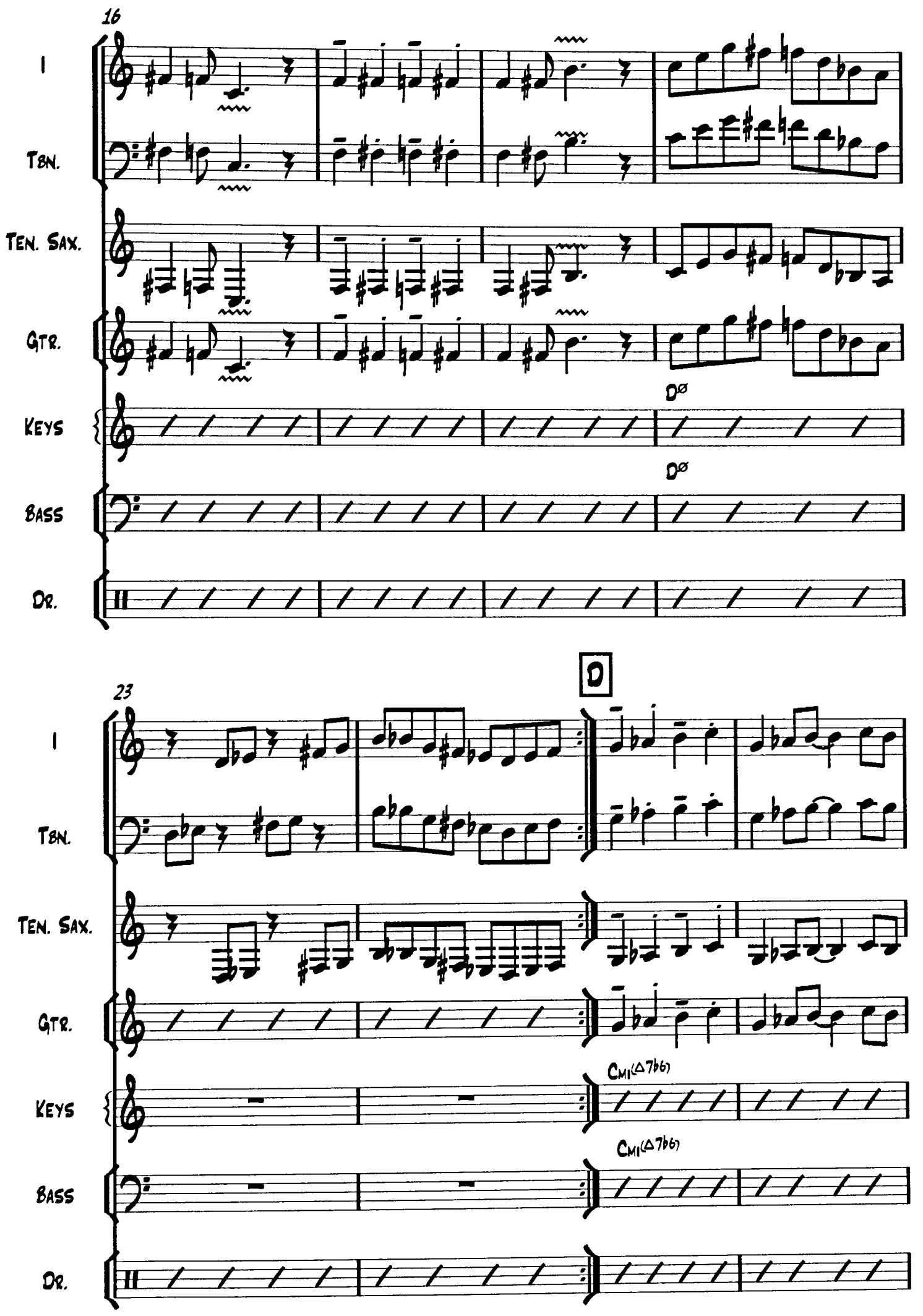




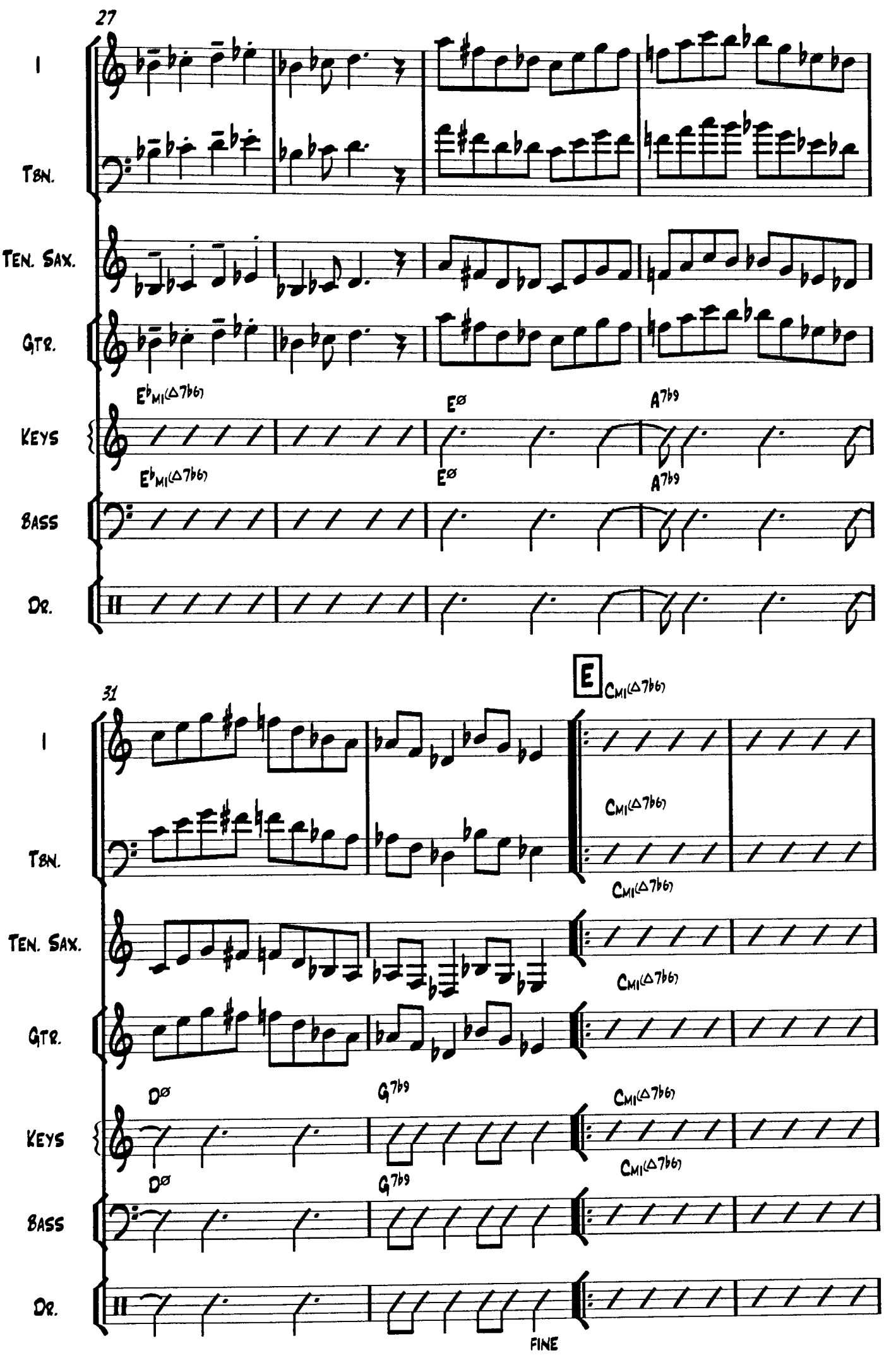



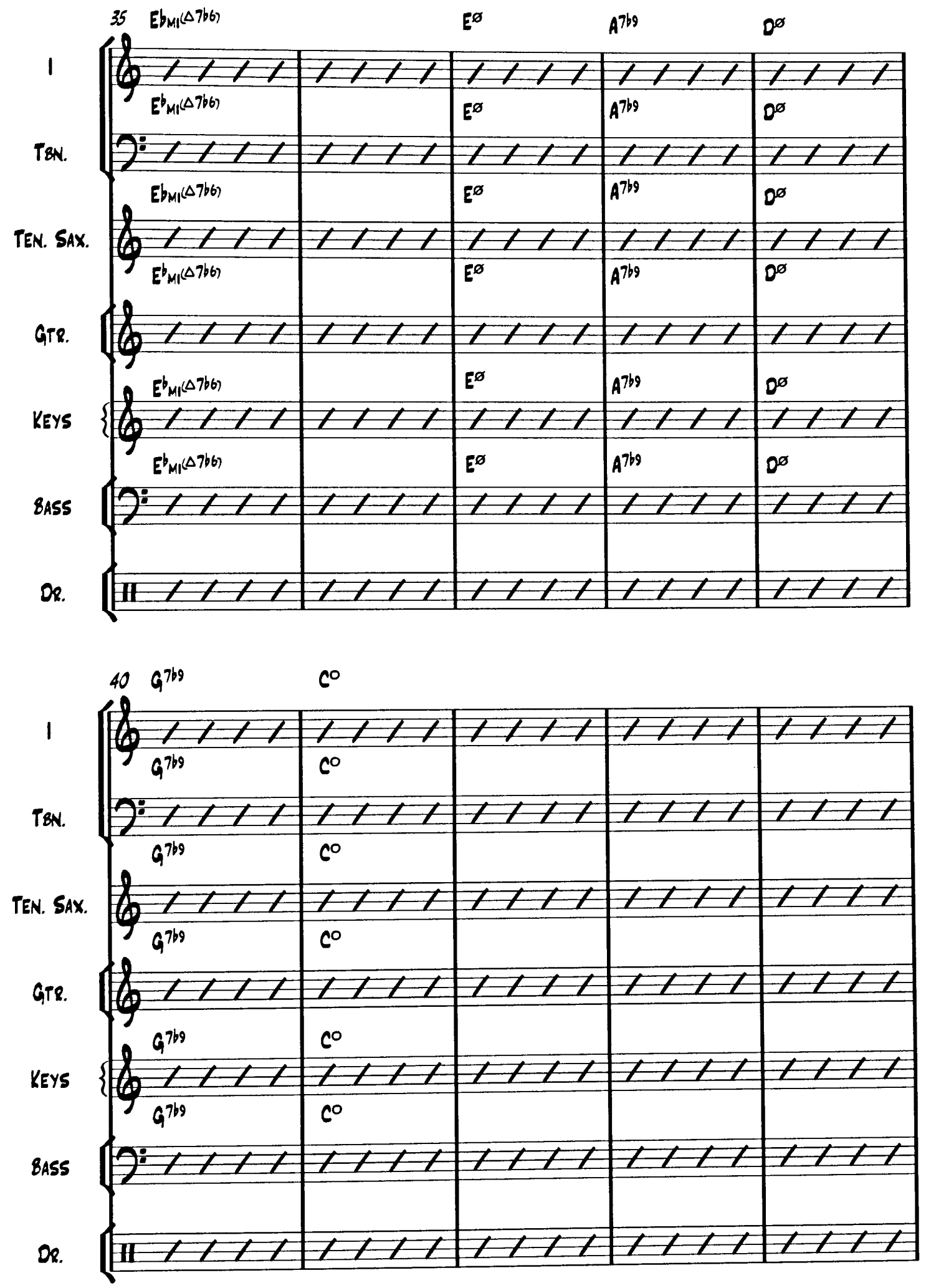

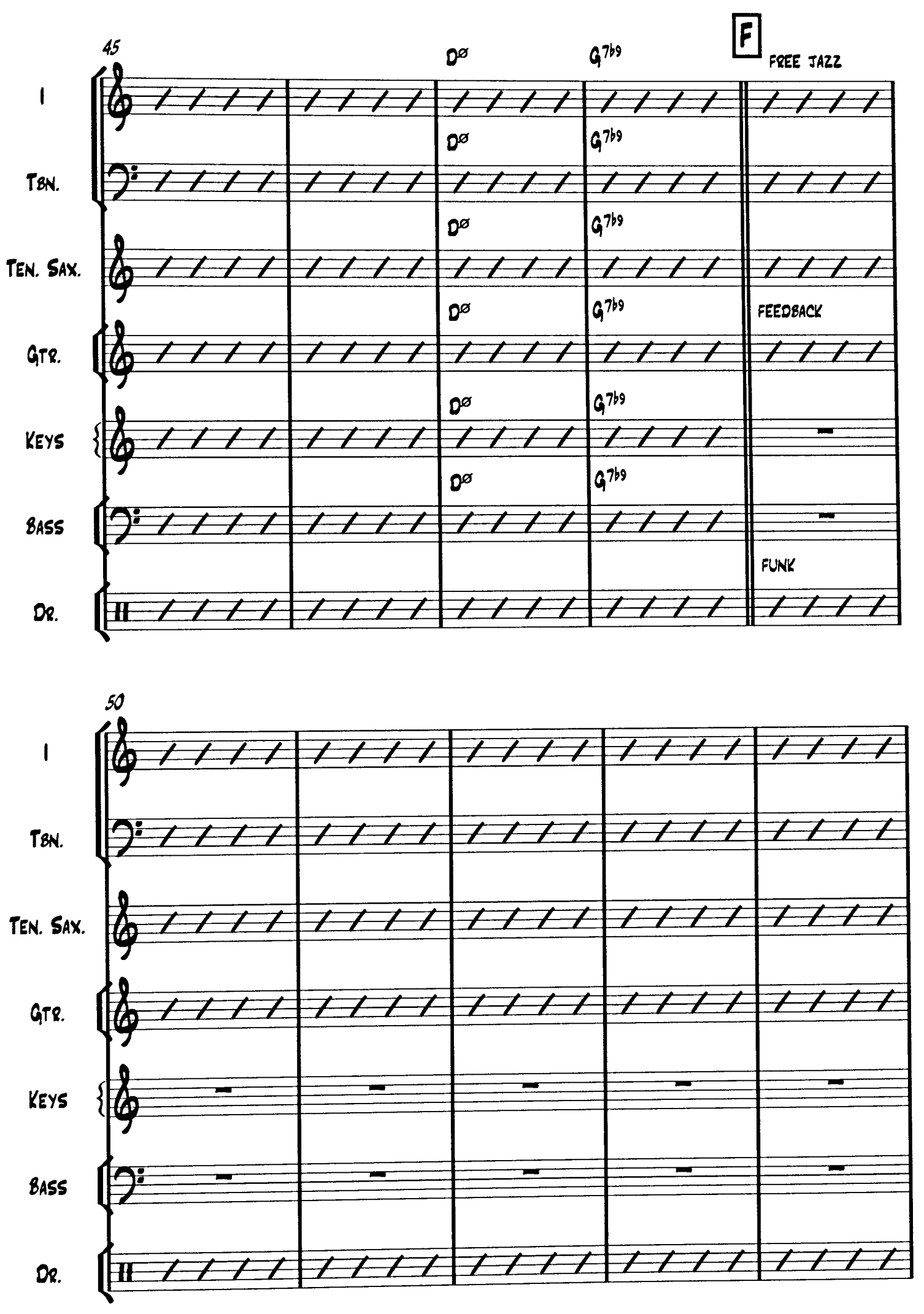

27 

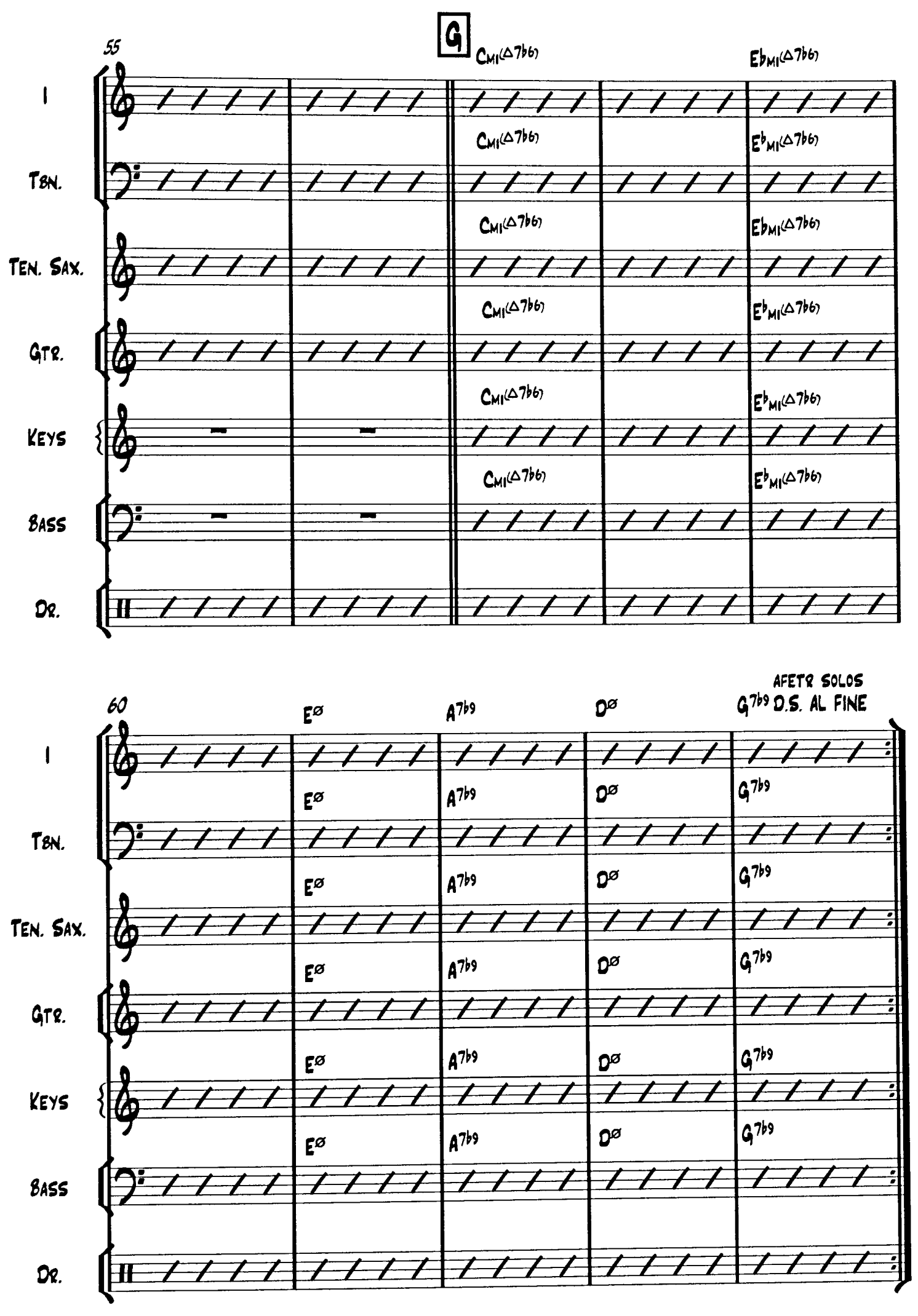

28 

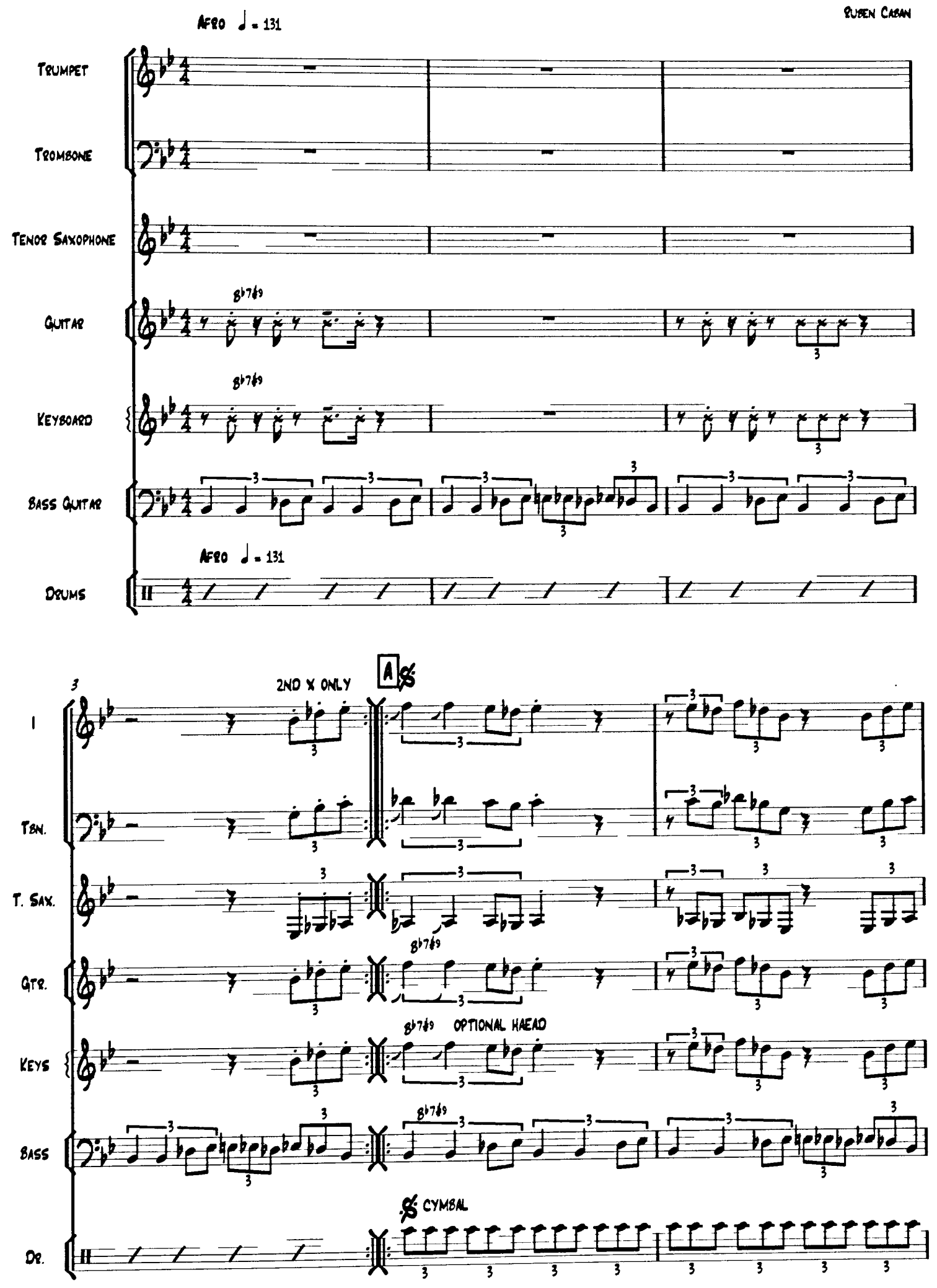


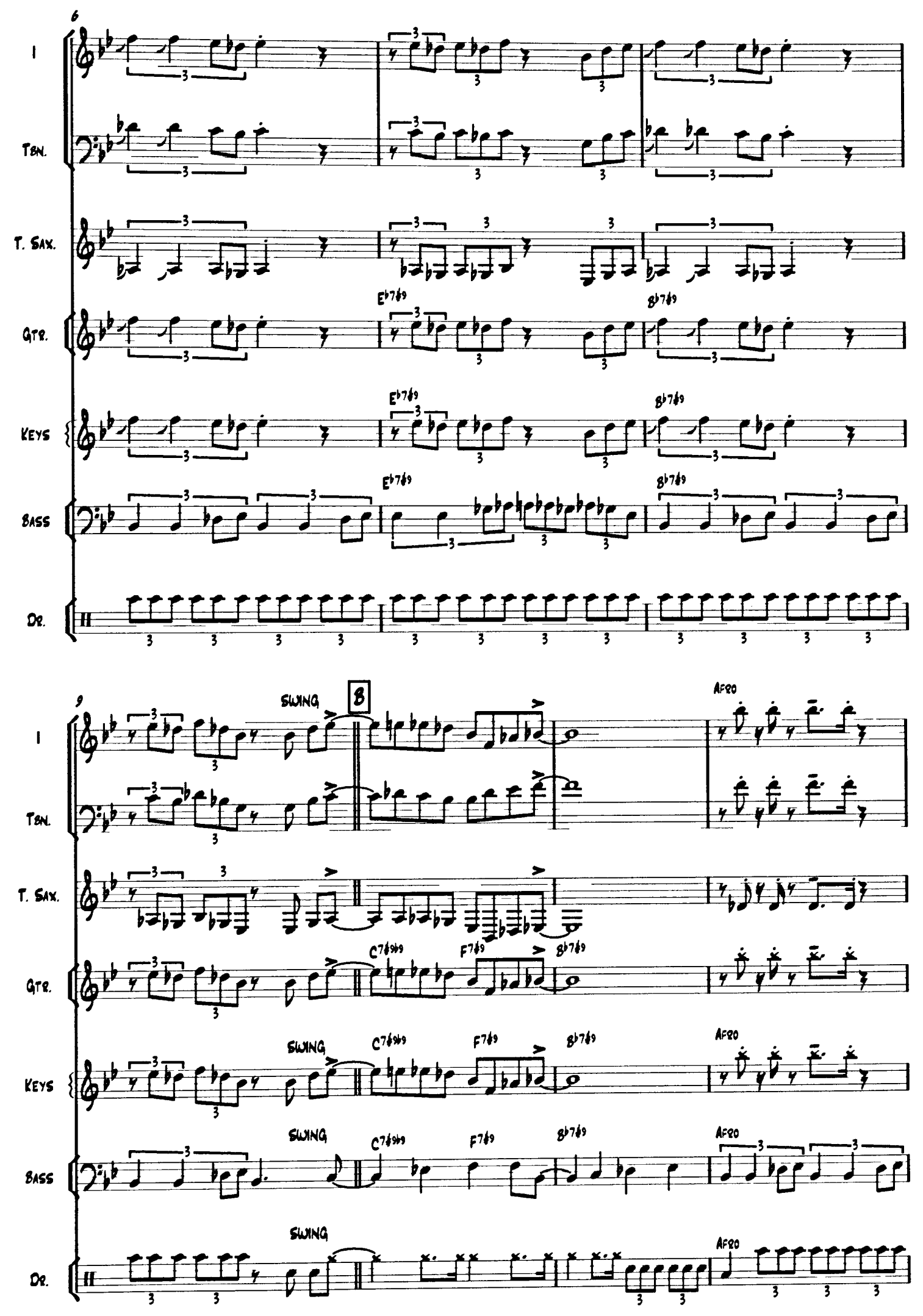




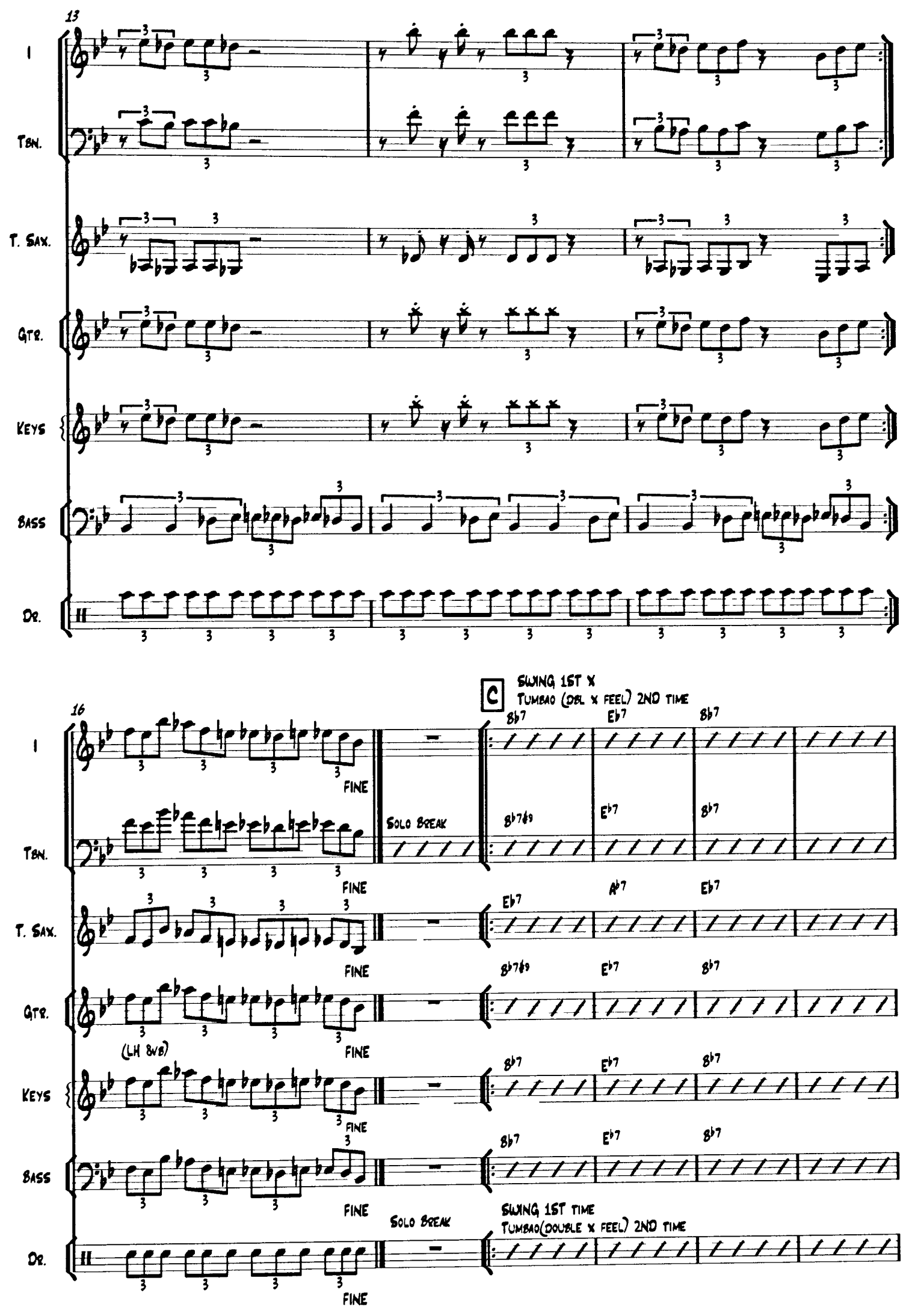




\begin{tabular}{|c|c|c|c|c|c|c|}
\hline & & 857 & $a^{7}$ & c-7 & F & (8) \\
\hline \multirow[t]{2}{*}{1} & $6|>1 /| 1 / 1$ & $1 / 11$ & I/I & 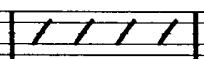 & $|/ / Z|$ & I/IR \\
\hline & E⿱⿱亠䒑十七 & 8 & $a^{7}$ & $c-7$ & $F$ & gin \\
\hline \multirow[t]{2}{*}{ Tow. } & $b^{b} I I I A I I$ & 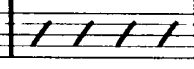 & II & $|x| x \mid$ & 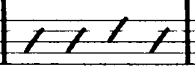 & $|c| c \mid$ \\
\hline & Eb & 867 & $a^{9}$ & $c^{7}$ & F1 & $8 b 7$ \\
\hline \multirow[t]{2}{*}{ inx. } & $|t| 1 \mid 1$ & $1 / 1 / 1$ & $|l| l \mid$ & $|1111|$ & $|1| 1 \mid$ & 1111 \\
\hline & E⿱⺌兀 & $8 n$ & $a^{9}$ & c-l & F? & $g$ \\
\hline & $6 / / I t / / L$ & 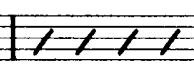 & $E I L$ & $\mid 1 / 1 / 1$ & $E / I A$ & 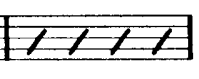 \\
\hline & 57 & $8^{n}$ & Q? & & & 8 \\
\hline & & & & & & \\
\hline & En & 87 & a' & $c-9$ & F & $8^{b 7}$ \\
\hline & $\left|2 b^{2}+1+1\right| \leq t$ & 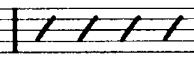 & 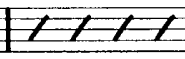 & $|c|$ & 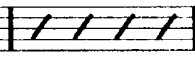 & 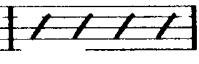 \\
\hline & 76 & 171 & & & & 7 \\
\hline
\end{tabular}

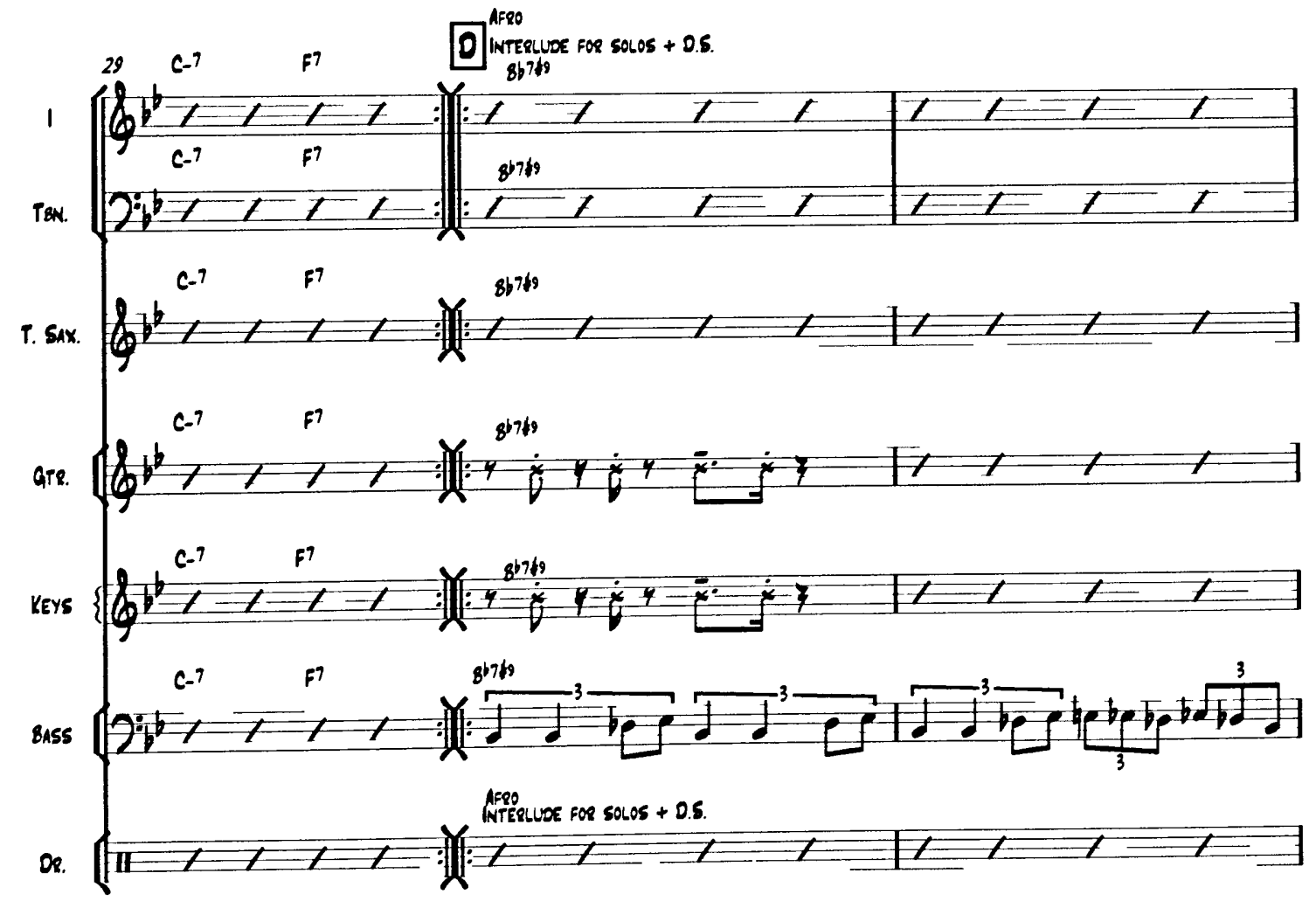




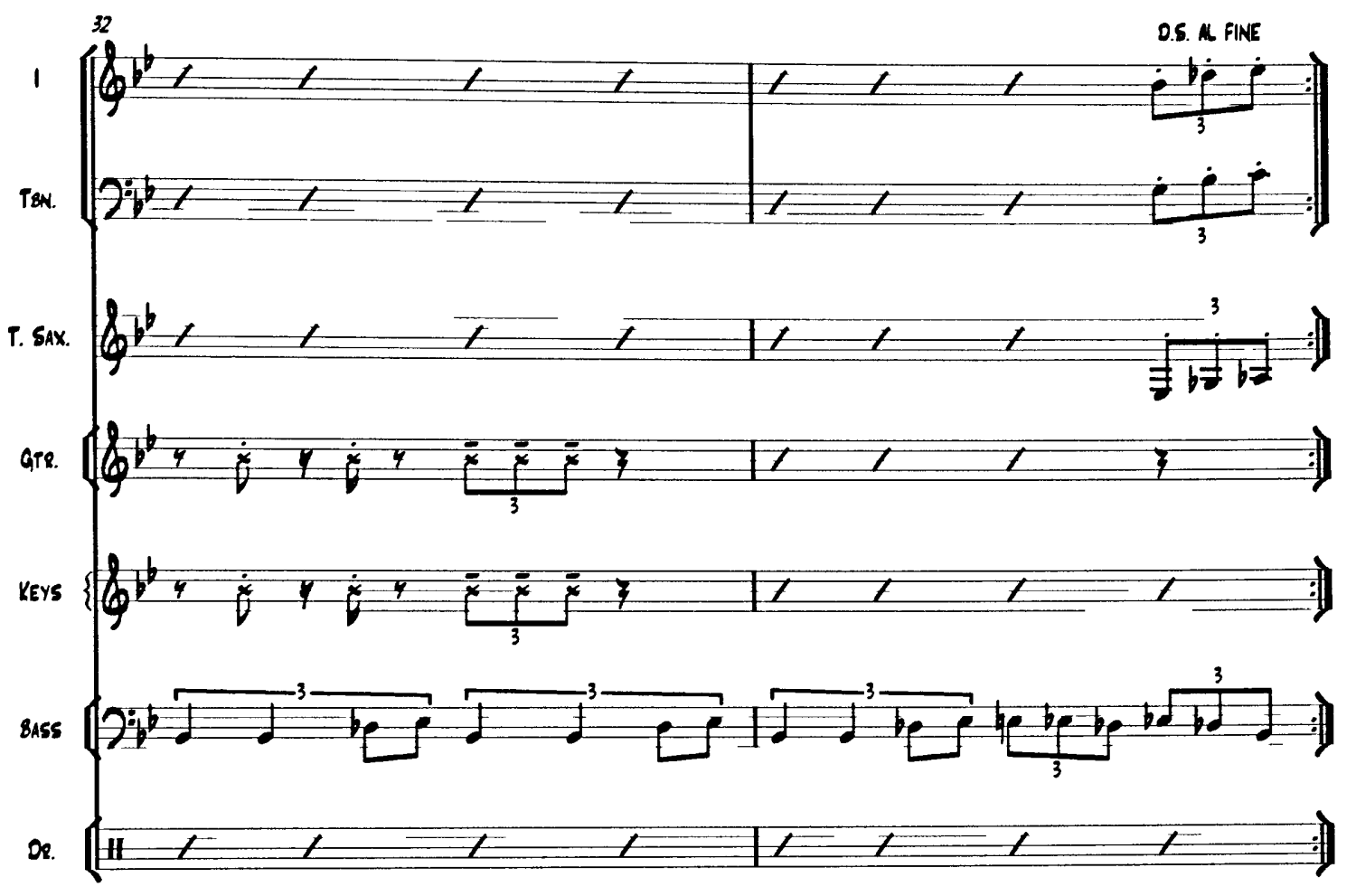

33 
SaIl Away

TOM Hares

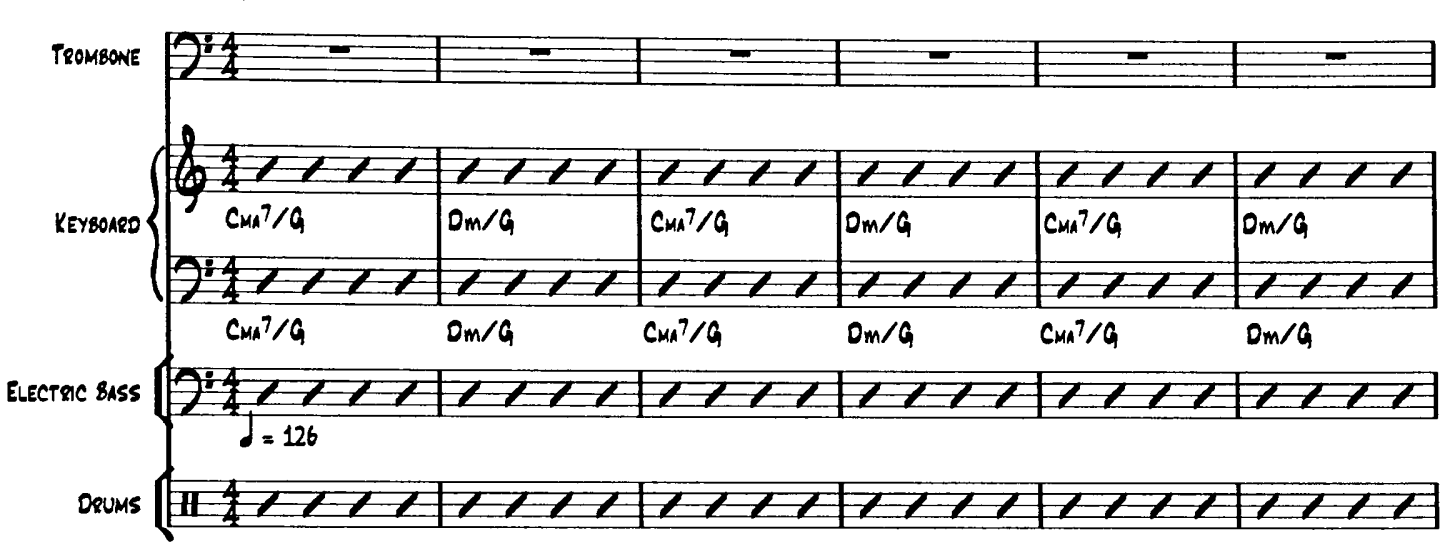

因必
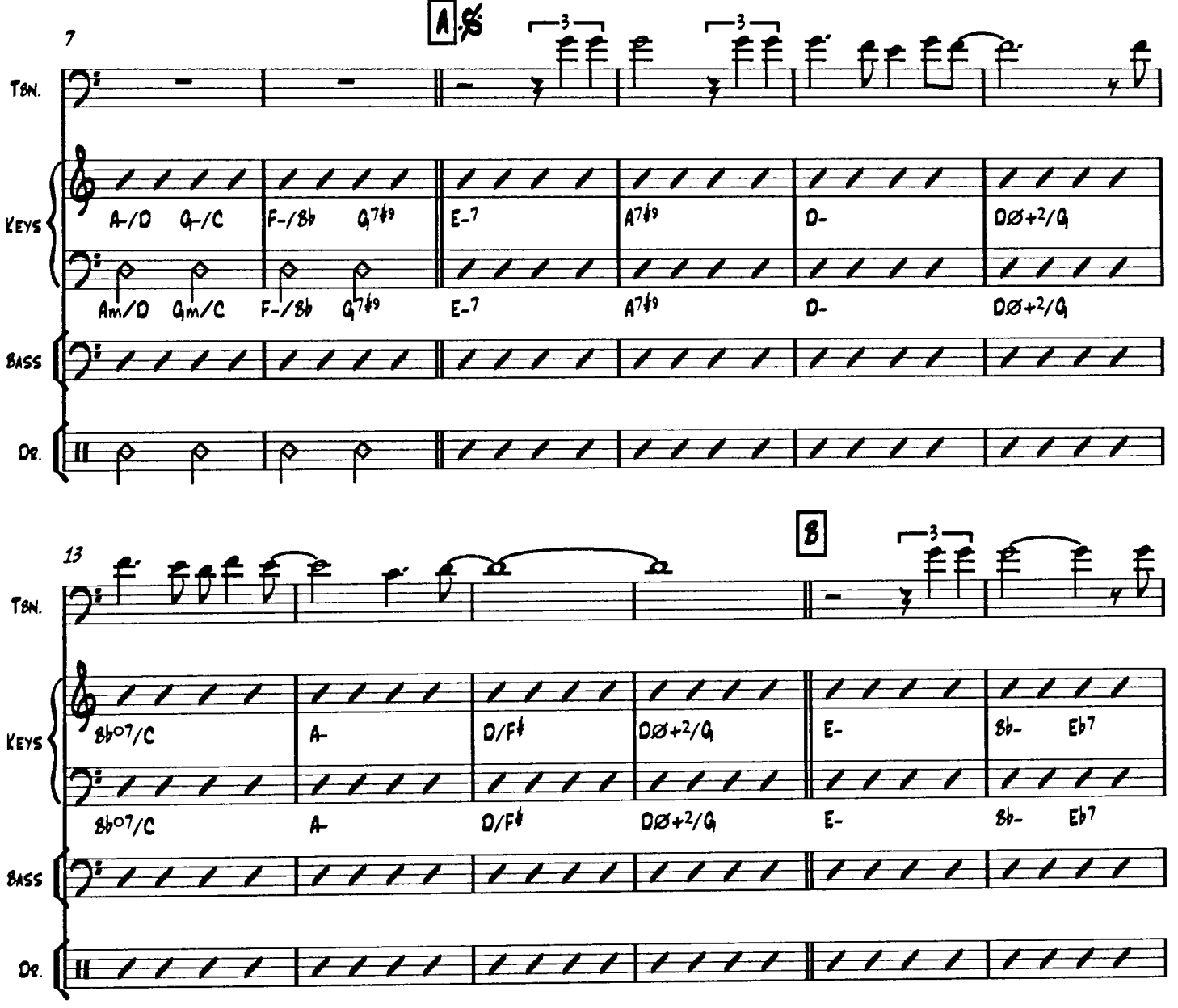

34 

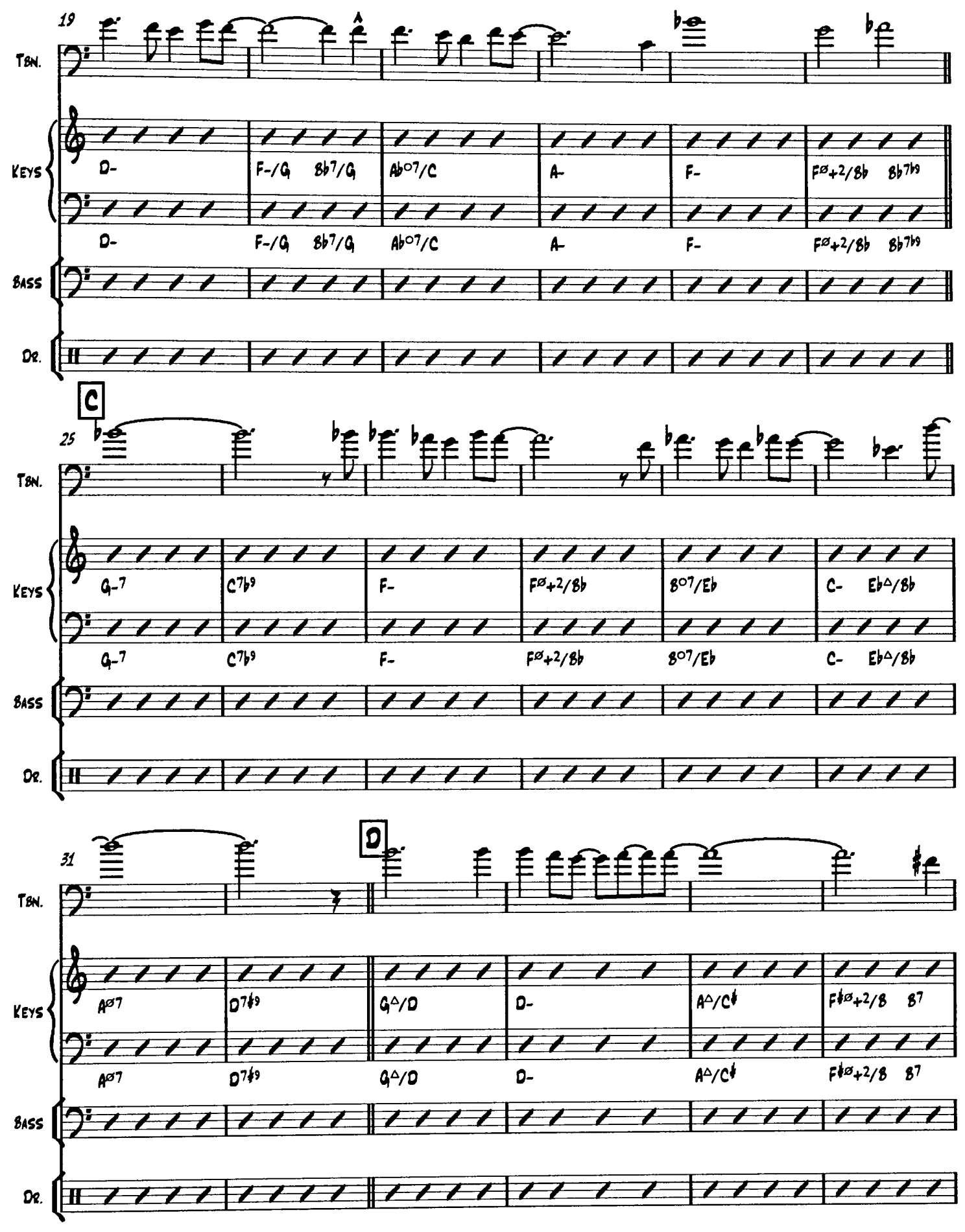

35 

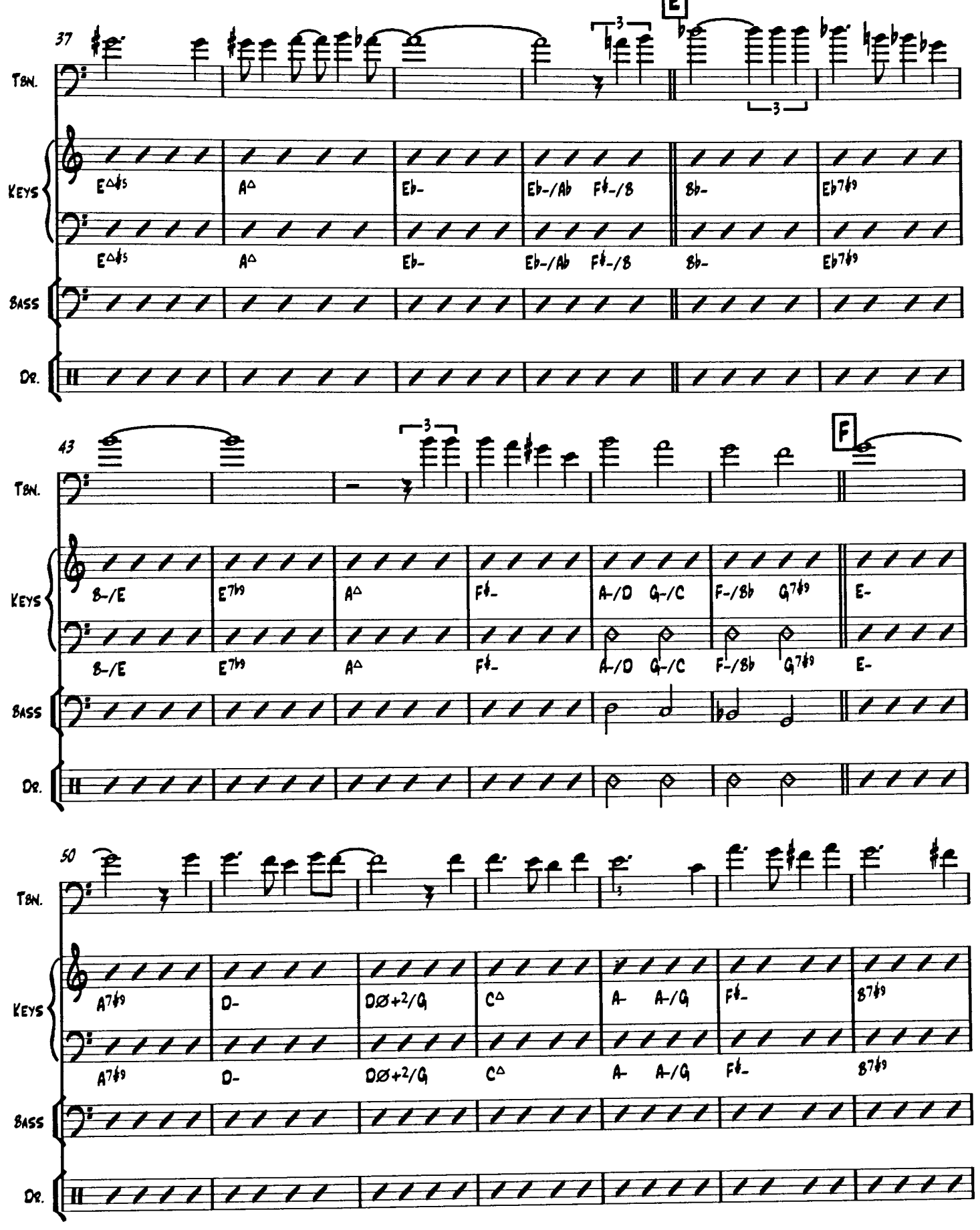

36 

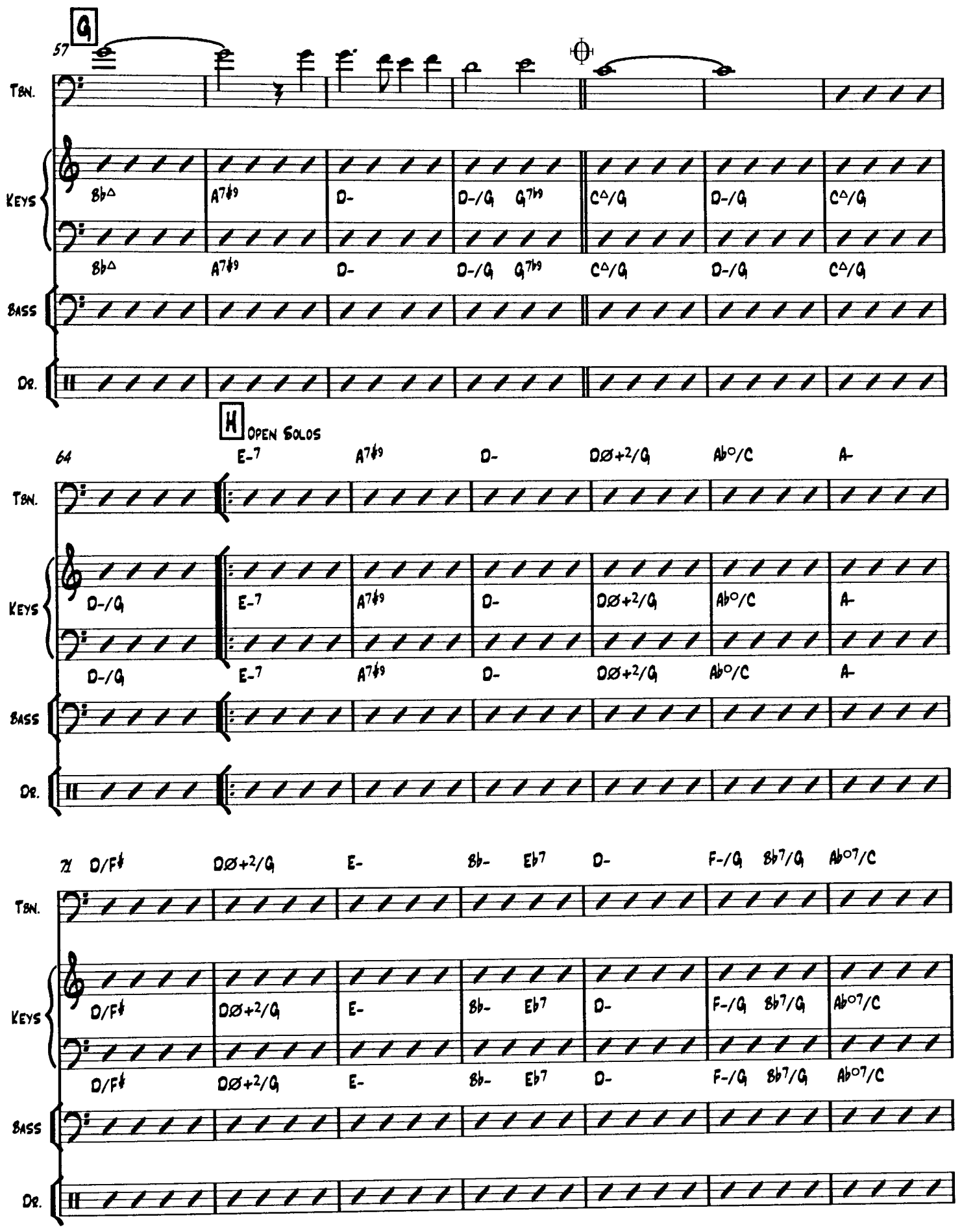

37 


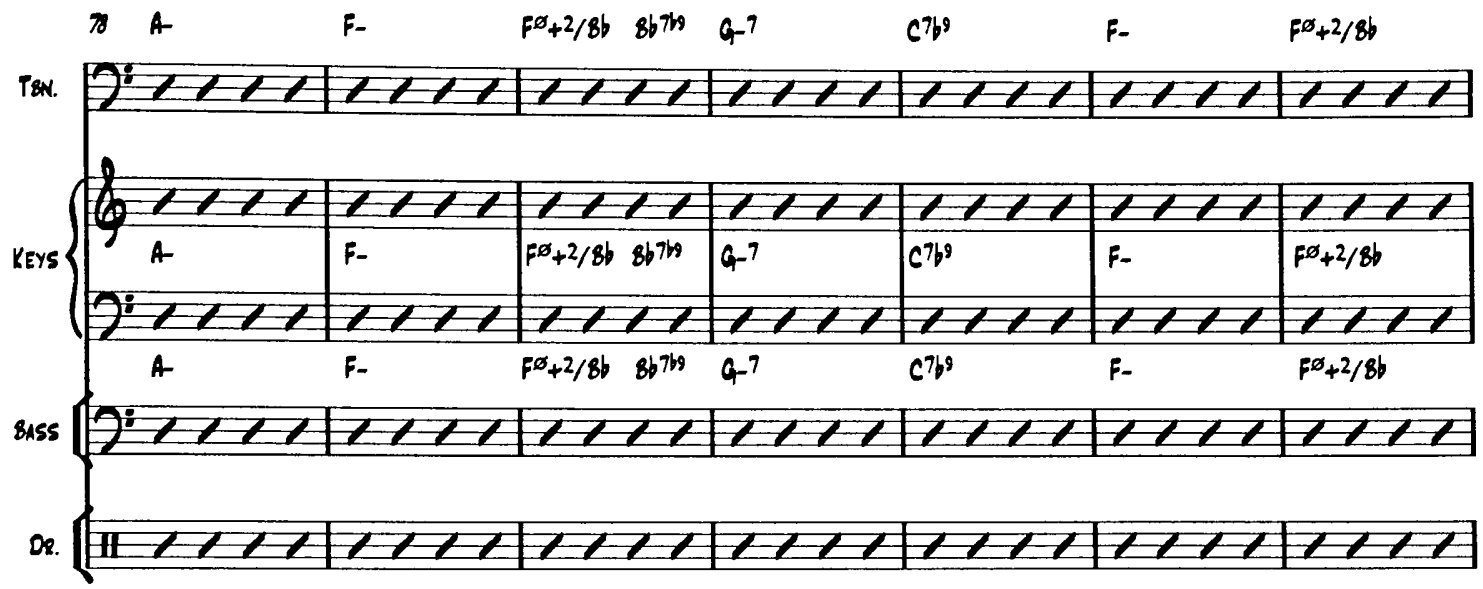

$858^{07 / E b}$

C- $86 \Delta / 8 b \quad A^{89}$

076

$Q \triangle 10$

o-

$A^{\Delta} / C^{k}$

TEN.

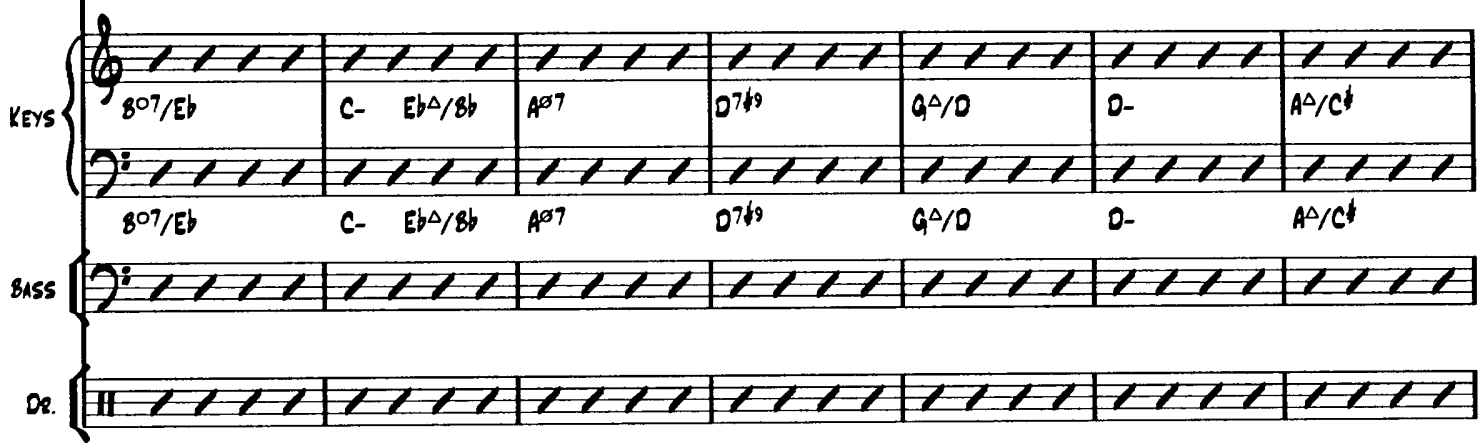

$92 F+6+2 / 8 \quad 87 \quad E \Delta t s$

$A^{\Delta}$

Eb-

Eb-/Ab Ft-/8 8b-

Eb7is

TEN.

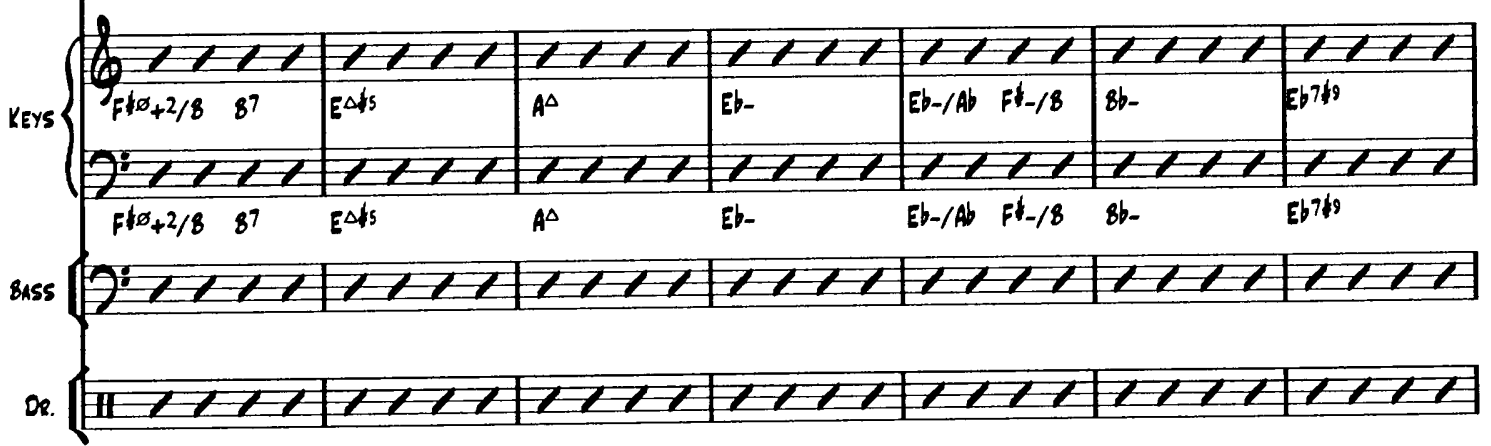

38 

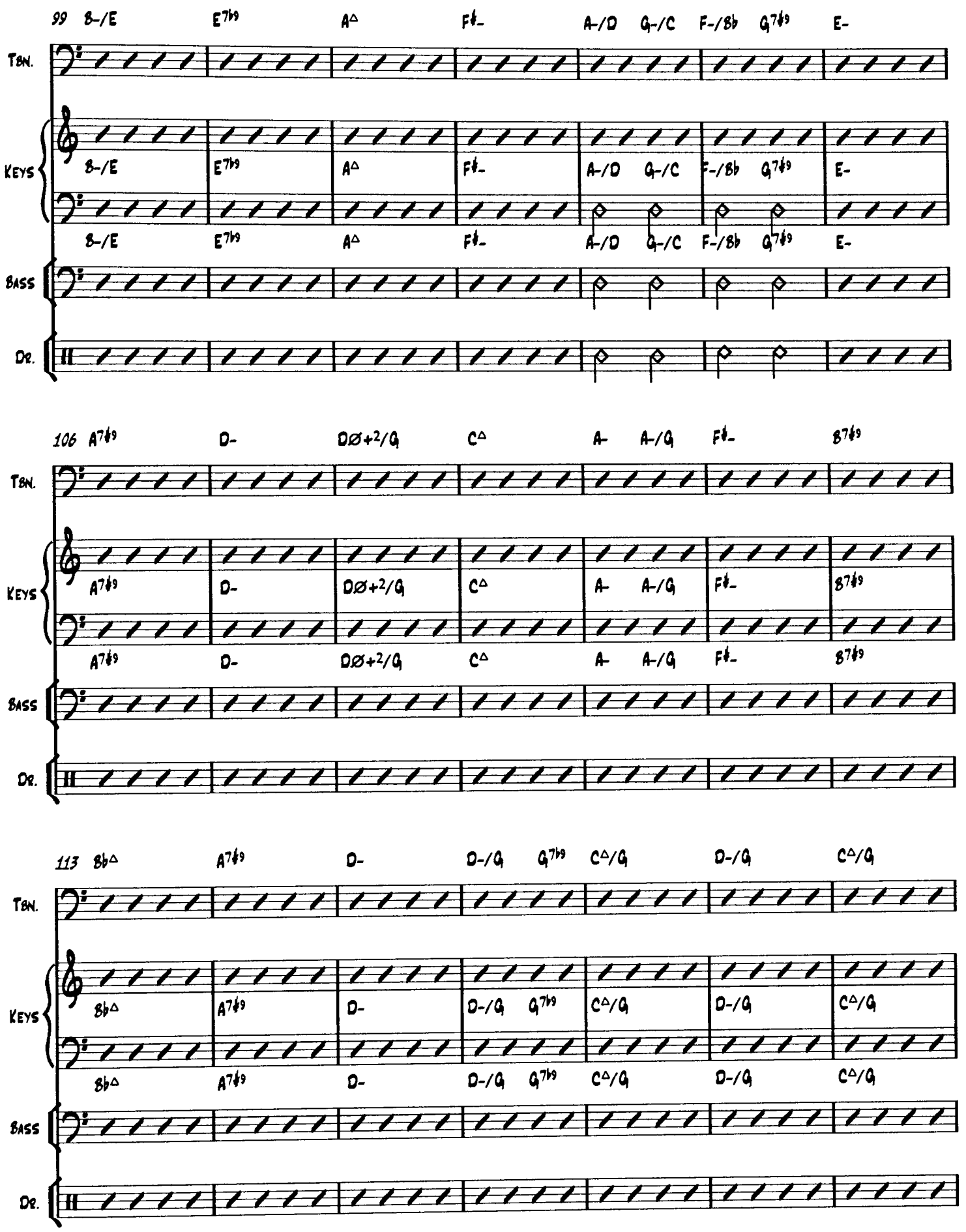

39 

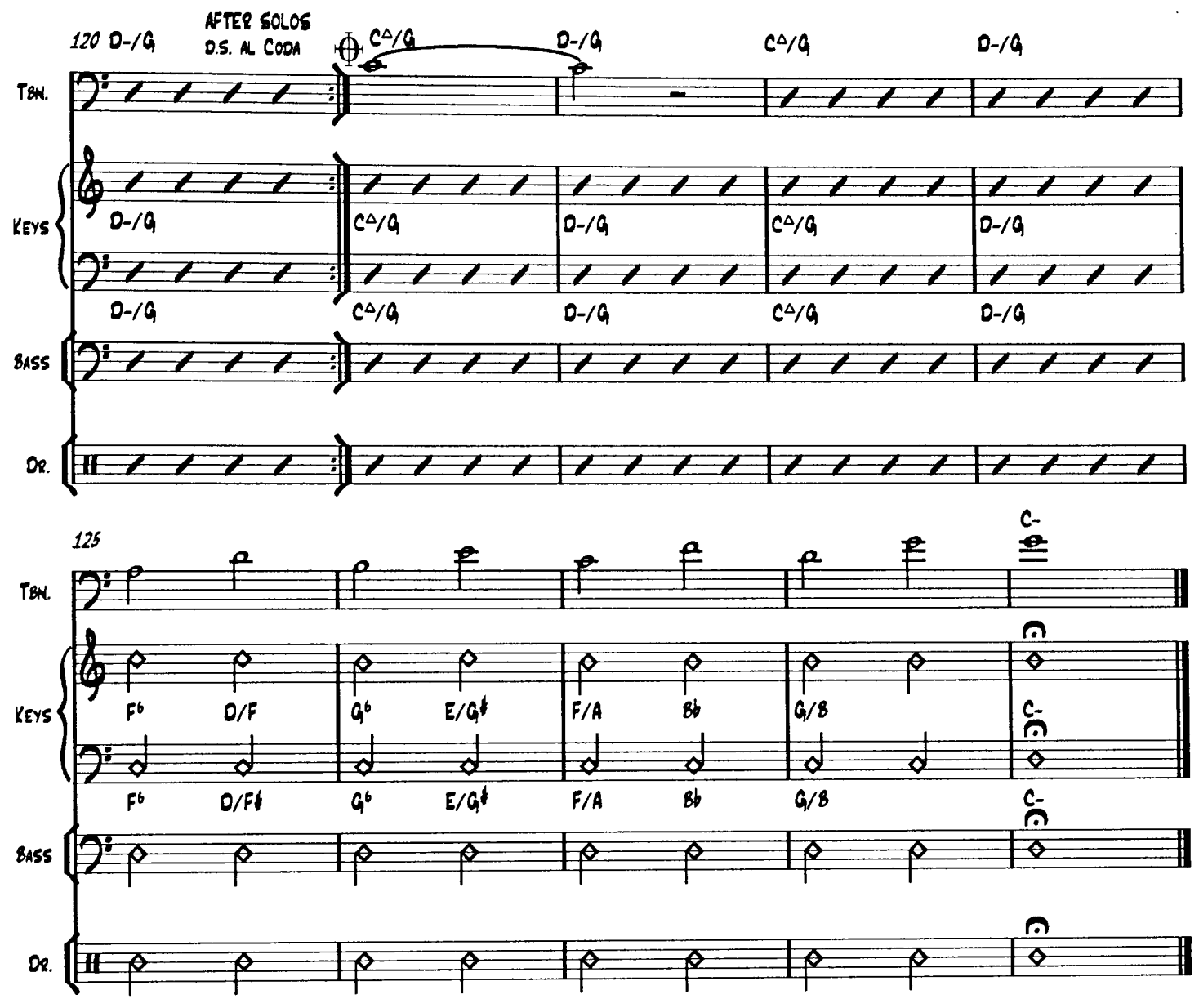

40 

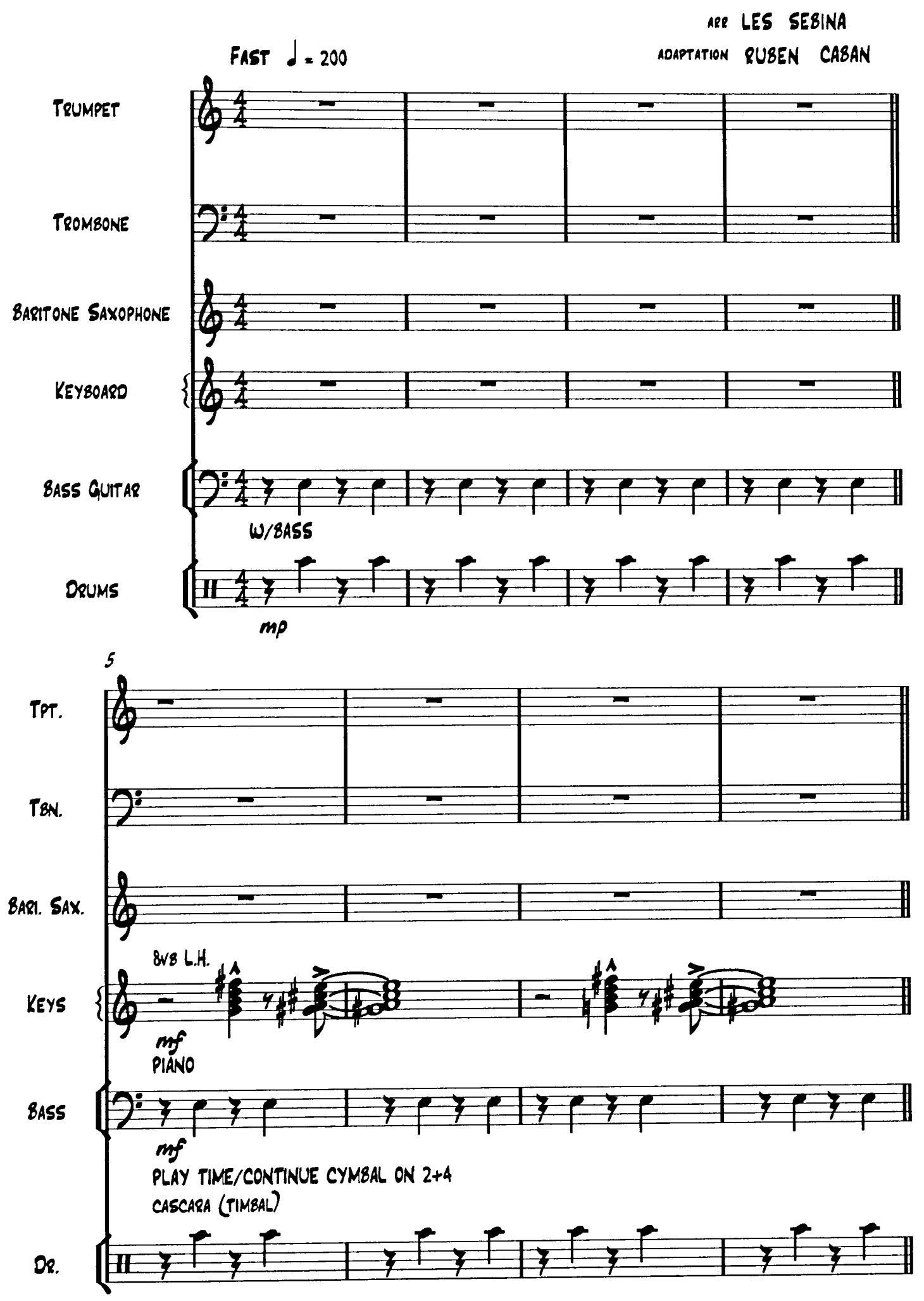


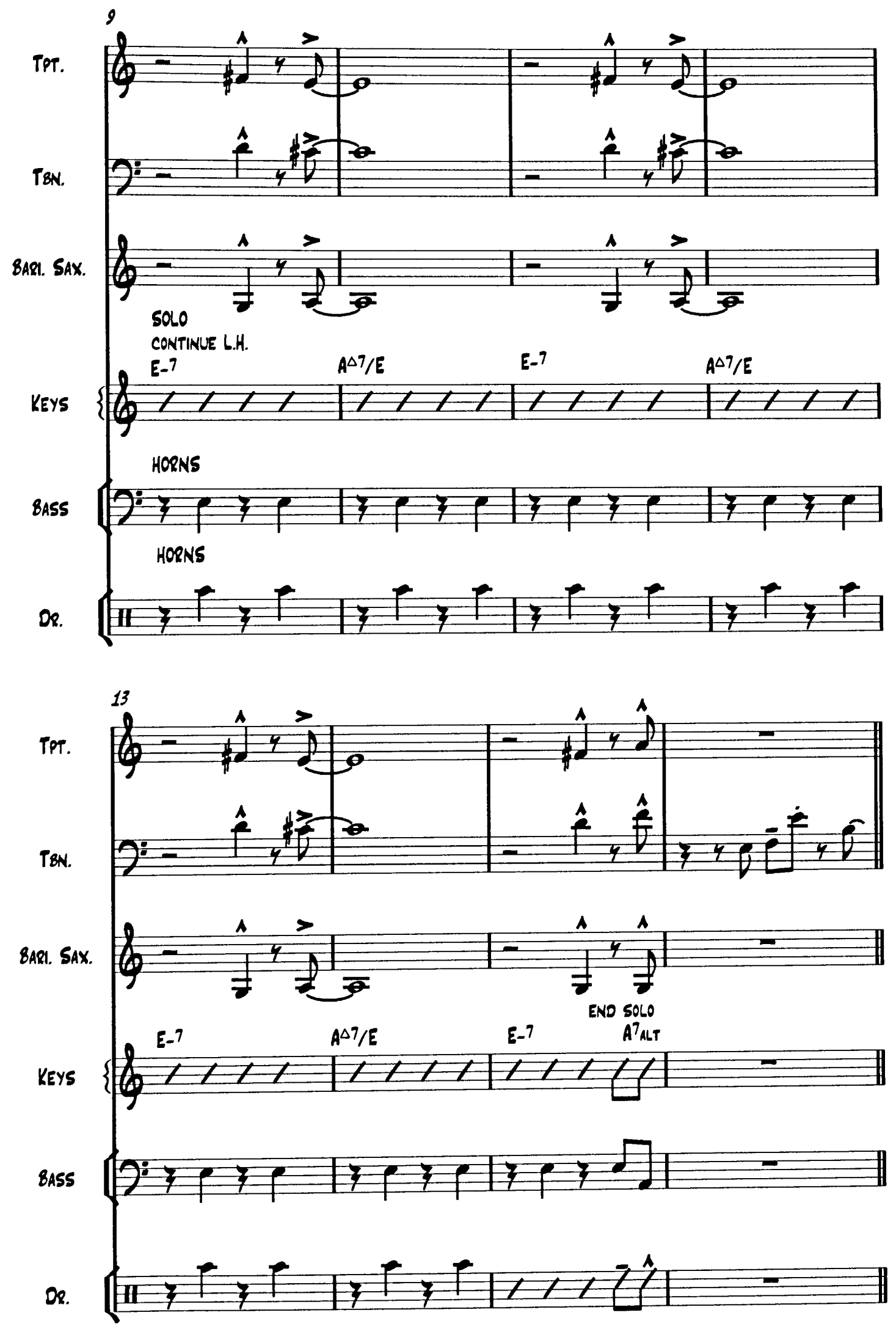




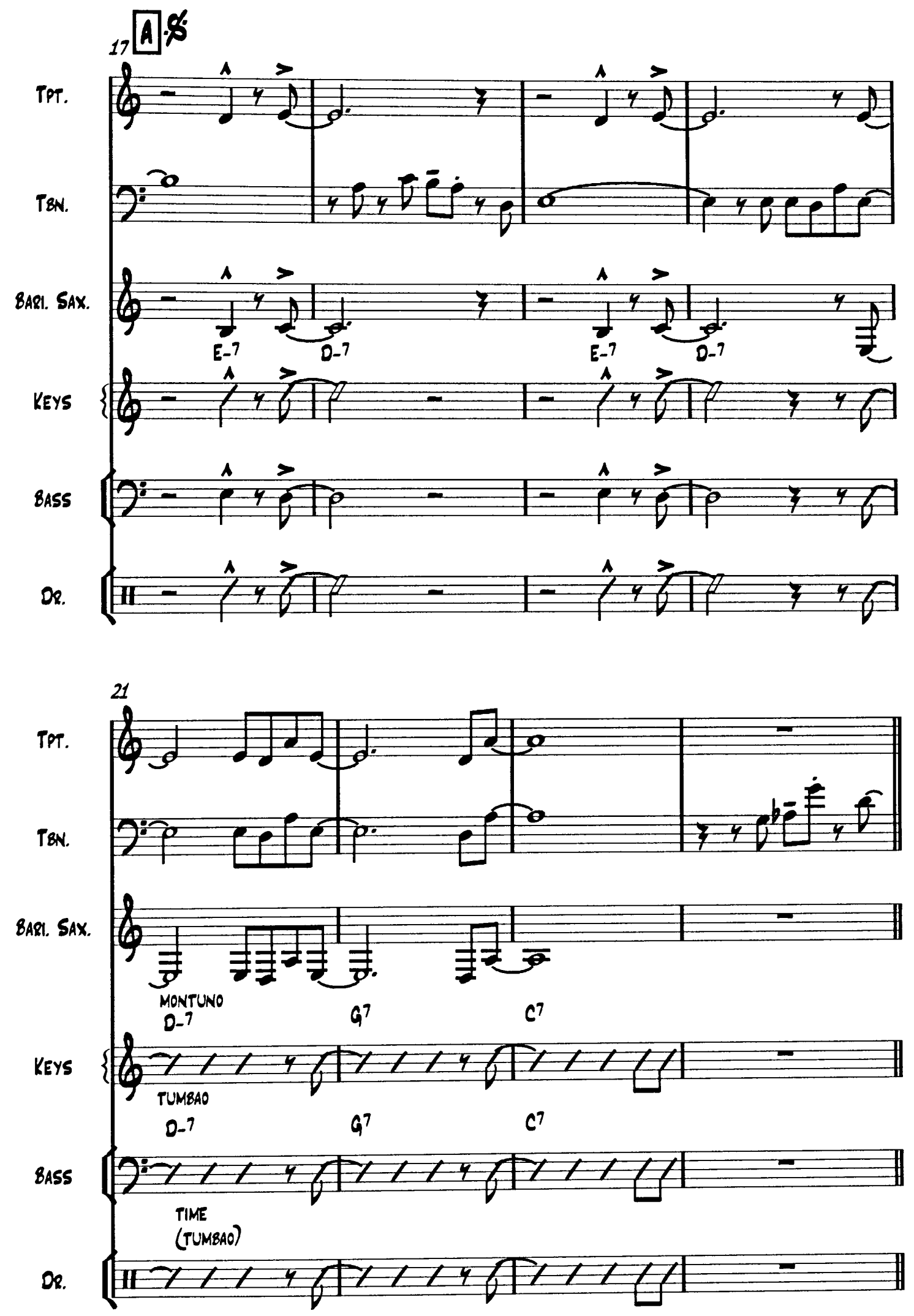



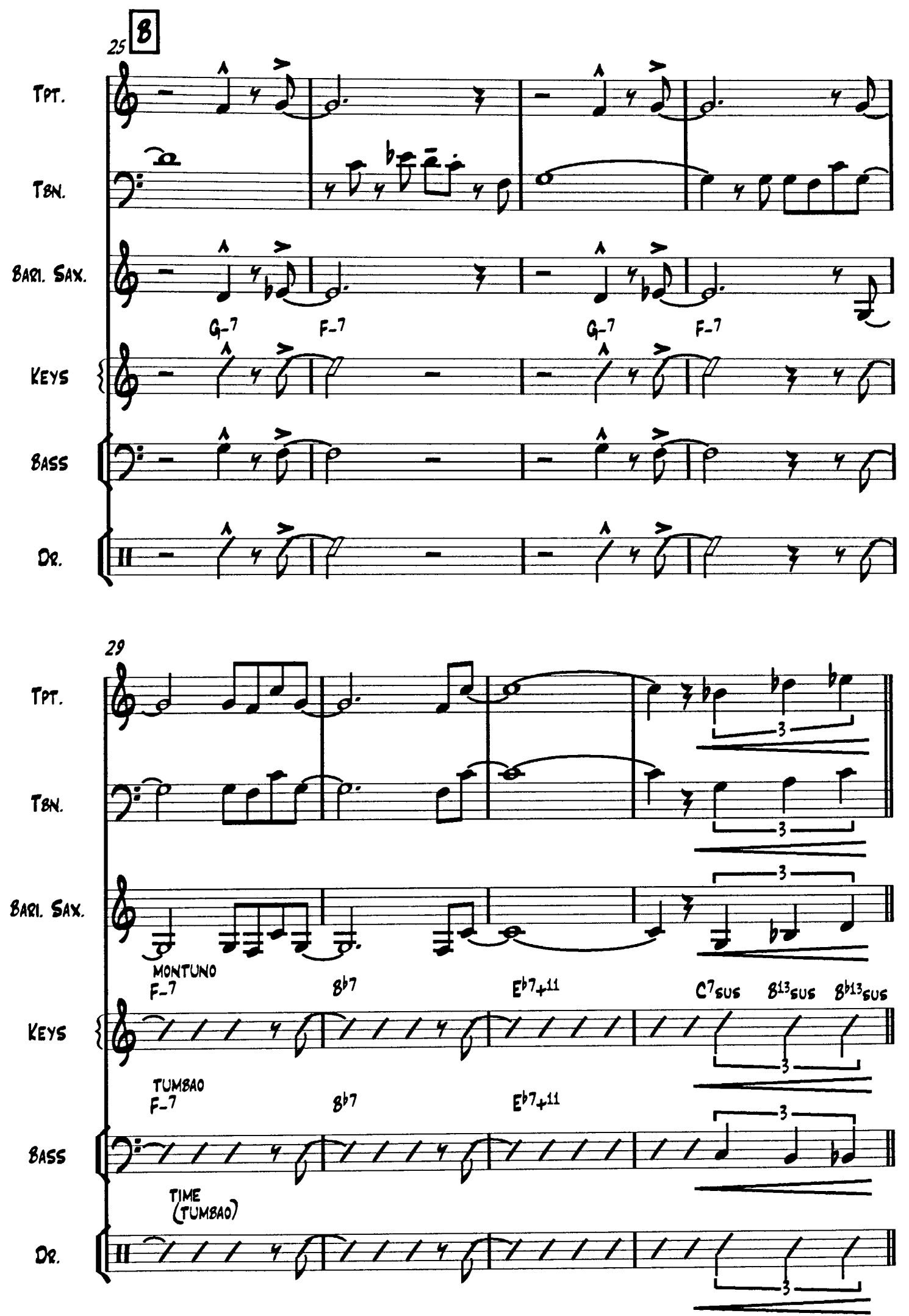

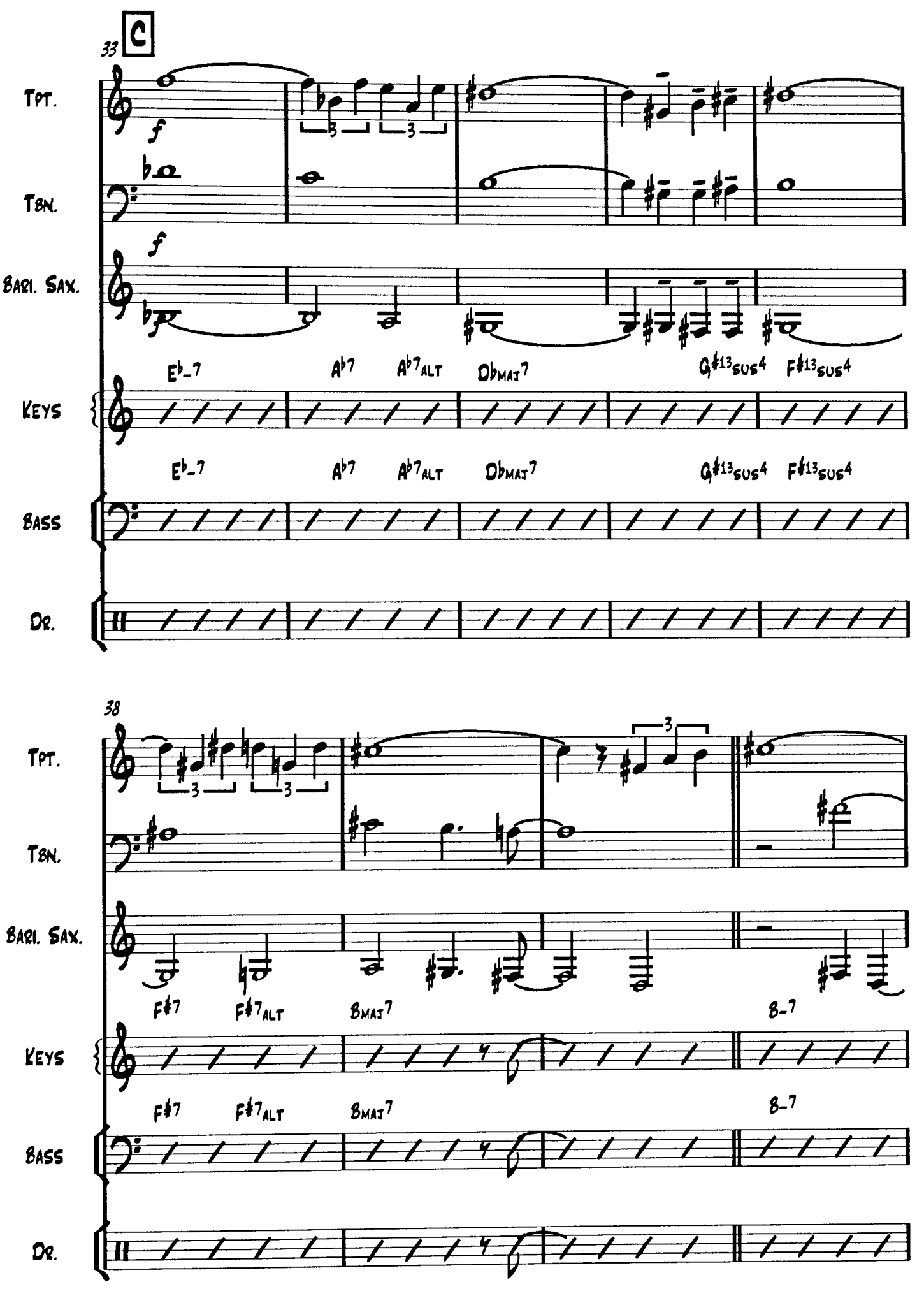

45 

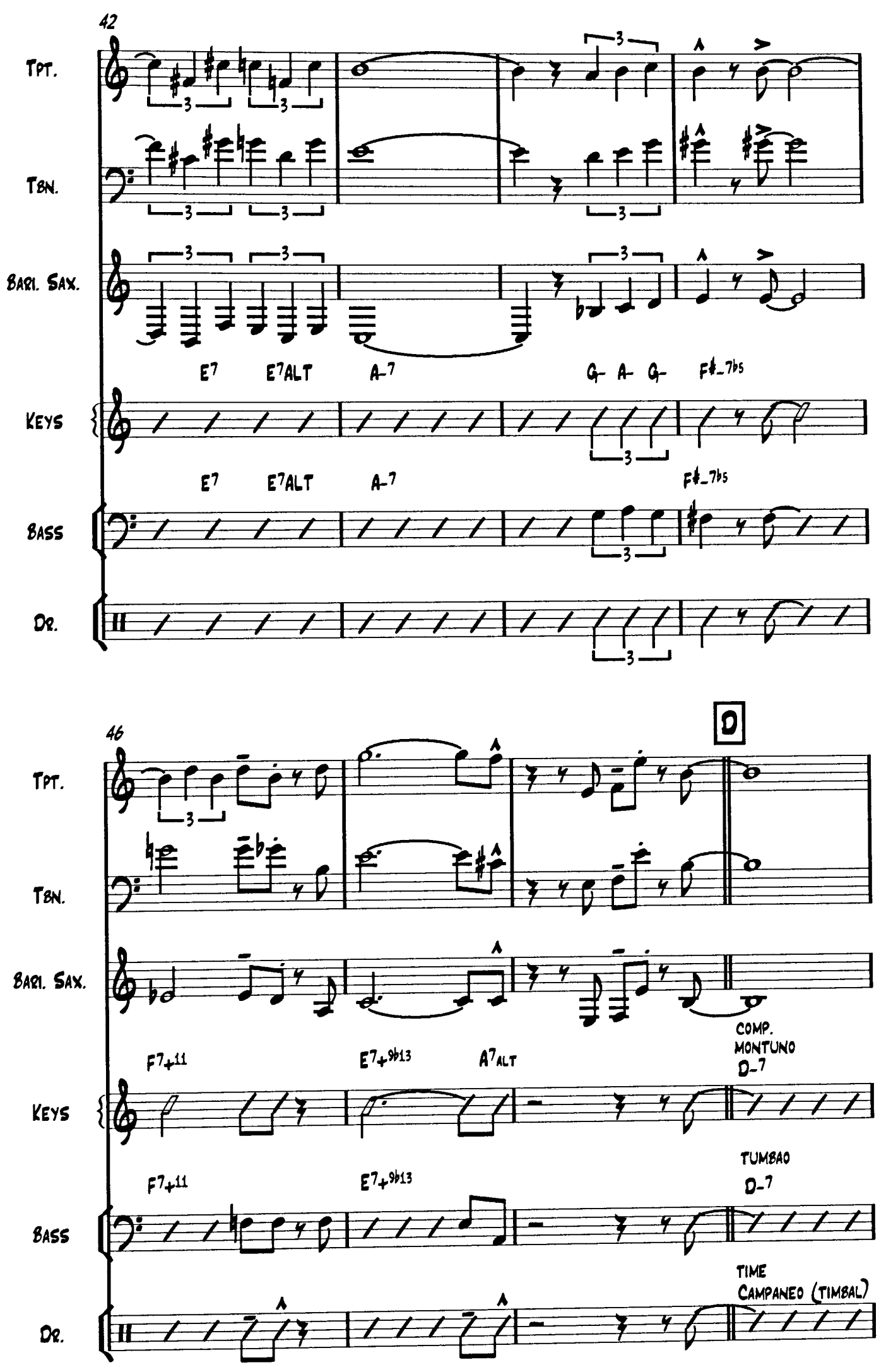

46 

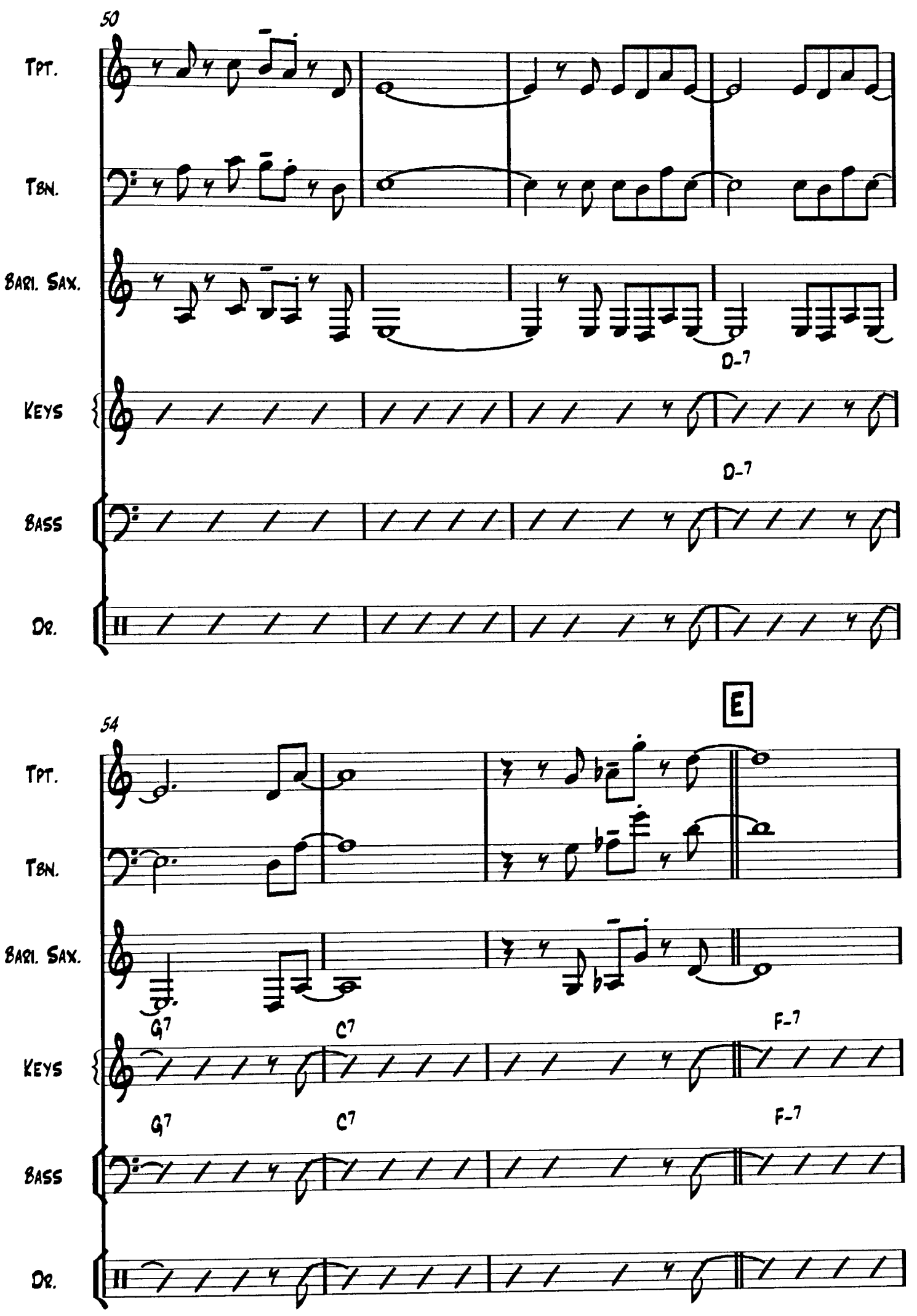


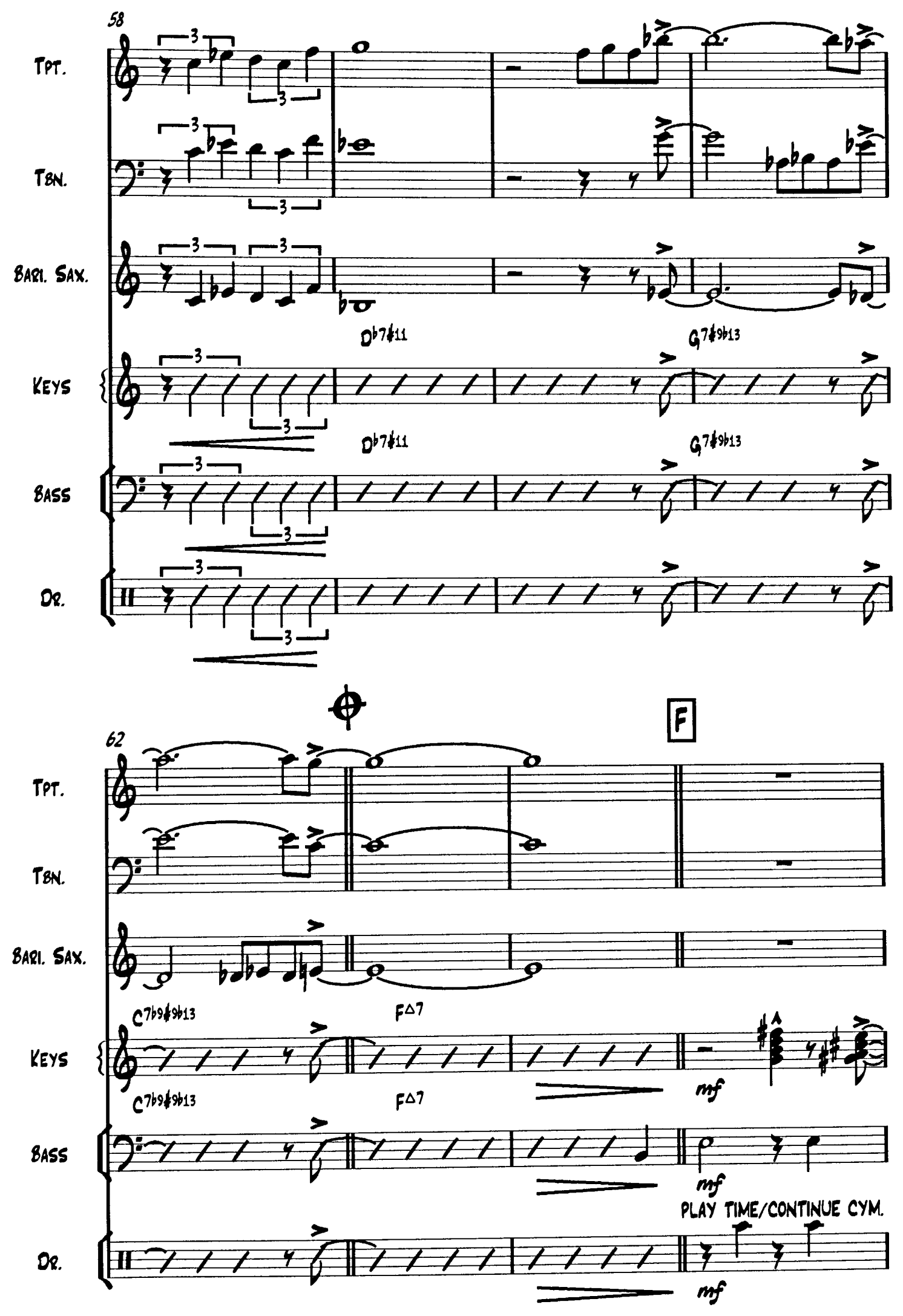



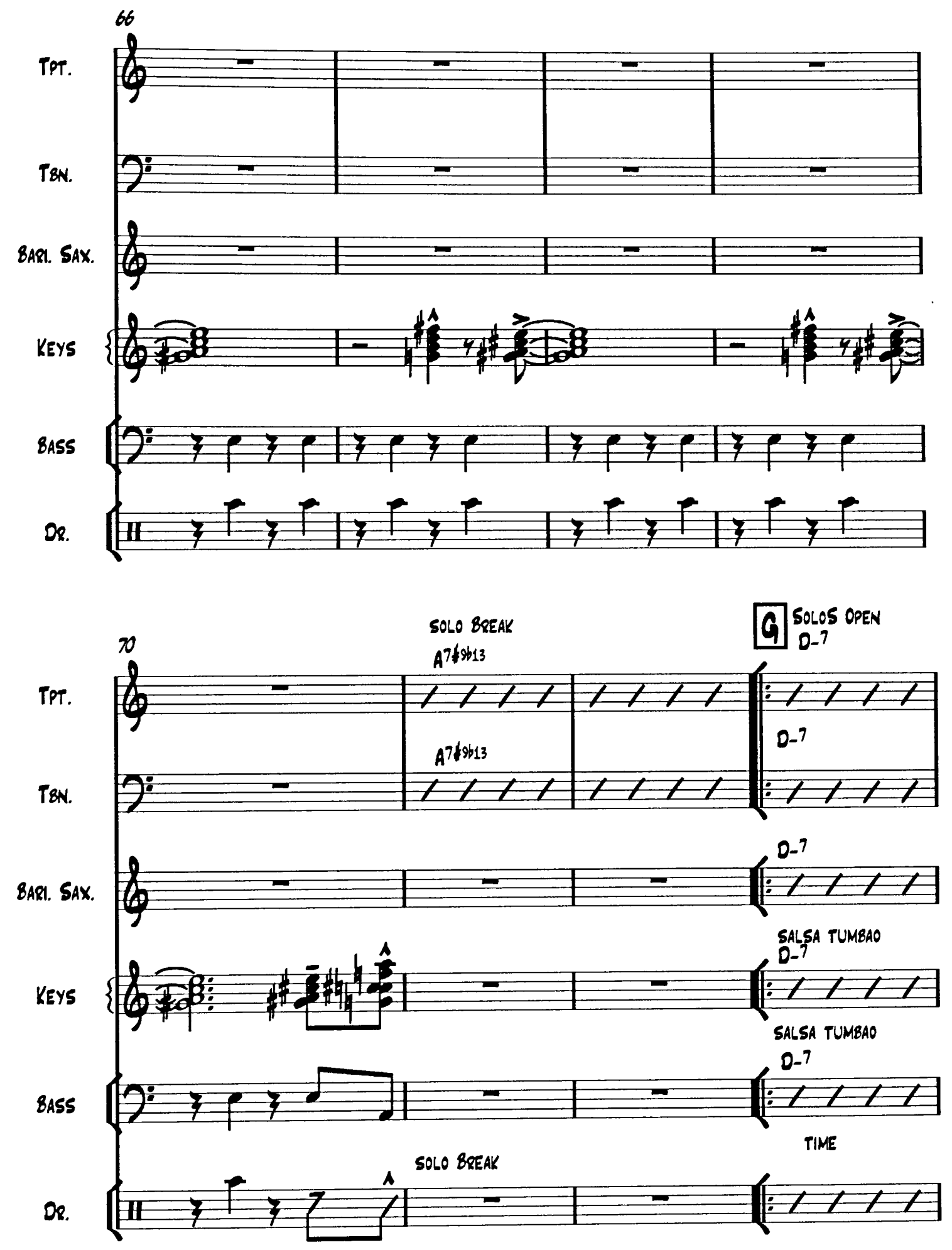

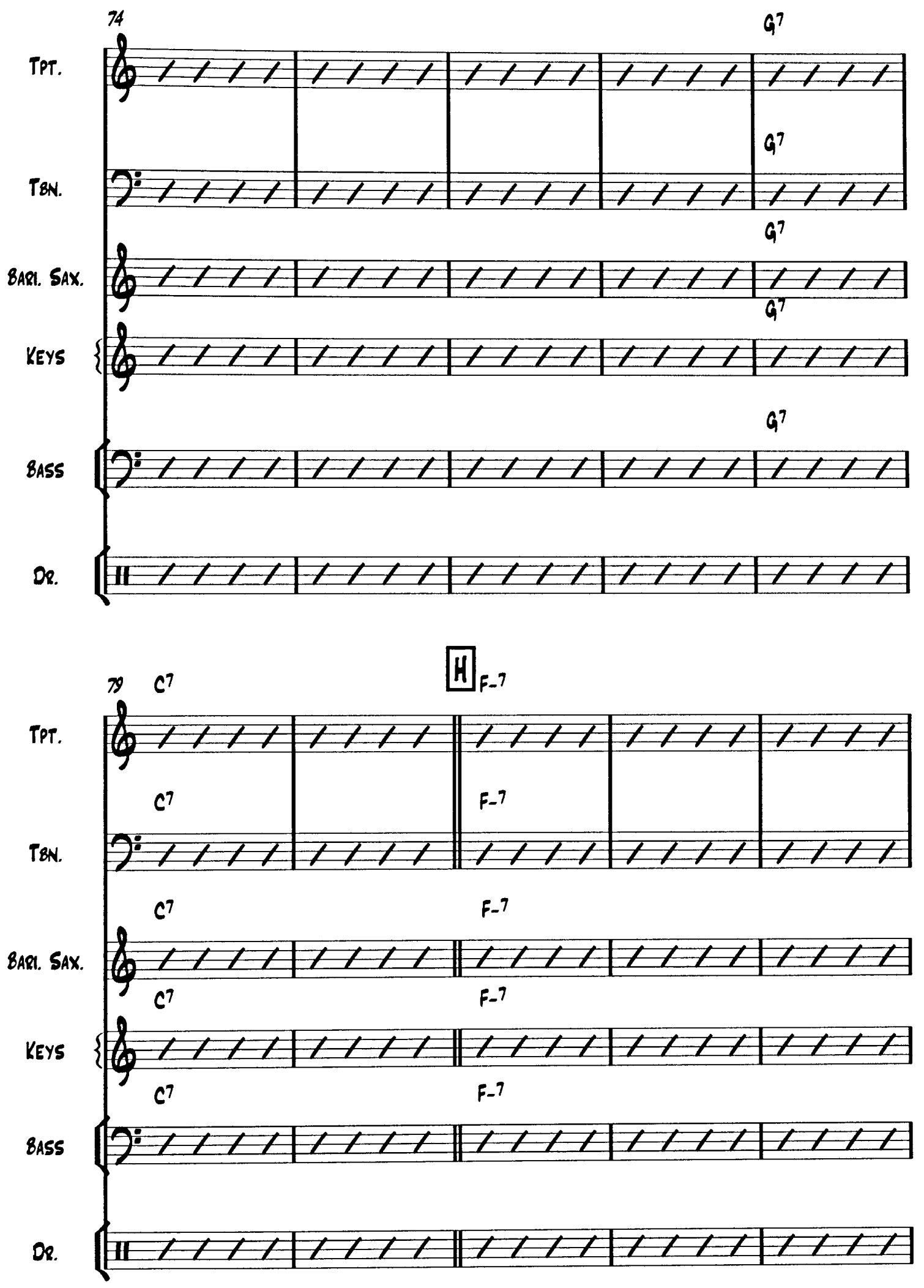

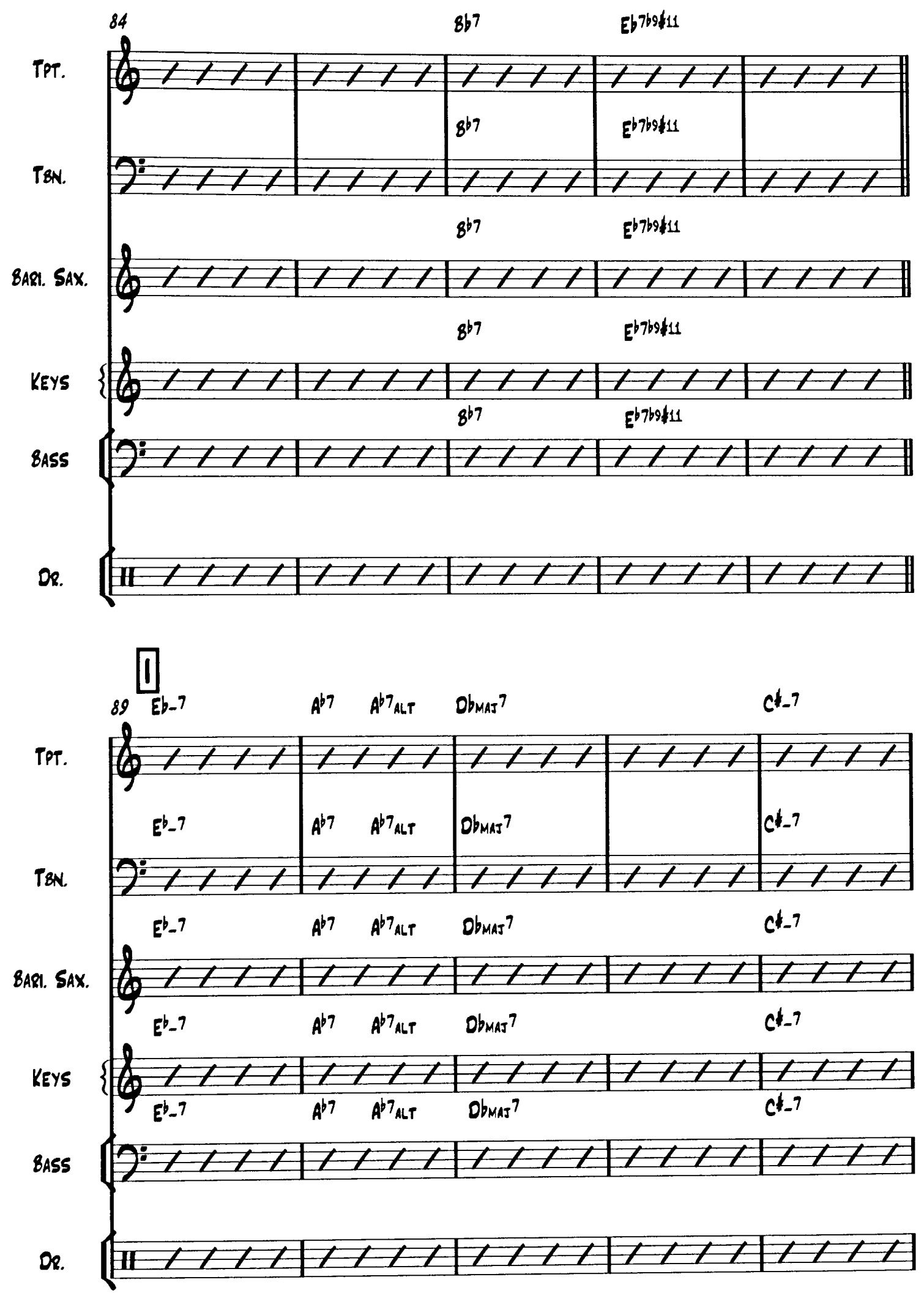


8BQ1. SAX.



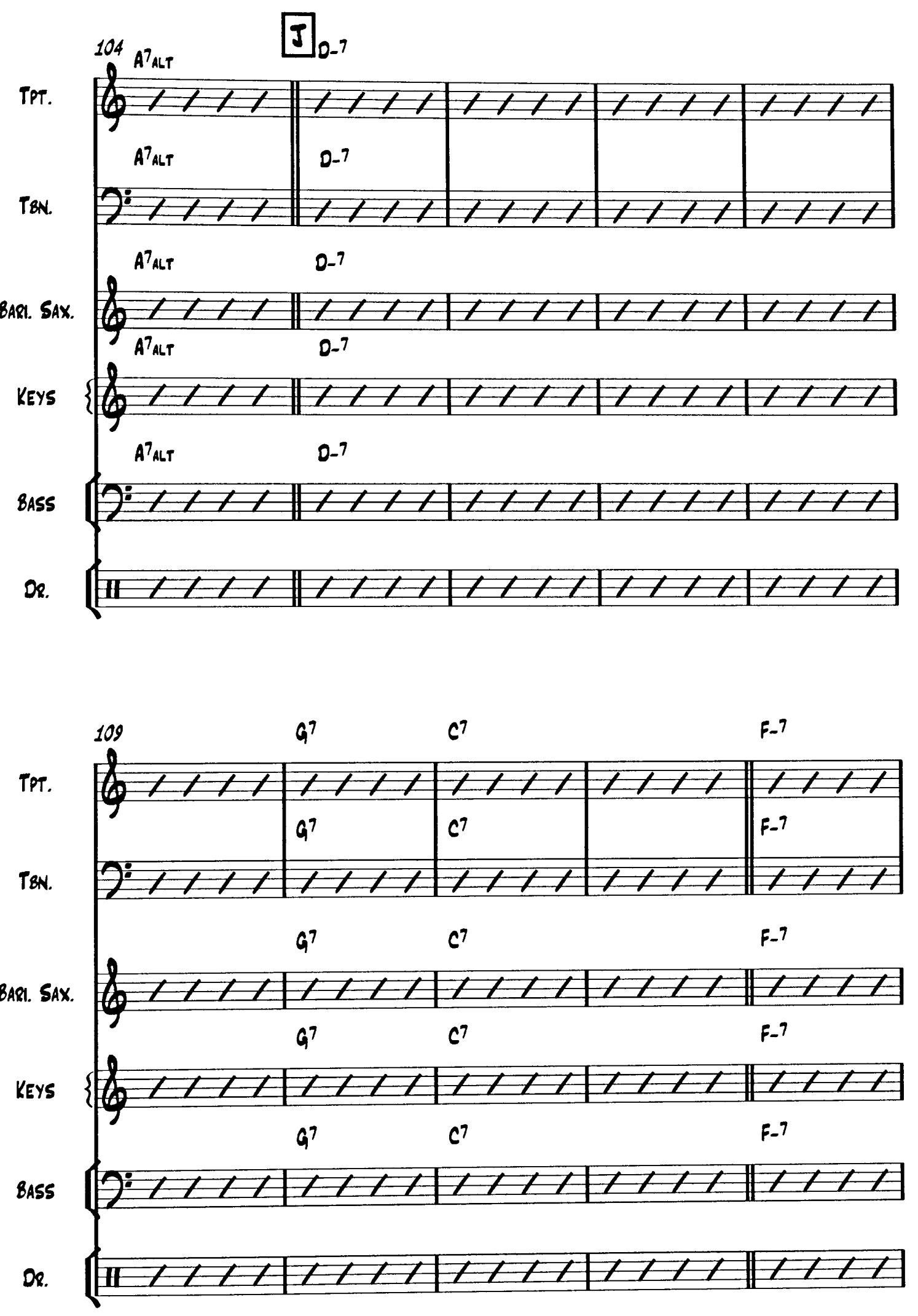

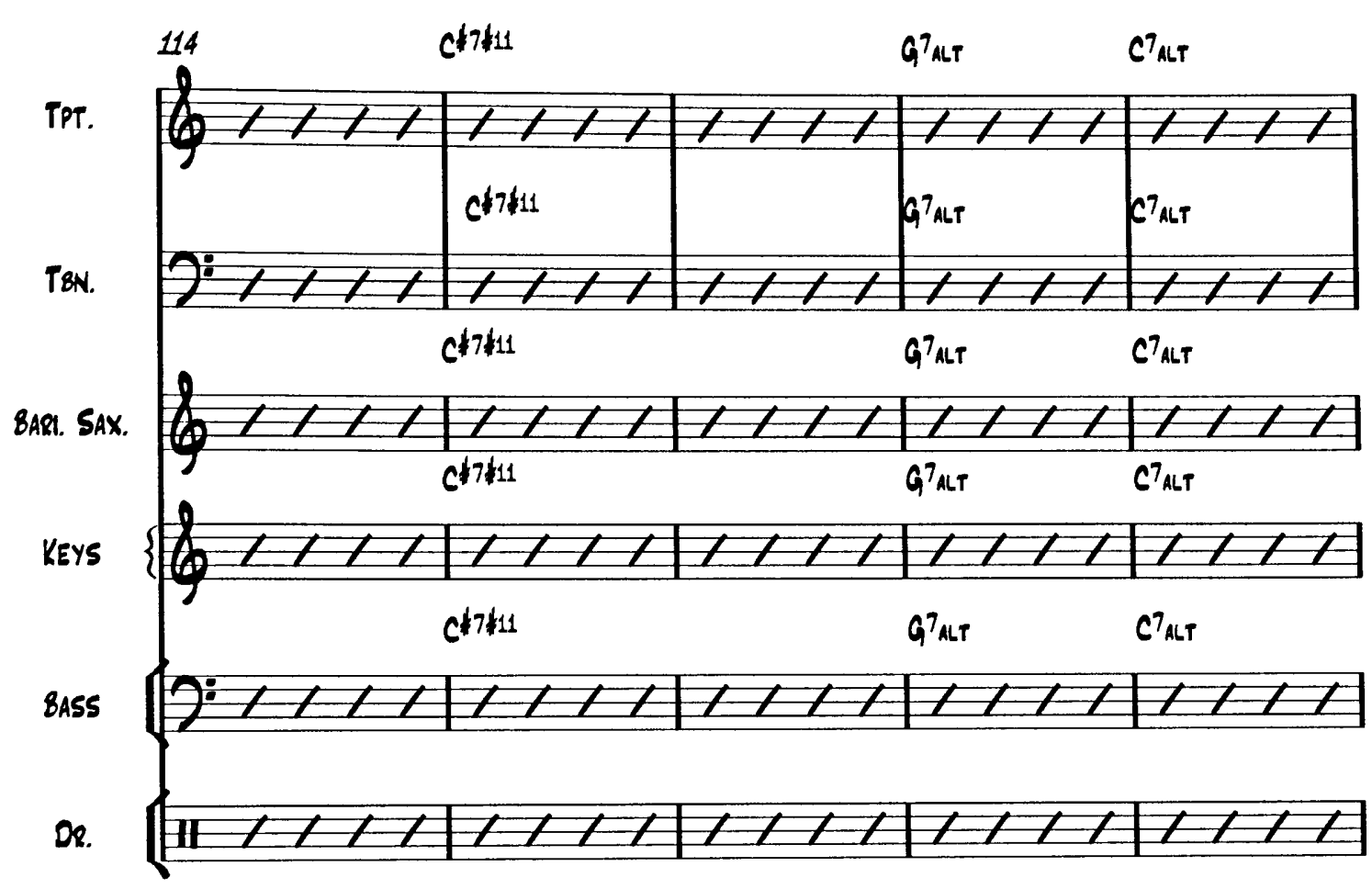

PT.

TEN.

BARI. SAX.

KEYS

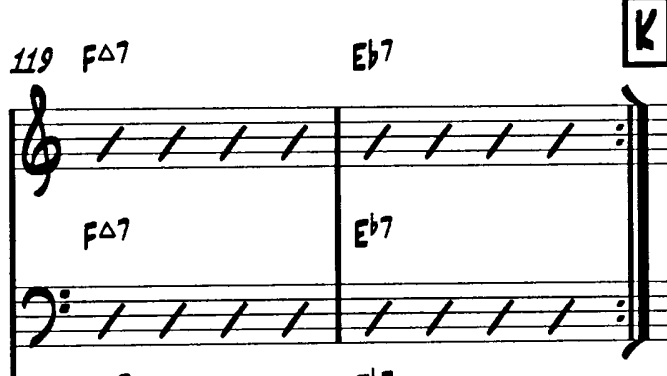

1) $\mathrm{sol}$

$\Delta 7$

Ebb

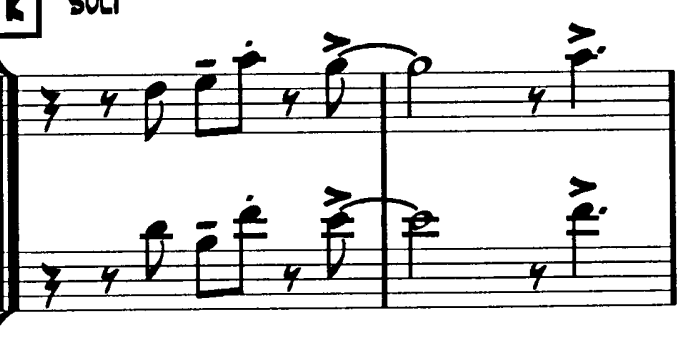

$\int_{0}$

7

BASS

or.

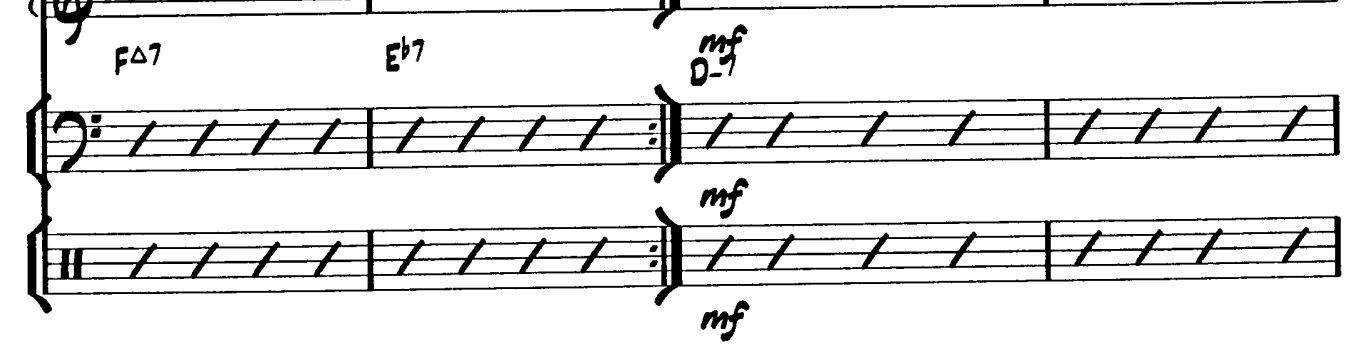

54 

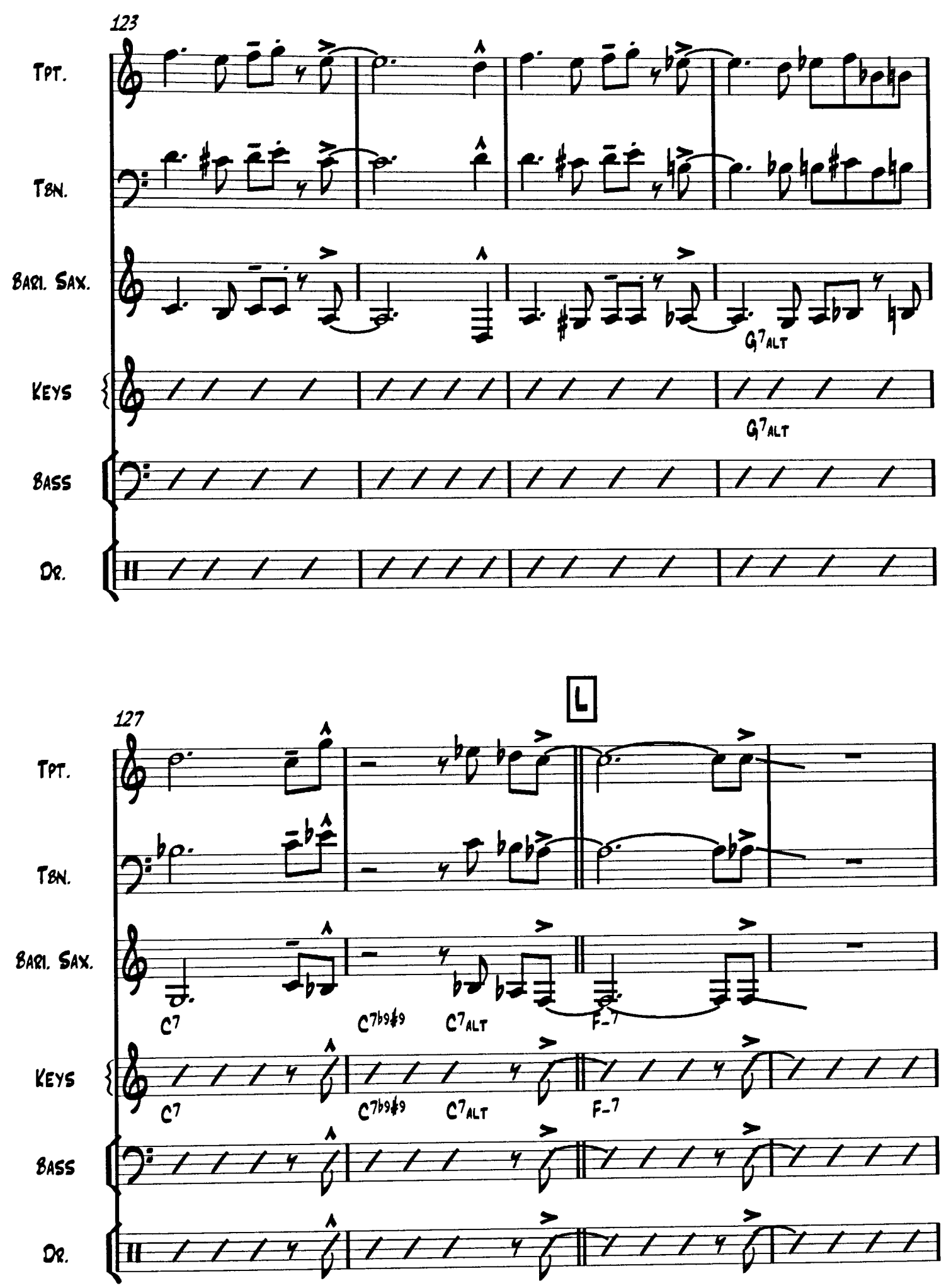

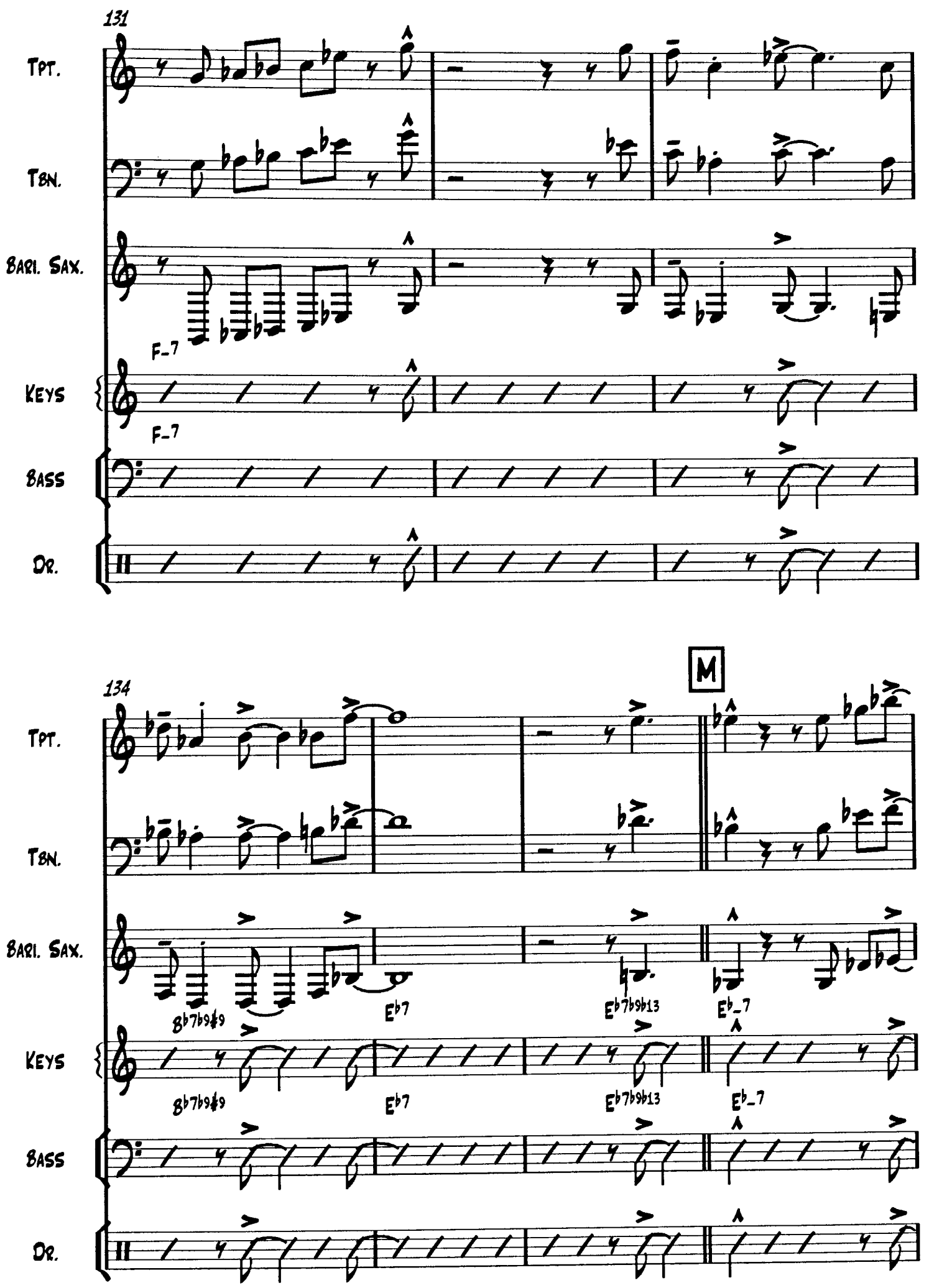


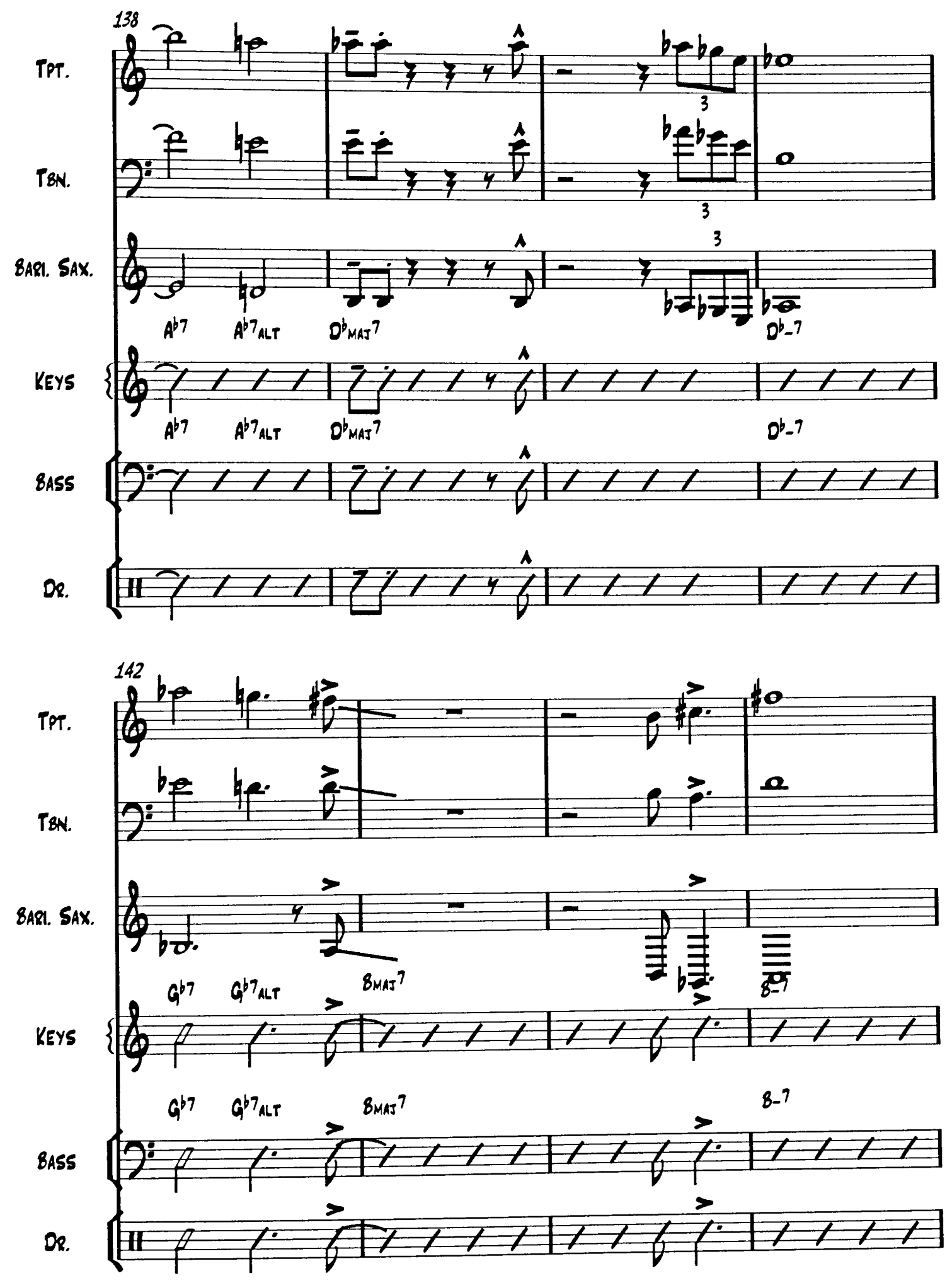



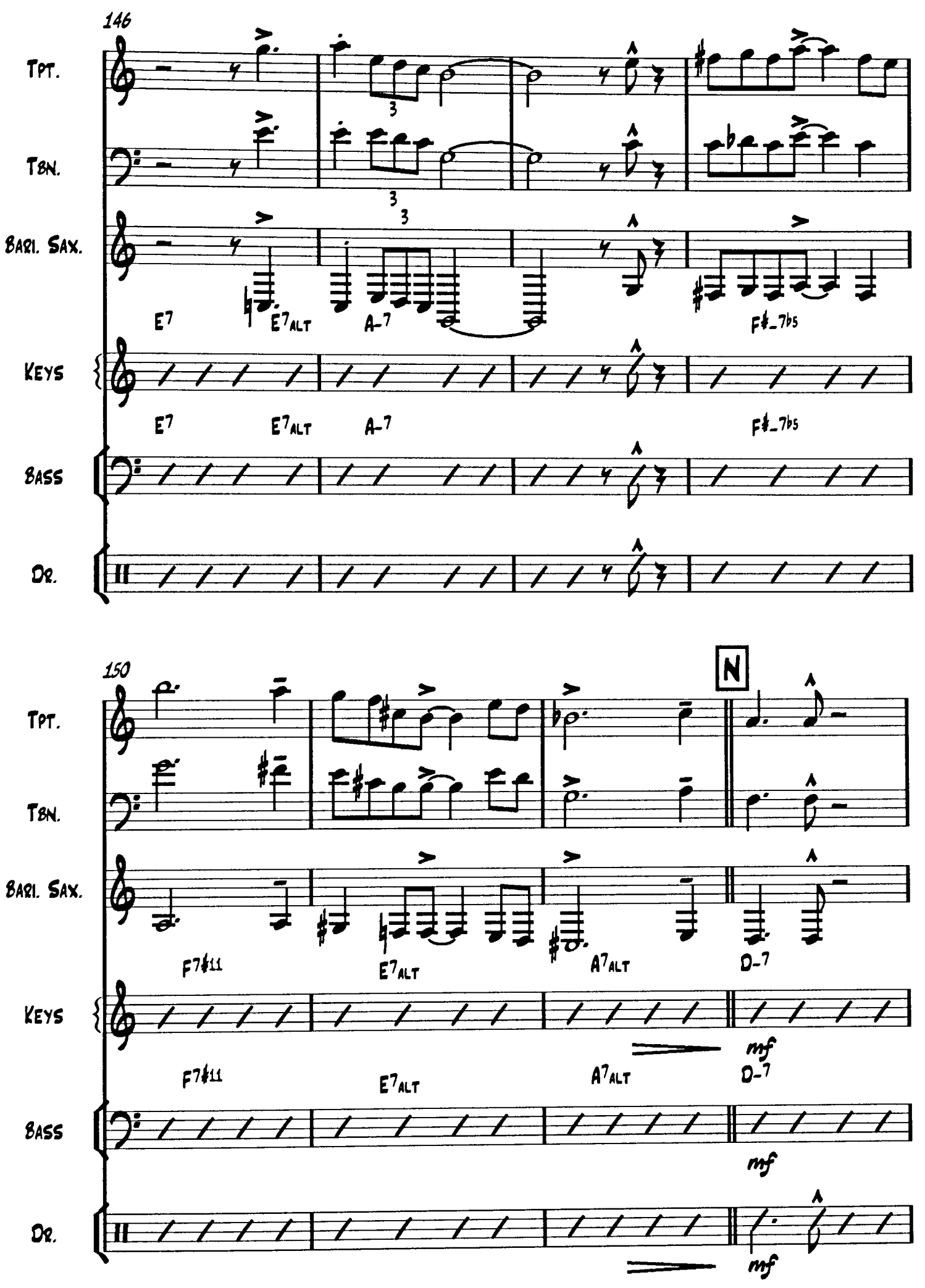


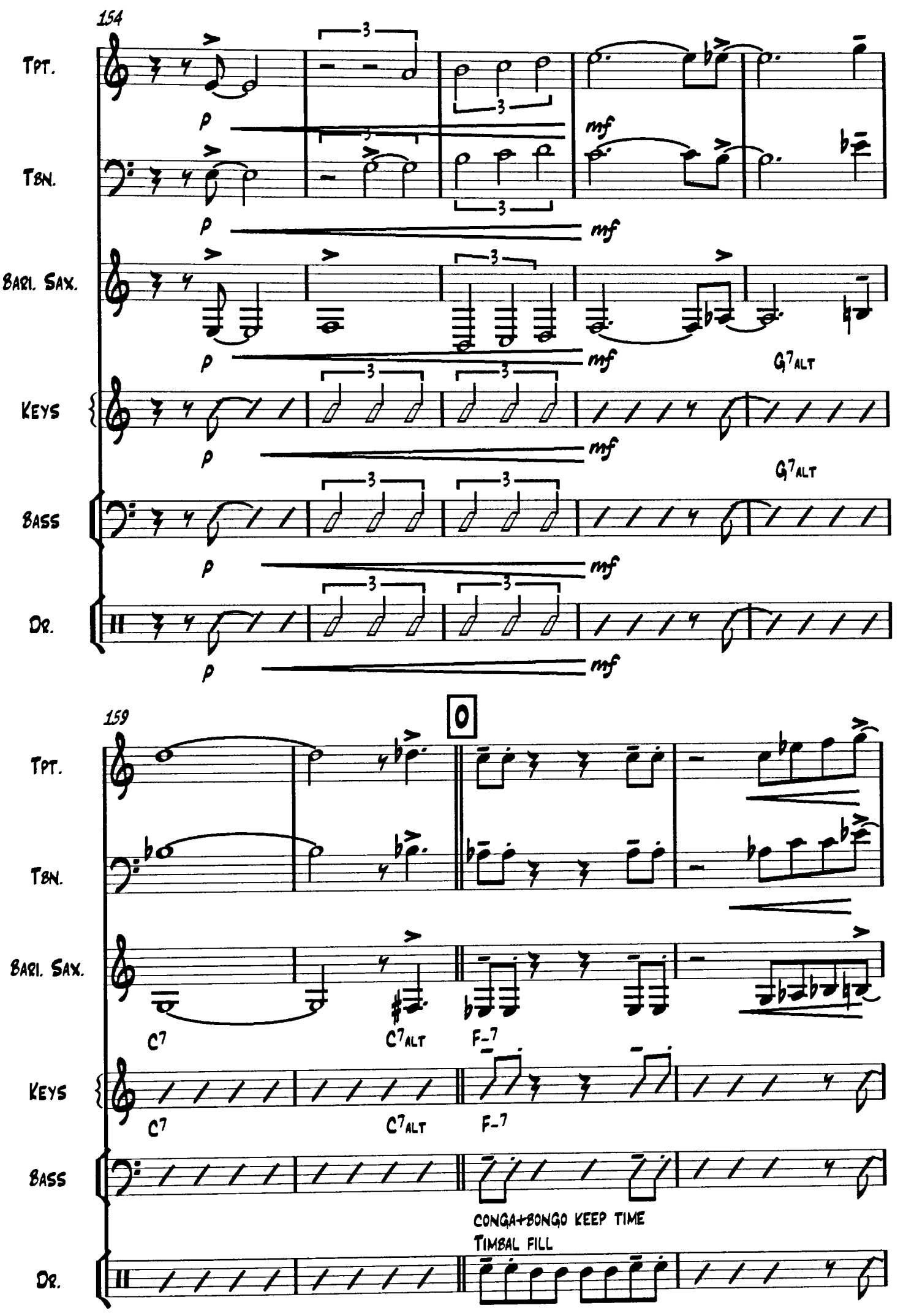



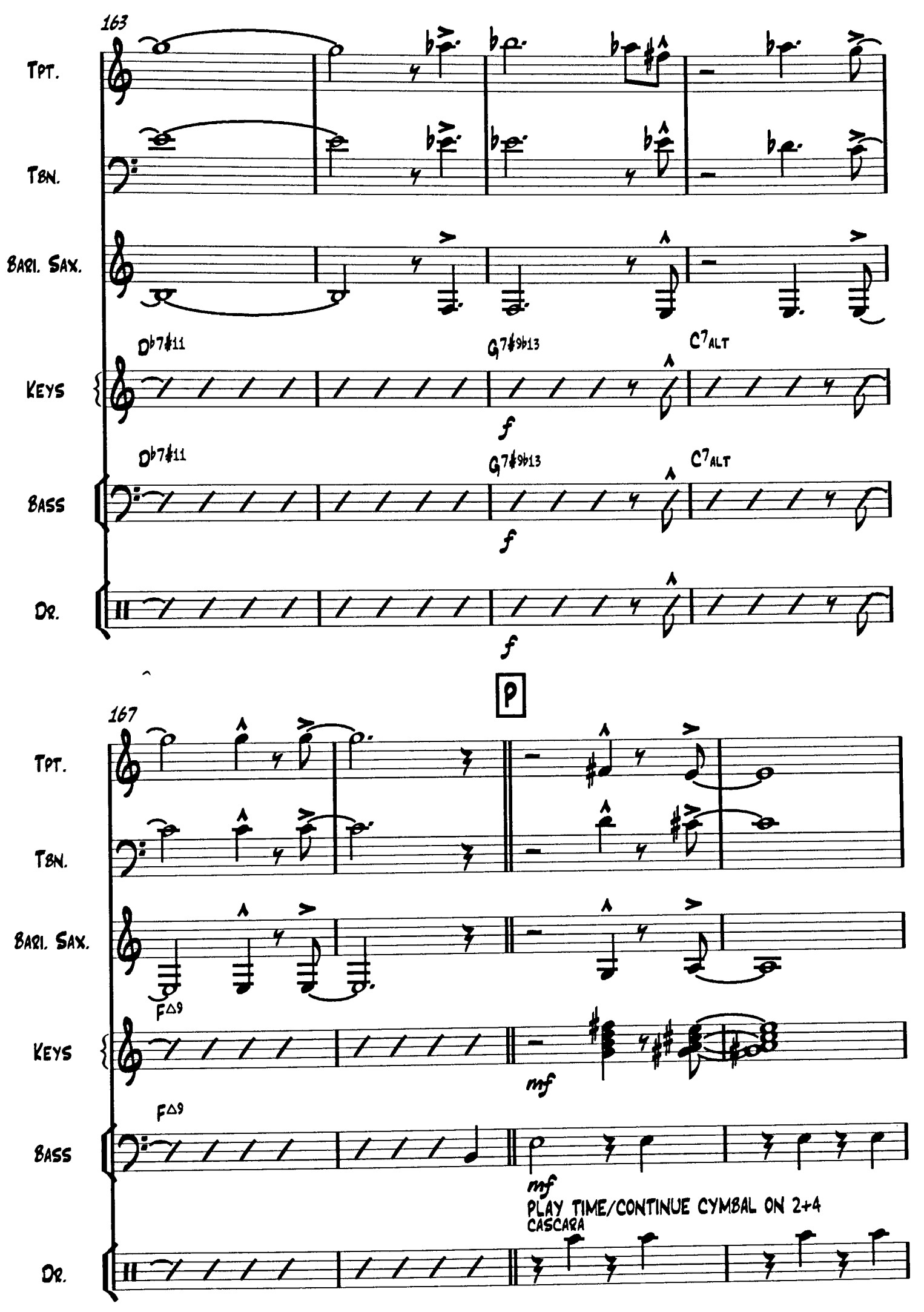

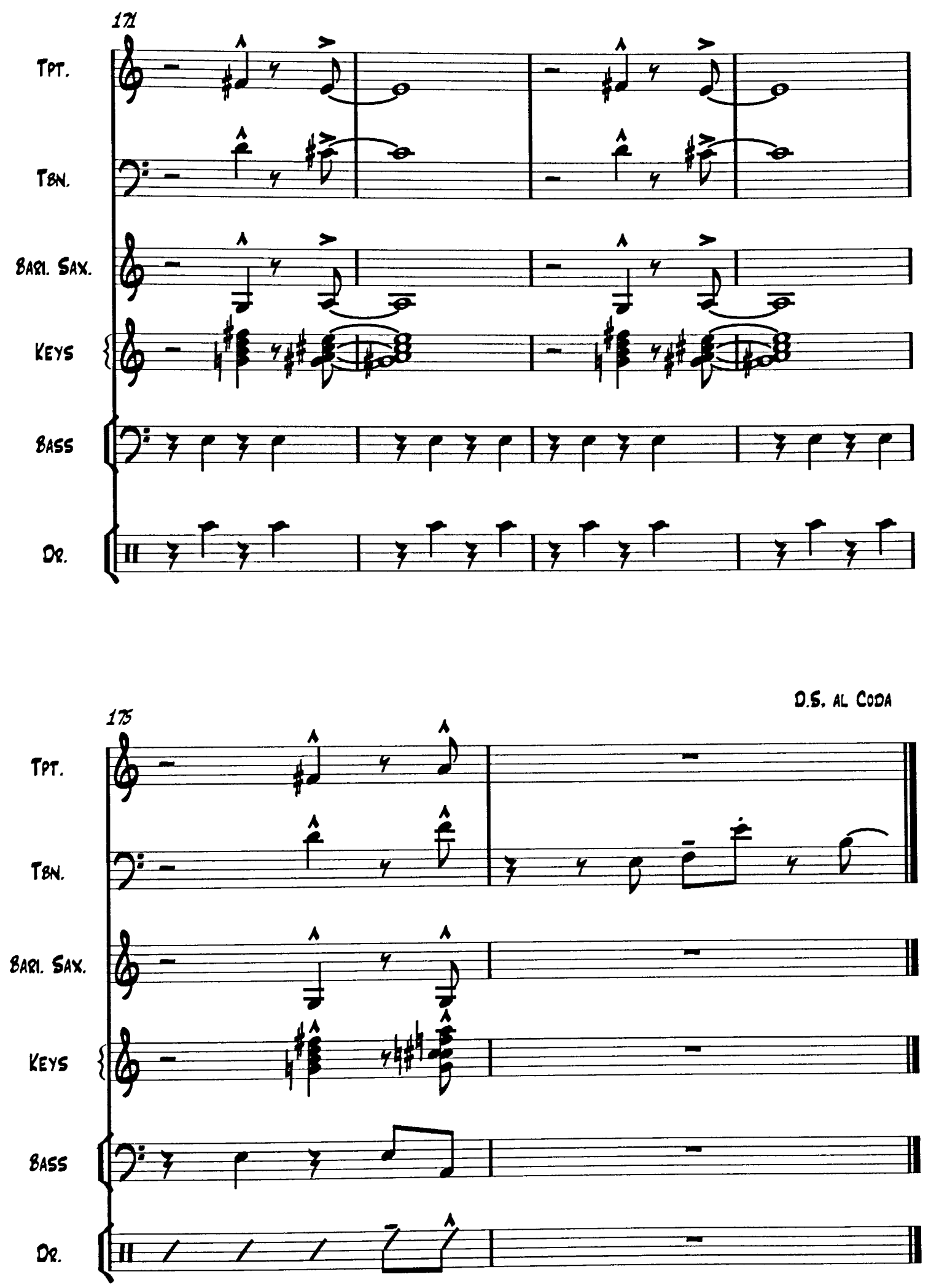


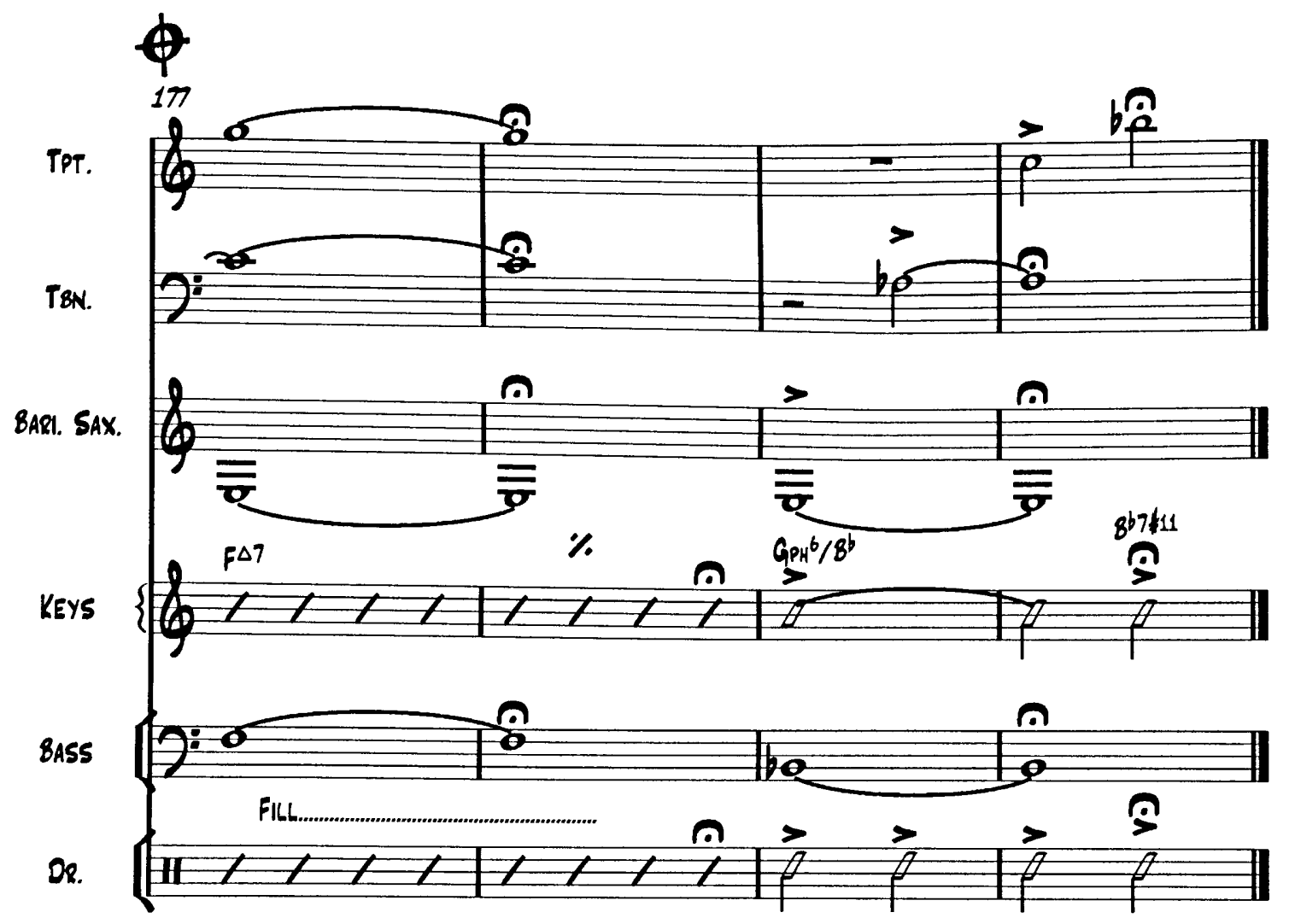




\section{SHAFTS OF SARCASM}

RUBEN CABAN
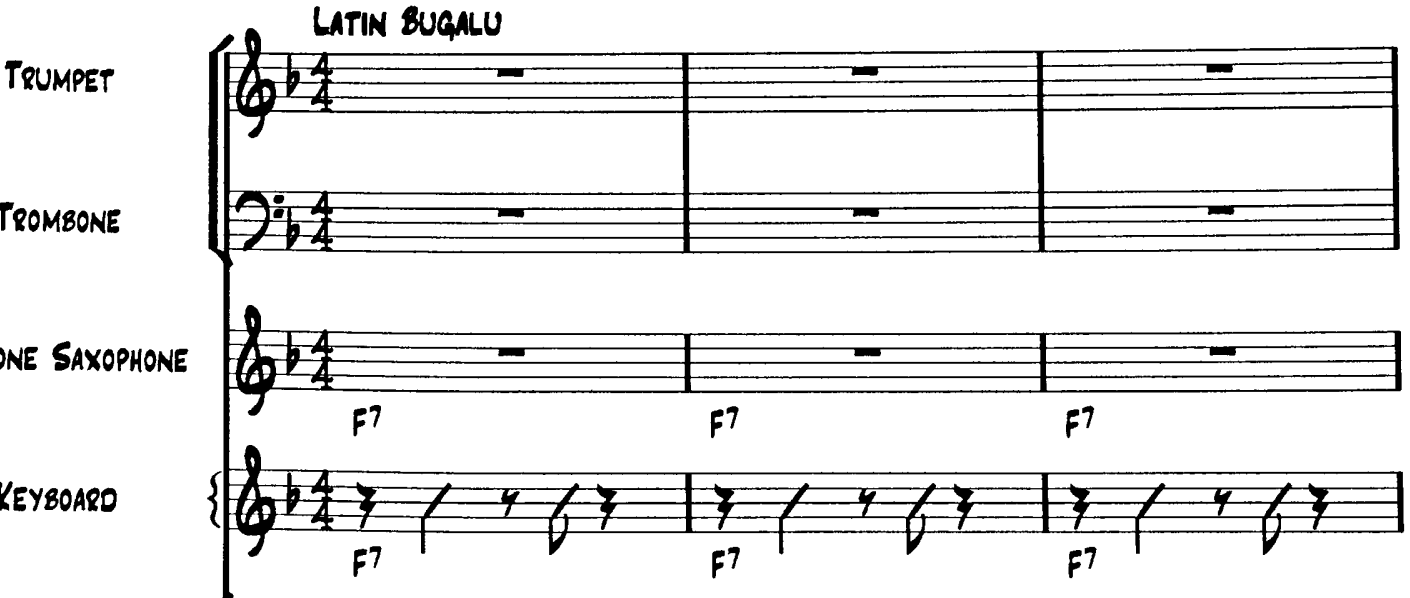

bass guitar

DRUMS
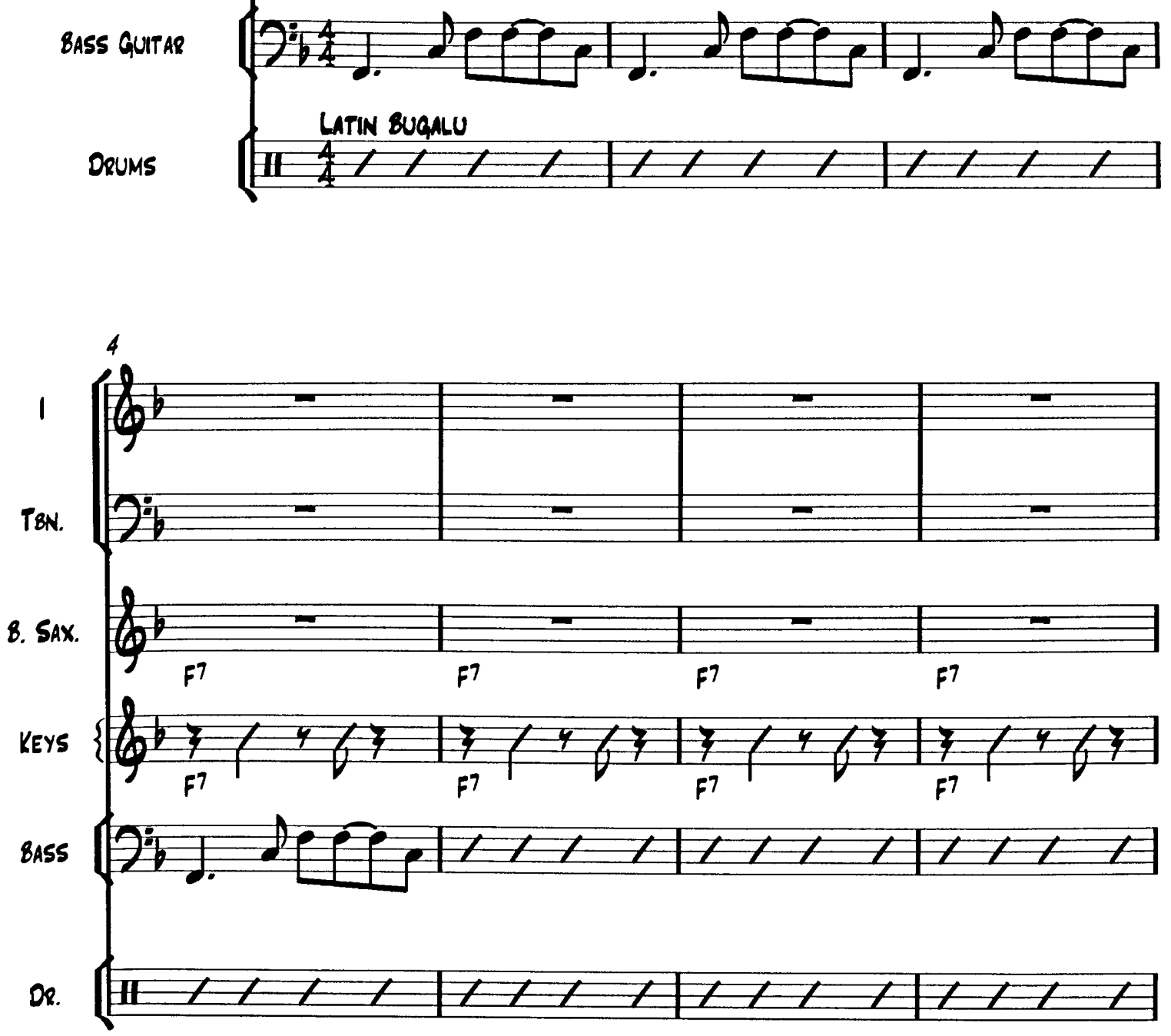

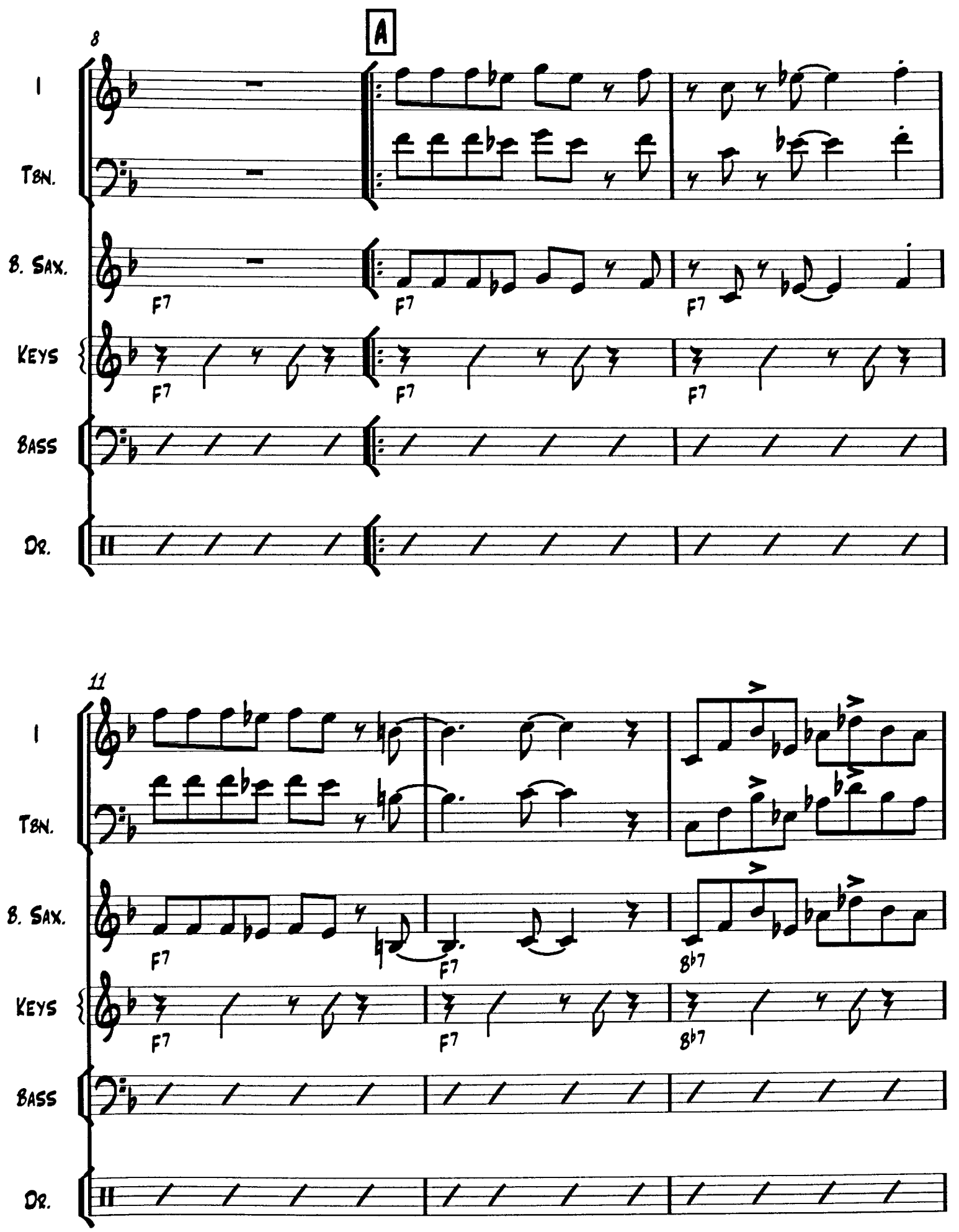

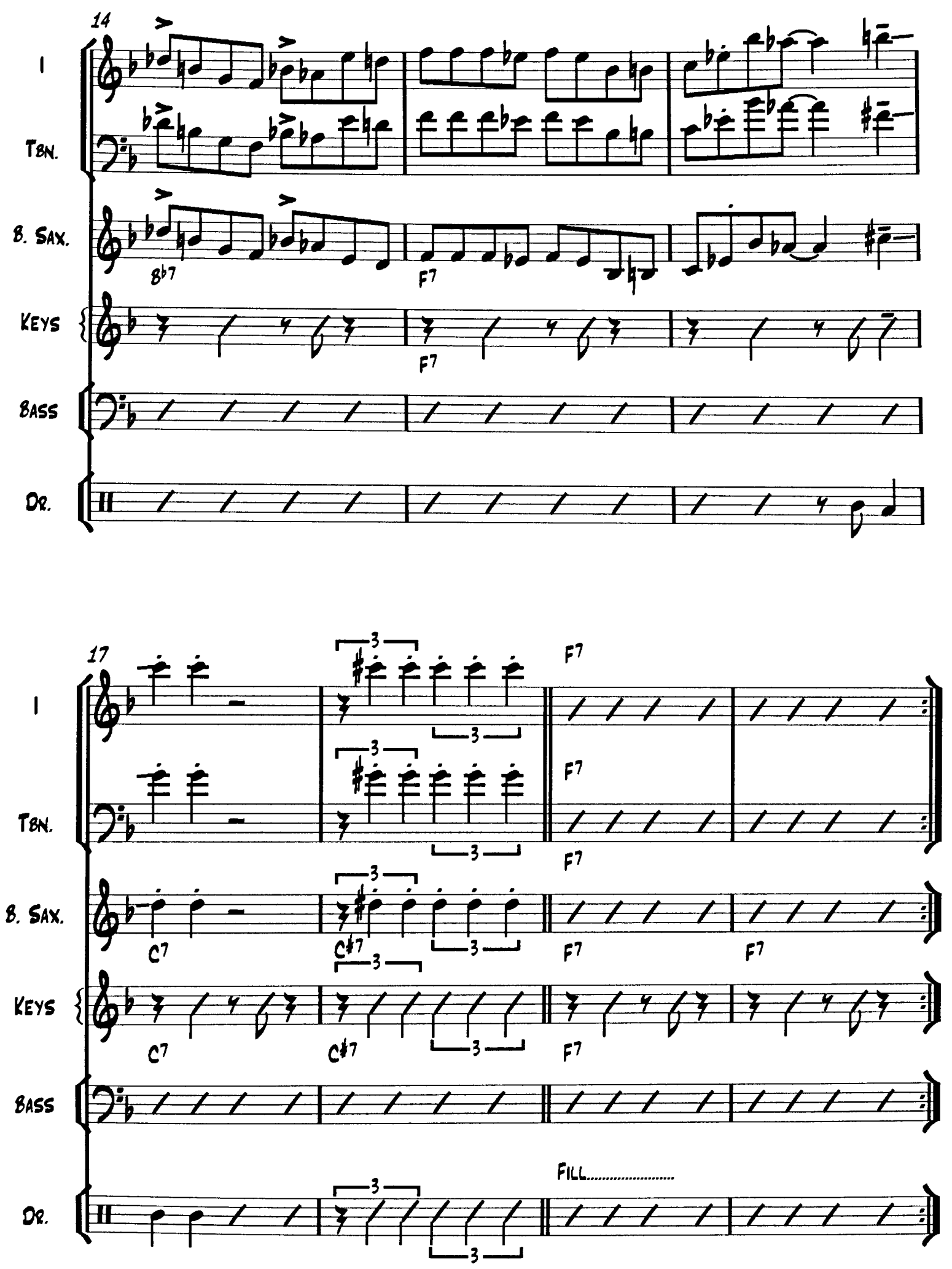

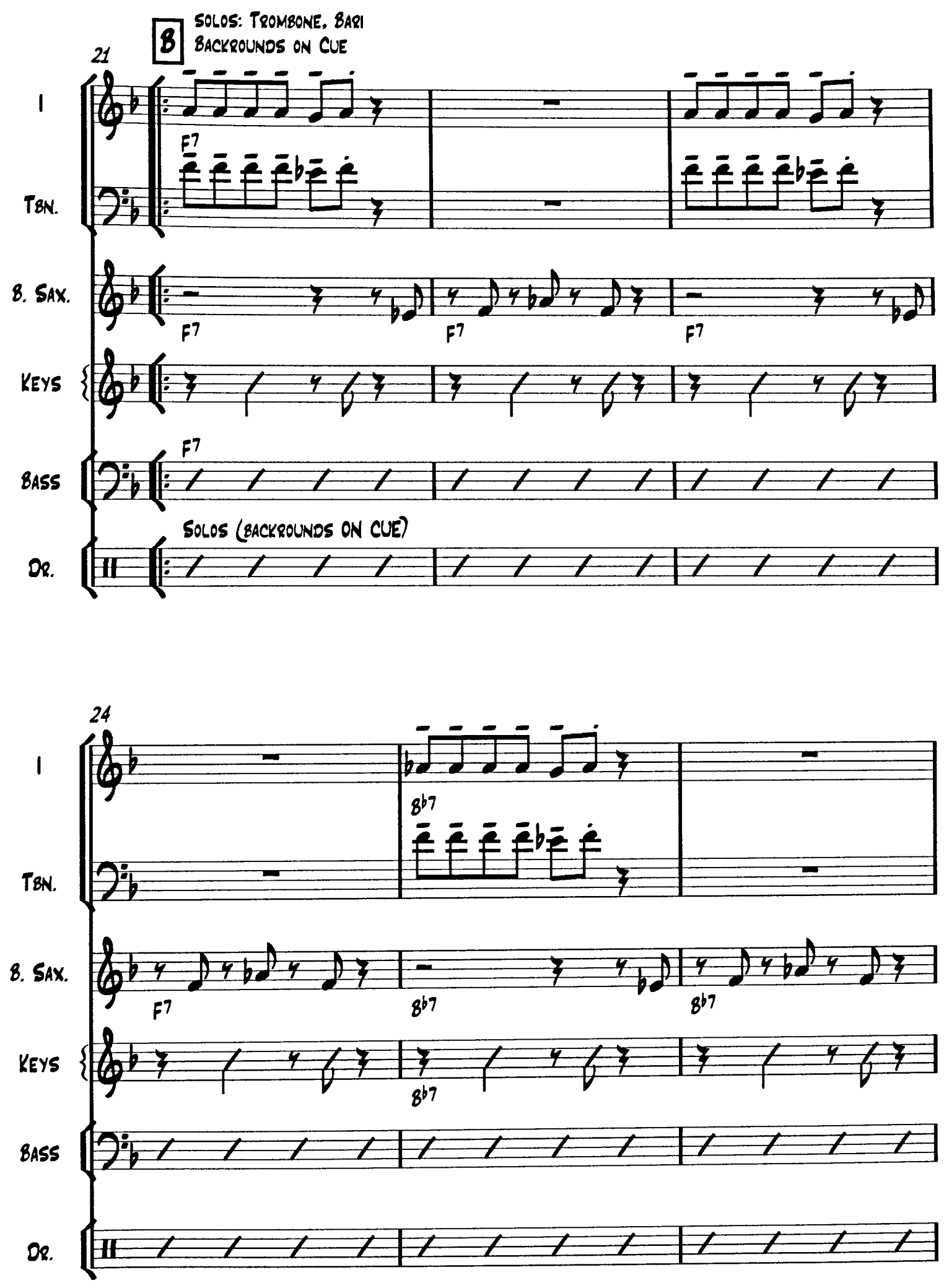

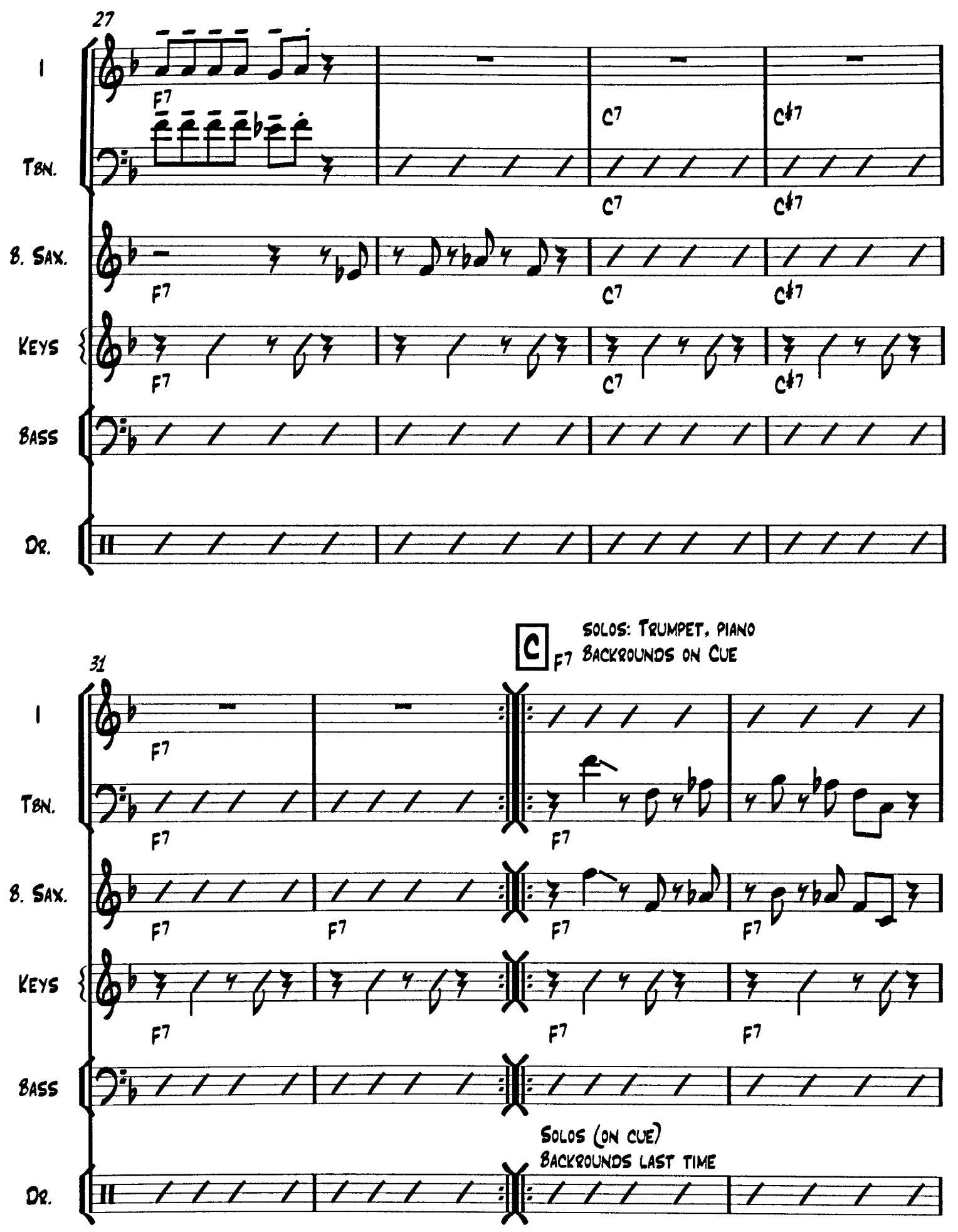

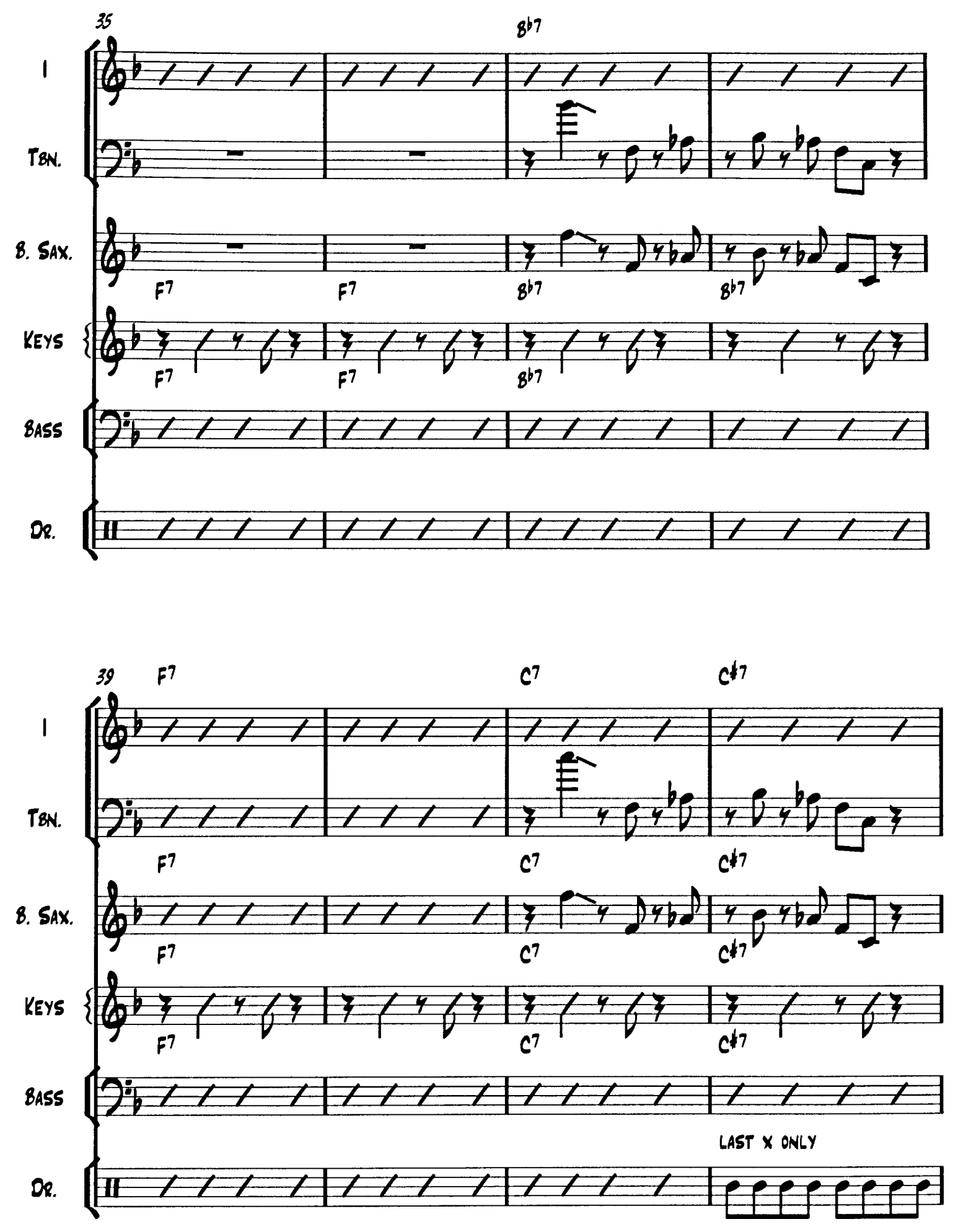

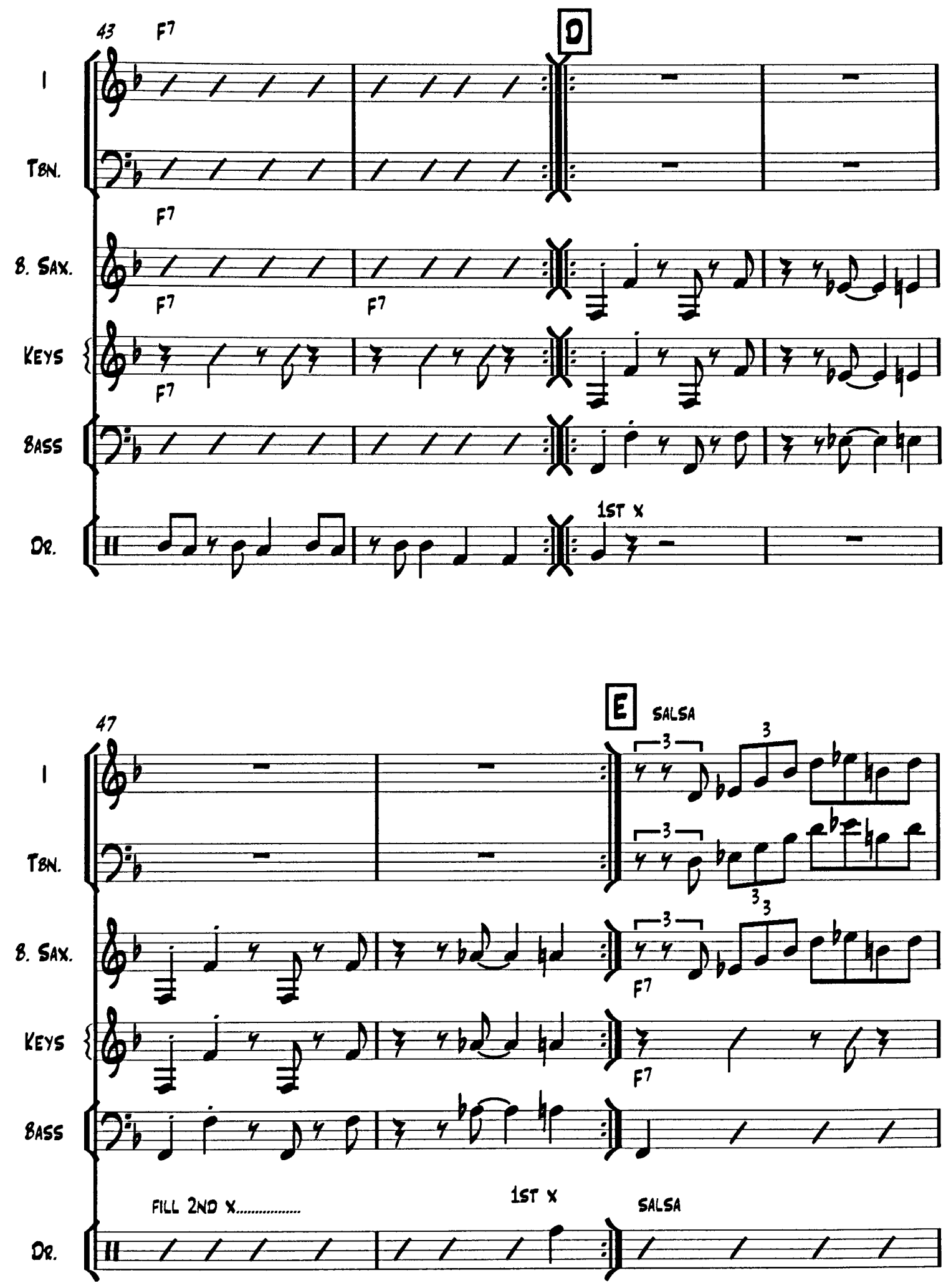

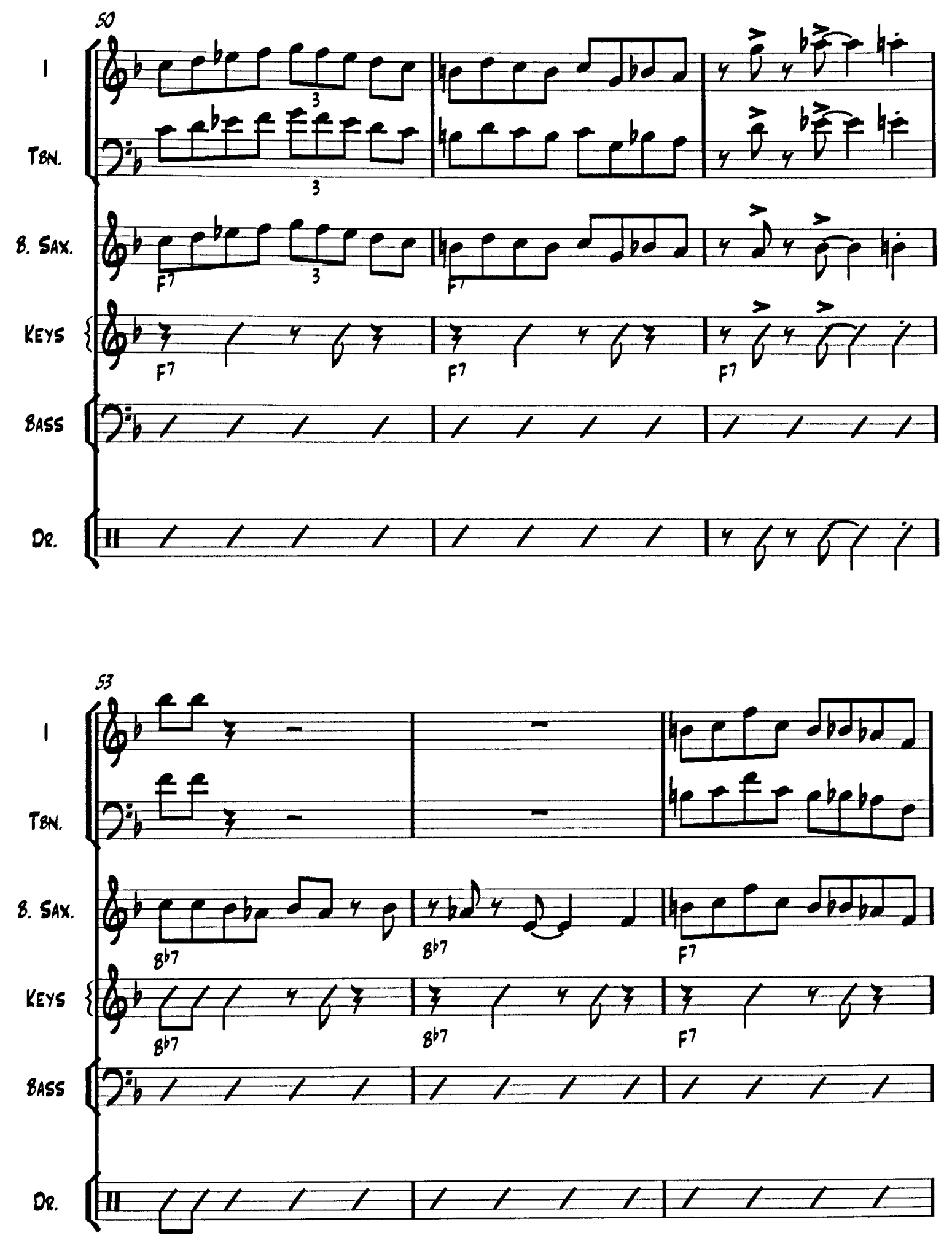

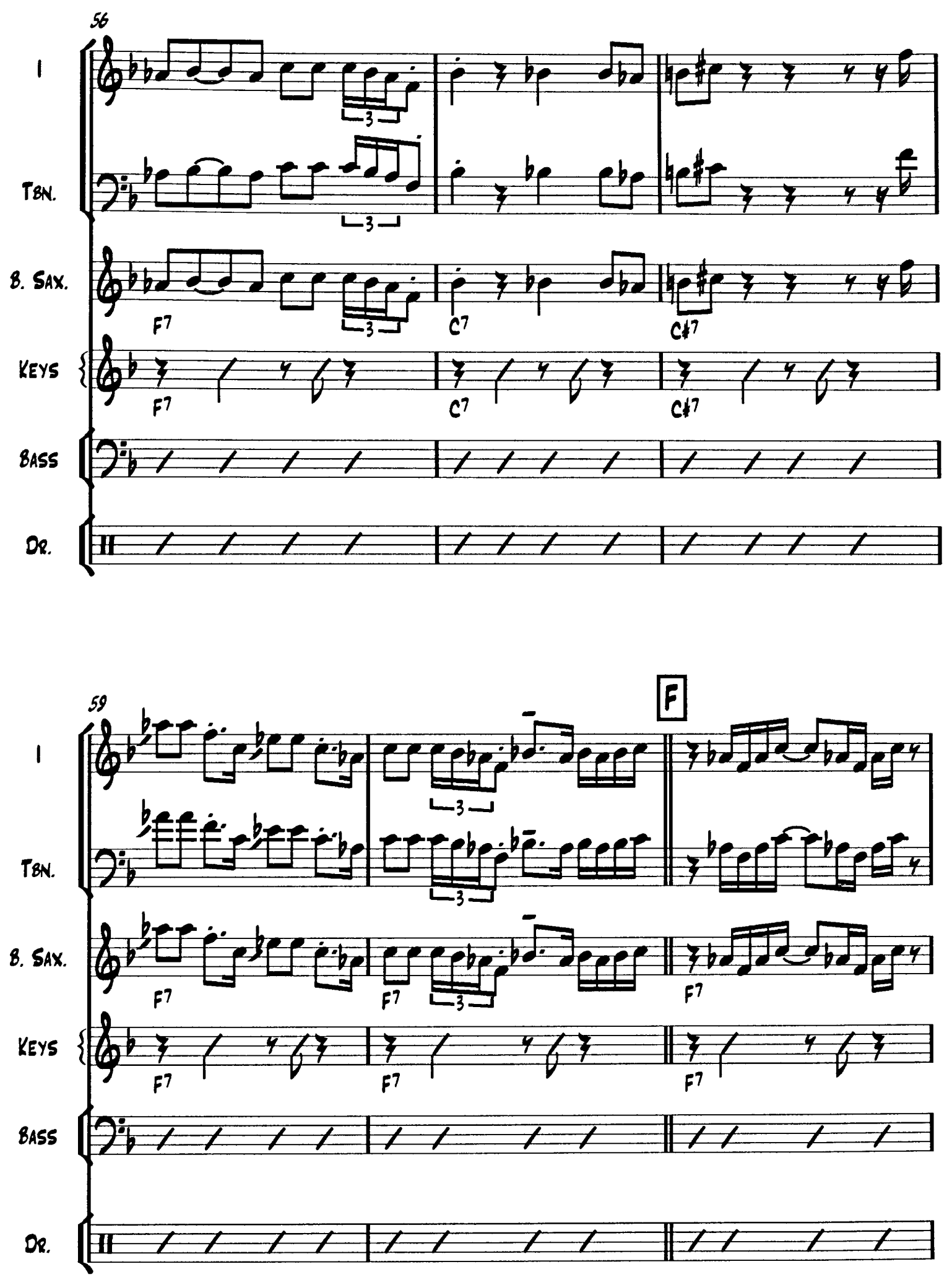

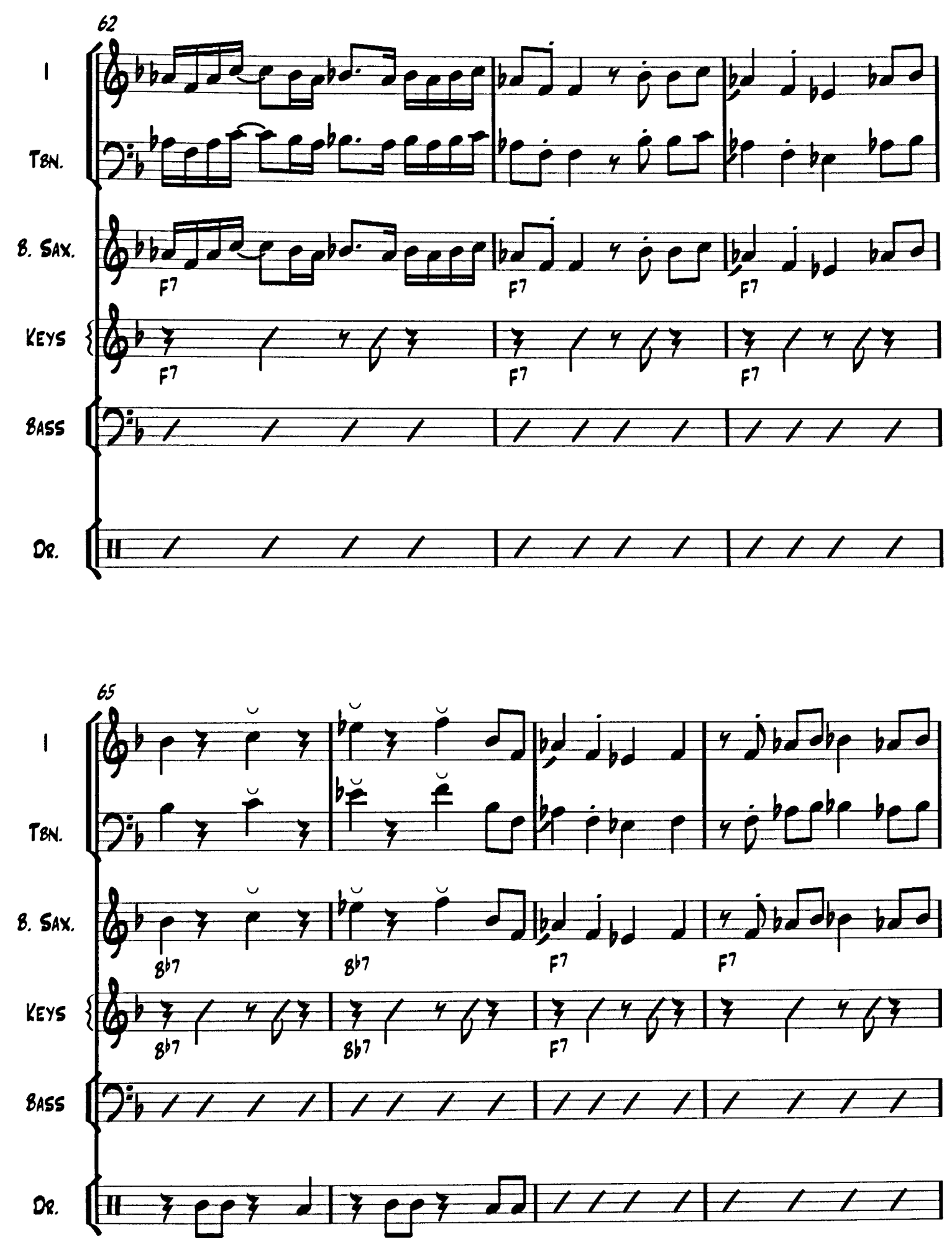

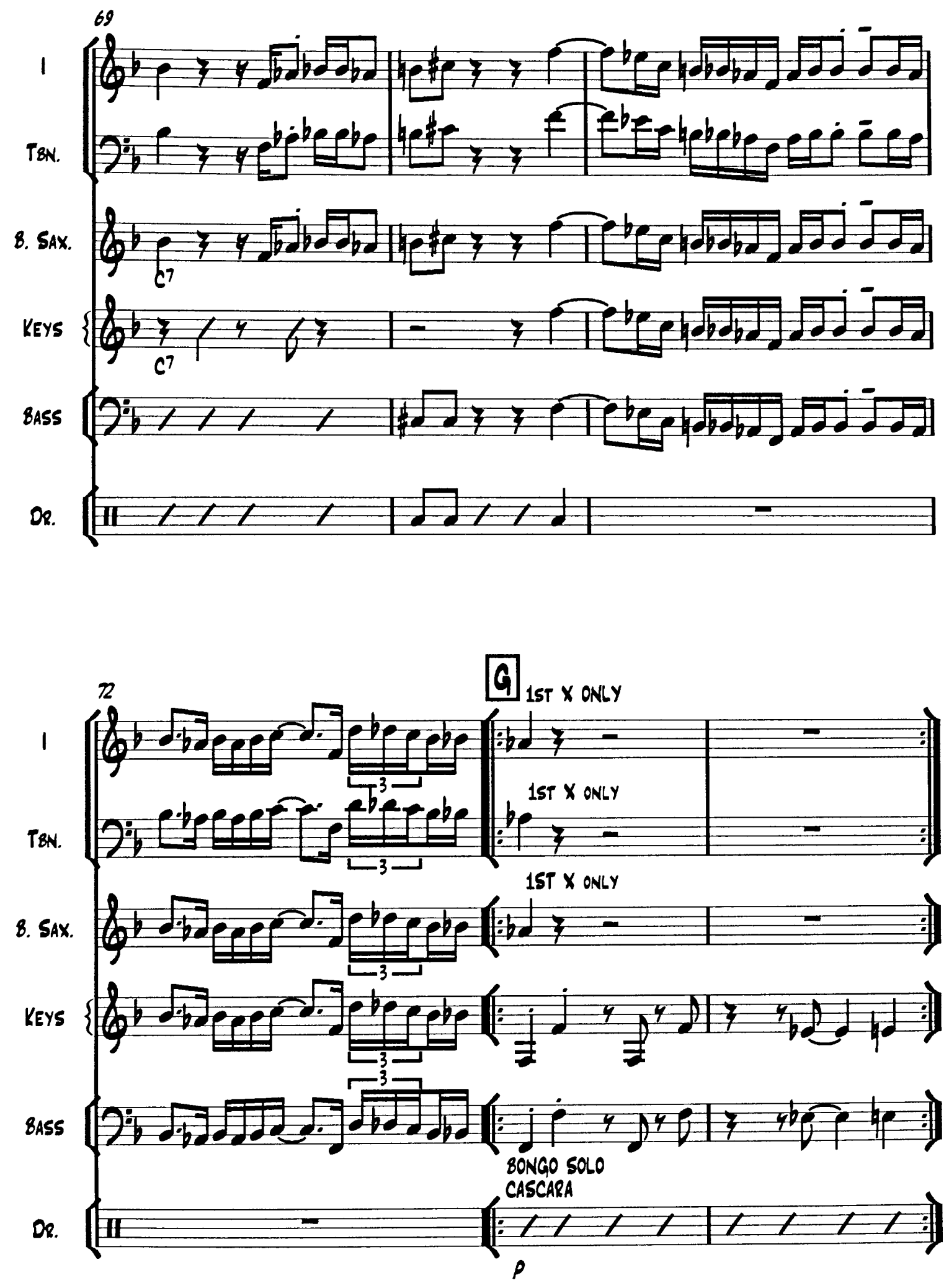

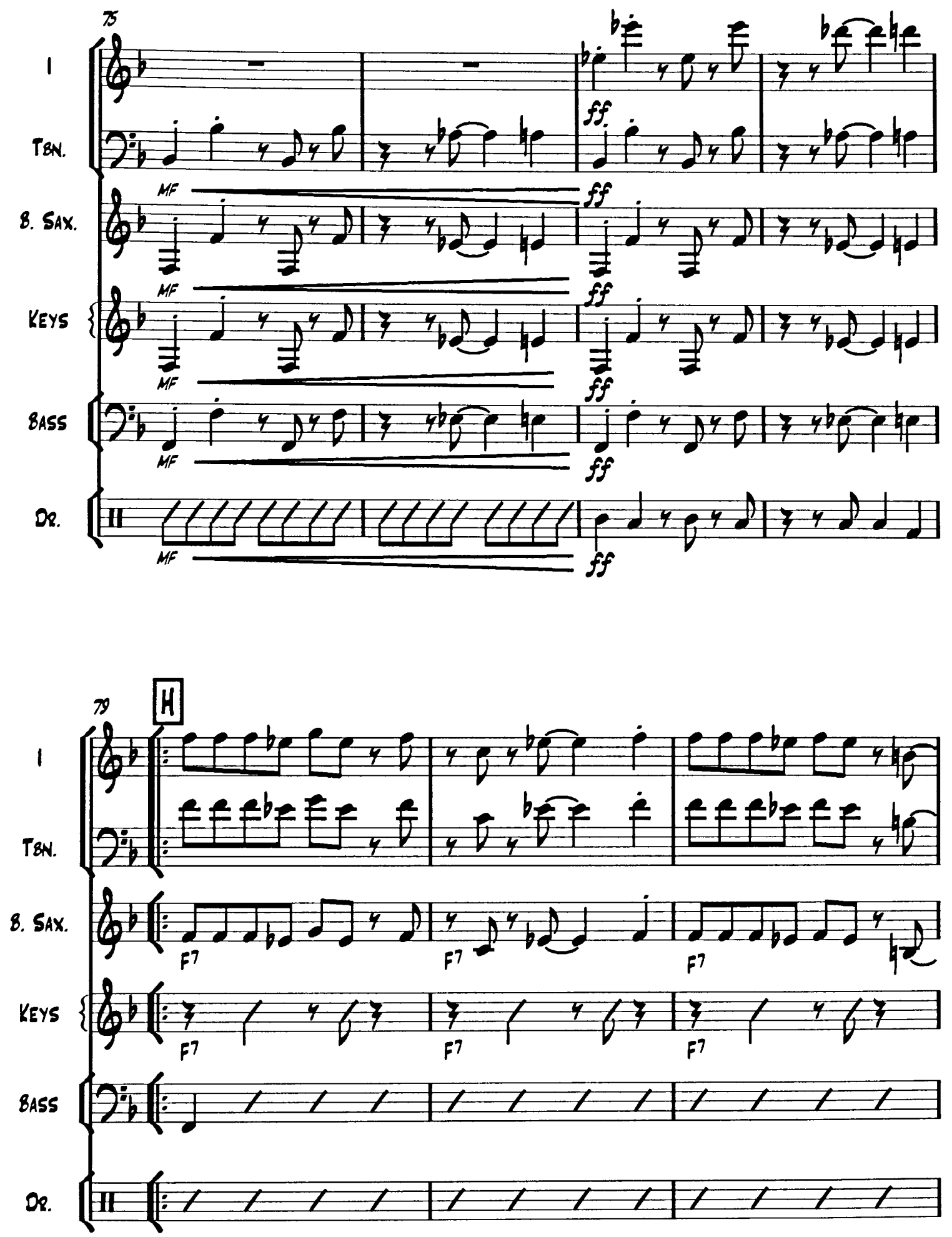

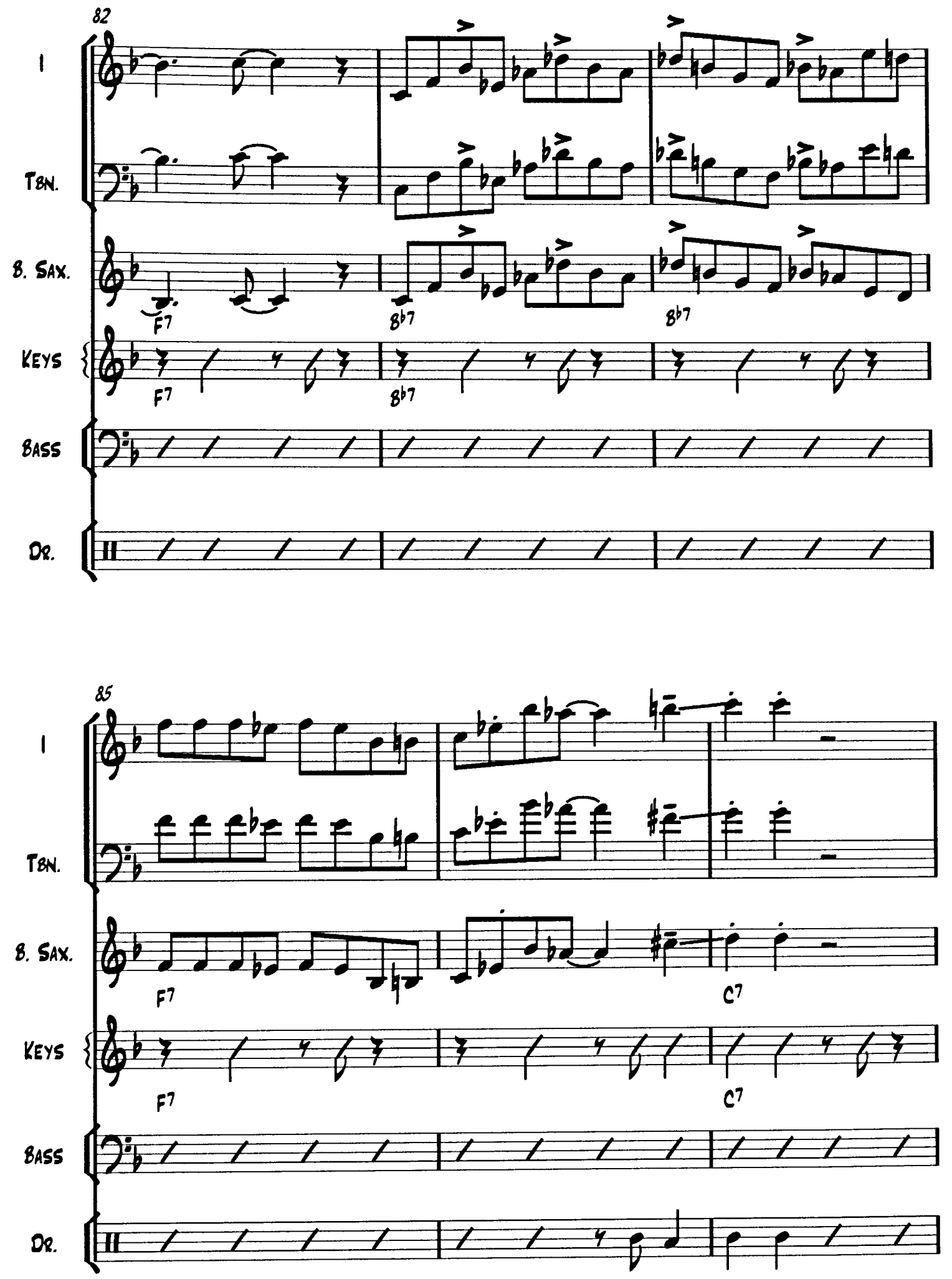